\title{
Cochrane
}

Cochrane Database of Systematic Reviews

\section{Alternatives, and adjuncts, to prophylactic platelet transfusion for people with haematological malignancies undergoing intensive chemotherapy or stem cell transplantation (Review)}

Desborough M, Estcourt LJ, Doree C, Trivella M, Hopewell S, Stanworth SJ, Murphy MF

Desborough M, Estcourt LJ, Doree C, Trivella M, Hopewell S, Stanworth SJ, Murphy MF.

Alternatives, and adjuncts, to prophylactic platelet transfusion for people with haematological malignancies undergoing intensive chemotherapy or stem cell transplantation.

Cochrane Database of Systematic Reviews 2016, Issue 8. Art. No.: CD010982.

DOI: 10.1002/14651858.CD010982.pub2.

www.cochranelibrary.com

Alternatives, and adjuncts, to prophylactic platelet transfusion for people with haematological malignancies undergoing intensive chemotherapy or stem cell transplantation (Review)

Copyright @ 2016 The Cochrane Collaboration. Published by John Wiley \& Sons, Ltd. 
TABLE OF CONTENTS

HEADER . . . . . . . . . . . . . . . . . . . . . . . . . . . . . . . . . . . . . . . . . . . . .

ABSTRACT . . . . . . . . . . . . . . . . . . . . . . . . . . . . . . . . . . . . . . . . . . . . . . 1

PLAIN LANGUAGE SUMMARY . . . . . . . . . . . . . . . . . . . . . . . . . . . . . . . . . . . . . . . . . . . . . 2

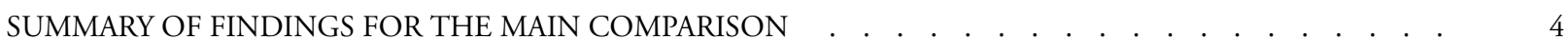

BACKGROUND . . . . . . . . . . . . . . . . . . . . . . . . . . . . . . . . . . . . . . . . . . . . . . 7

OBJECTIVES . . . . . . . . . . . . . . . . . . . . . . . . . . . . . . . . . . . . . . . . . . . . . . . . . .

METHODS . . . . . . . . . . . . . . . . . . . . . . . . . . . . . . . . . . . . . . . . .

RESULTS . . . . . . . . . . . . . . . . . . . . . . . . . . . . . . . . . . . . . . .

Figure 1. . . . . . . . . . . . . . . . . . . . . . . . . . . . . . . . . . . . . . . . 14

Figure 2. . . . . . . . . . . . . . . . . . . . . . . . . . . . . . . . . . . . . .

Figure 3. . . . . . . . . . . . . . . . . . . . . . . . . . . . . . . . . 20

Figure $4 . \quad$. . . . . . . . . . . . . . . . . . . . . . . . . . . . . . . . . . . . . . . .

Figure 5. . . . . . . . . . . . . . . . . . . . . . . . . . . . . . . . . . . . . 22

Figure 6. . . . . . . . . . . . . . . . . . . . . . . . . . . . . . . . . . . . . . . .

Figure $7 . \quad$. . . . . . . . . . . . . . . . . . . . . . . . . . . . . . . . . . . . .

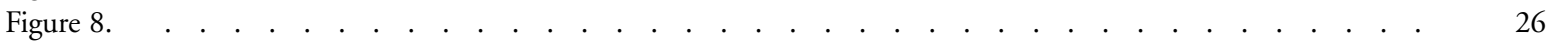

Figure 9. . . . . . . . . . . . . . . . . . . . . . . . . . . . . . . . . . . . . . . $\quad . \quad 27$

Figure 10. . . . . . . . . . . . . . . . . . . . . . . . . . . . . . . . . . . . . . . . . .

ADDITIONAL SUMMARY OF FINDINGS . . . . . . . . . . . . . . . . . . . . . . . . . . . . . . . . . $\quad 29$

DISCUSSION . . . . . . . . . . . . . . . . . . . . . . . . . . . . . . . . . . . . . . 32

AUTHORS' CONCLUSIONS . . . . . . . . . . . . . . . . . . . . . . . . . . . . . . . . . . . . . . .

ACKNOWLEDGEMENTS . . . . . . . . . . . . . . . . . . . . . . . . . . . . . . . . . . . . . .

REFERENCES . . . . . . . . . . . . . . . . . . . . . . . . . . . . . . . . . . . . . . 35

CHARACTERISTICS OF STUDIES . . . . . . . . . . . . . . . . . . . . . . . . . . . . . . . . . . . . . 47

DATA AND ANALYSES . . . . . . . . . . . . . . . . . . . . . . . . . . . . . . . . . . . 86

Analysis 1.1. Comparison 1 Thrombopoietin (TPO) mimetics versus placebo or standard care, Outcome 1 Number of participants with at least 1 bleeding episode.

Analysis 1.2. Comparison 1 Thrombopoietin (TPO) mimetics versus placebo or standard care, Outcome 2 Number of

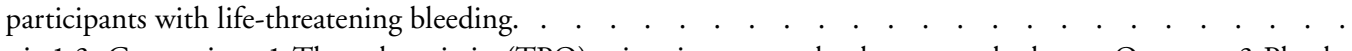

Analysis 1.3. Comparison 1 Thrombopoietin (TPO) mimetics versus placebo or standard care, Outcome 3 Platelet transfusions.

Analysis 1.4. Comparison 1 Thrombopoietin (TPO) mimetics versus placebo or standard care, Outcome 4 All-cause mortality.

Analysis 1.5. Comparison 1 Thrombopoietin (TPO) mimetics versus placebo or standard care, Outcome 5 Duration of thrombocytopenia.

Analysis 1.6. Comparison 1 Thrombopoietin (TPO) mimetics versus placebo or standard care, Outcome 6 Participants in

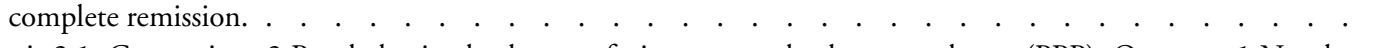

Analysis 2.1. Comparison 2 Prophylactic platelet transfusion versus platelet-poor plasma (PPP), Outcome 1 Number of participants with at least 1 bleeding episode.

Analysis 2.2. Comparison 2 Prophylactic platelet transfusion versus platelet-poor plasma (PPP), Outcome 2 Number of participants with life-threatening bleeding.

Analysis 2.3. Comparison 2 Prophylactic platelet transfusion versus platelet-poor plasma (PPP), Outcome 3 Mortality due to bleeding.

Analysis 2.4. Comparison 2 Prophylactic platelet transfusion versus platelet-poor plasma (PPP), Outcome 4 Adverse events: formation of anti-human leukocyte antigen antibodies.

APPENDICES

WHAT'S NEW

HISTORY . . . . . . . . . . . . . . . . . . . . . . . . . . . . . . . . . . . . . . . . 101

CONTRIBUTIONS OF AUTHORS . . . . . . . . . . . . . . . . . . . . . . . . . . . . . . . . . . . . . . . . . . . . .

DECLARATIONS OF INTEREST . . . . . . . . . . . . . . . . . . . . . . . . . . . . . . . . . . . . . . . . . 102

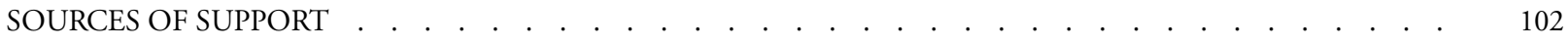

Alternatives, and adjuncts, to prophylactic platelet transfusion for people with haematological malignancies undergoing intensive

chemotherapy or stem cell transplantation (Review)

Copyright $\odot 2016$ The Cochrane Collaboration. Published by John Wiley \& Sons, Ltd. 
DIFFERENCES BETWEEN PROTOCOL AND REVIEW . . . . . . . . . . . . . . . . . . . . . . 102

NOTES . . . . . . . . . . . . . . . . . . . . . . . . . . . . . . . . . . . . . . . . 105

Alternatives, and adjuncts, to prophylactic platelet transfusion for people with haematological malignancies undergoing intensive chemotherapy or stem cell transplantation (Review)

Copyright $\odot 2016$ The Cochrane Collaboration. Published by John Wiley \& Sons, Ltd. 


\title{
[Intervention Review] \\ Alternatives, and adjuncts, to prophylactic platelet transfusion for people with haematological malignancies undergoing intensive chemotherapy or stem cell transplantation
}

\author{
Michael Desborough $^{1}$, Lise J Estcourt ${ }^{1}$, Carolyn Doree ${ }^{2}$, Marialena Trivella ${ }^{3}$, Sally Hopewell ${ }^{4}$, Simon J Stanworth ${ }^{5}$, Michael F Murphy \\ ${ }^{1}$ Haematology/Transfusion Medicine, NHS Blood and Transplant, Oxford, UK. ${ }^{2}$ Systematic Review Initiative, NHS Blood and \\ Transplant, Oxford, UK. ${ }^{3}$ Centre for Statistics in Medicine, University of Oxford, Oxford, UK. ${ }^{4}$ Oxford Clinical Trials Research Unit, \\ University of Oxford, Oxford, UK. ${ }^{5}$ National Institute for Health Research (NIHR) Oxford Biomedical Research Centre, Oxford \\ University Hospitals NHS Foundation Trust and University of Oxford, Oxford, UK. ${ }^{6}$ NHS Blood and Transplant; National Institute \\ for Health Research (NIHR) Oxford Biomedical Research Centre, Oxford University Hospitals NHS Foundation Trust and University \\ of Oxford, Oxford, UK
}

Contact address: Lise J Estcourt, Haematology/Transfusion Medicine, NHS Blood and Transplant, Oxford, UK. lise.estcourt@nhsbt.nhs.uk. lise.estcourt@ndcls.ox.ac.uk.

Editorial group: Cochrane Haematological Malignancies Group.

Publication status and date: New, published in Issue 8, 2016.

Review content assessed as up-to-date: 19 May 2016.

Citation: Desborough M, Estcourt LJ, Doree C, Trivella M, Hopewell S, Stanworth SJ, Murphy MF. Alternatives, and adjuncts, to prophylactic platelet transfusion for people with haematological malignancies undergoing intensive chemotherapy or stem cell transplantation. Cochrane Database of Systematic Reviews 2016, Issue 8. Art. No.: CD010982. DOI: 10.1002/14651858.CD010982.pub2.

Copyright (C) 2016 The Cochrane Collaboration. Published by John Wiley \& Sons, Ltd.

\begin{abstract}
A B S T R A C T
Background

Platelet transfusions are used in modern clinical practice to prevent and treat bleeding in people with thrombocytopenia. Although considerable advances have been made in platelet transfusion therapy since the mid-1970s, some areas continue to provoke debate especially concerning the use of prophylactic platelet transfusions for the prevention of thrombocytopenic bleeding.
\end{abstract}

Objectives

To determine whether agents that can be used as alternatives, or adjuncts, to platelet transfusions for people with haematological malignancies undergoing intensive chemotherapy or stem cell transplantation are safe and effective at preventing bleeding.

Search methods

We searched 11 bibliographic databases and four ongoing trials databases including the Cochrane Central Register of Controlled Trials (CENTRAL, 2016, Issue 4), MEDLINE (OvidSP, 1946 to 19 May 2016), Embase (OvidSP, 1974 to 19 May 2016), PubMed (epublications only: searched 19 May 2016), ClinicalTrials.gov, World Health Organization (WHO) ICTRP and the ISRCTN Register (searched 19 May 2016).

\section{Selection criteria}

We included randomised controlled trials in people with haematological malignancies undergoing intensive chemotherapy or stem cell transplantation who were allocated to either an alternative to platelet transfusion (artificial platelet substitutes, platelet-poor plasma, fibrinogen concentrate, recombinant activated factor VII, desmopressin (DDAVP), or thrombopoietin (TPO) mimetics) or a comparator (placebo, standard care or platelet transfusion). We excluded studies of antifibrinolytic drugs, as they were the focus of another review.

Alternatives, and adjuncts, to prophylactic platelet transfusion for people with haematological malignancies undergoing intensive 


\section{Data collection and analysis}

Two review authors screened all electronically derived citations and abstracts of papers identified by the review search strategy. Two review authors assessed risk of bias in the included studies and extracted data independently.

\section{Main results}

We identified 16 eligible trials. Four trials are ongoing and two have been completed but the results have not yet been published (trial completion dates: April 2012 to February 2017). Therefore, the review included 10 trials in eight references with 554 participants. Six trials (336 participants) only included participants with acute myeloid leukaemia undergoing intensive chemotherapy, two trials (38 participants) included participants with lymphoma undergoing intensive chemotherapy and two trials (180 participants) reported participants undergoing allogeneic stem cell transplantation. Men and women were equally well represented in the trials. The age range of participants included in the trials was from 16 years to 81 years. All trials took place in high-income countries. The manufacturers of the agent sponsored eight trials that were under investigation, and two trials did not report their source of funding.

No trials assessed artificial platelet substitutes, fibrinogen concentrate, recombinant activated factor VII or desmopressin.

Nine trials compared a TPO mimetic to placebo or standard care; seven of these used pegylated recombinant human megakaryocyte growth and differentiation factor (PEG-rHuMGDF) and two used recombinant human thrombopoietin (rhTPO).

One trial compared platelet-poor plasma to platelet transfusion.

We considered that all the trials included in this review were at high risk of bias and meta-analysis was not possible in seven trials due to problems with the way data were reported.

We are very uncertain whether TPO mimetics reduce the number of participants with any bleeding episode (odds ratio (OR) 0.40 , $95 \%$ confidence interval (CI) 0.10 to 1.62 , one trial, 120 participants, very low quality evidence). We are very uncertain whether TPO mimetics reduce the risk of a life-threatening bleed after 30 days (OR 1.46, 95\% CI 0.06 to 33.14, three trials, 209 participants, very low quality evidence); or after 90 days (OR 1.00, 95\% CI 0.06 to 16.37, one trial, 120 participants, very low quality evidence). We are very uncertain whether TPO mimetics reduce platelet transfusion requirements after 30 days (mean difference -3.00 units, $95 \% \mathrm{CI}$ 5.39 to -0.61 , one trial, 120 participants, very low quality evidence). No deaths occurred in either group after 30 days (one trial, 120 participants, very low quality evidence). We are very uncertain whether TPO mimetics reduce all-cause mortality at 90 days (OR 1.00 , 95\% CI 0.24 to 4.20, one trial, 120 participants, very low quality evidence). No thromboembolic events occurred for participants treated with TPO mimetics or control at 30 days (two trials, 209 participants, very low quality evidence). We found no trials that looked at: number of days on which bleeding occurred, time from randomisation to first bleed or quality of life.

One trial with 18 participants compared platelet-poor plasma transfusion with platelet transfusion. We are very uncertain whether platelet-poor plasma reduces the number of participants with any bleeding episode (OR 16.00, 95\% CI 1.32 to 194.62, one trial, 18 participants, very low quality evidence). We are very uncertain whether platelet-poor plasma reduces the number of participants with severe or life-threatening bleeding (OR 4.00, 95\% CI 0.56 to 28.40, one trial, 18 participants, very low quality evidence). We found no trials that looked at: number of days on which bleeding occurred, time from randomisation to first bleed, number of platelet transfusions, all-cause mortality, thromboembolic events or quality of life.

\section{Authors' conclusions}

There is insufficient evidence to determine if platelet-poor plasma or TPO mimetics reduce bleeding for participants with haematological malignancies undergoing intensive chemotherapy or stem cell transplantation. To detect a decrease in the proportion of participants with clinically significant bleeding from 12 in 100 to 6 in 100 would require a trial containing at least 708 participants (80\% power, $5 \%$ significance). The six ongoing trials will provide additional information about the TPO mimetic comparison (424 participants) but this will still be underpowered to demonstrate this level of reduction in bleeding. None of the included or ongoing trials include children. There are no completed or ongoing trials assessing artificial platelet substitutes, fibrinogen concentrate, recombinant activated factor VII or desmopressin in people undergoing intensive chemotherapy or stem cell transplantation for haematological malignancies.

\section{PLAIN LANGUAGE SUMMARY}

Alternative or additional agents to platelet transfusions to prevent bleeding in people with blood cancers receiving intensive treatment

Alternatives, and adjuncts, to prophylactic platelet transfusion for people with haematological malignancies undergoing intensive 


\section{Review question}

What is the best way to prevent bleeding for people being treated with intensive chemotherapy or stem cell transplantation for blood, or bone marrow cancers? Should we use platelet transfusions (the current standard treatment), or use other agents instead of (or as well as) platelet transfusions.

\section{Background}

Approximately one in eight cancers arise from the blood, bone marrow, or lymph nodes. These cancers are divided into many different types that are treated differently. Examples include acute myeloid leukaemia and lymphoma. Some of these cancers can be cured with high-dose (intensive) chemotherapy or stem cell transplantation. These treatments destroy the cancer but can also damage the normal blood-producing cells. One consequence of this is a reduction in the number of platelets in the blood. Platelets are essential to make the blood clot normally. Consequently, people receiving these treatments are vulnerable to bleeding until their platelets increase in number.

Platelet transfusions (taken from a blood donor) are often given to try to prevent people with blood cancer from bleeding. We do not know how well these transfused platelets work. We know that there are risks from platelet transfusion, such as transmission of infections. It is possible that there are better ways to prevent bleeding in this setting. In this review, we examined whether other agents could be used instead of (or as well as) platelet transfusion to prevent bleeding. We also assessed the risk of serious side effects, such as forming abnormal blood clots (thromboembolic events). Potential agents include artificial platelets, platelet-poor plasma, fibrinogen concentrate, recombinant activated factor VII, desmopressin and thrombopoietin mimetics. Terms and treatments are described in the glossary in the 'Published notes' section of this review).

\section{Study characteristics}

The evidence is current to May 2016. We identified 16 clinical trials: 10 completed trials and six ongoing trials. We included the 10 completed trials in this review. Six trials included adults with acute myeloid leukaemia undergoing intensive chemotherapy, two trials included adults with lymphoma undergoing intensive chemotherapy and two trials included adults undergoing allogeneic stem cell transplantation. The age range of participants was between 16 and 81 years. Men and women were equally well represented. All trials took place in high-income countries. The manufacturer of the agent that was under investigation sponsored eight trials, and two trials did not report their source of funding. We identified nine trials (536 participants) assessing thrombopoietin mimetics and one trial (18 participants) assessing platelet-poor plasma. These trials were conducted between 1974 and 2015. No trial assessed artificial platelets, fibrinogen concentrate, recombinant activated factor VII or desmopressin).

\section{Key results}

For adults treated with thrombopoietin mimetics, we are very uncertain whether there is a difference in the number of participants with: any bleeding, risk of life-threatening bleeding, number of platelet transfusions, overall risk of death or thromboembolic events because the quality of the evidence was very low. We found no trials of thrombopoietin mimetics that looked at: the number of days on which bleeding occurred, time from start of trial to first bleed or quality of life.

For adults treated with platelet-poor plasma, we are very uncertain whether there is a difference in the number of participants with: any bleeding or risk of life-threatening bleeding. We found no trials that looked at: the number of days on which bleeding occurred, time from start of trial to first bleeding episode, number of platelet transfusions, overall risk of death, thromboembolic events or quality of life.

\section{Quality of the evidence}

The quality of the evidence was very low, making it difficult to draw conclusions or make recommendations regarding the usefulness and safety of thrombopoietin mimetics or platelet-poor plasma. There was no trial evidence for artificial platelets, fibrinogen concentrate, recombinant activated factor VII or desmopressin. 
SUMMARY OF FINDINGS FOR THE MAIN COMPARISON [Explanation]

\section{Thrombopoietin mimetics versus placebo or standard care}

Population: people with haematological disorders undergoing intensive chemotherapy or stem cell transplantation

Intervention: thrombopoietin mimetics

Comparison: placebo or standard care

\begin{tabular}{|c|c|c|c|c|c|c|}
\hline \multirow[t]{2}{*}{ Outcomes } & \multicolumn{2}{|c|}{ Anticipated absolute effects ${ }^{*}(95 \% \mathrm{Cl})$} & \multirow{2}{*}{$\begin{array}{l}\text { Relative effect } \\
(95 \% \mathrm{Cl})\end{array}$} & \multirow{2}{*}{$\begin{array}{l}\text { No of participants } \\
\text { (trials) }\end{array}$} & \multirow{2}{*}{$\begin{array}{l}\text { Quality of the evidence } \\
\text { (GRADE) }\end{array}$} & \multirow{2}{*}{ Comments } \\
\hline & $\begin{array}{l}\text { Risk with placebo or } \\
\text { standard care }\end{array}$ & $\begin{array}{l}\text { Risk with thrombopoi- } \\
\text { etin mimetics }\end{array}$ & & & & \\
\hline \multirow{4}{*}{$\begin{array}{l}\text { Number of participants } \\
\text { with at least } 1 \text { bleeding } \\
\text { episode } \\
\text { follow-up: } 30 \text { days }\end{array}$} & Trial population & & \multirow{4}{*}{$\begin{array}{l}\text { OR } 0.40 \\
(0.10 \text { to } 1.62)\end{array}$} & \multirow{4}{*}{$\begin{array}{l}120 \\
(1 \mathrm{RCT})\end{array}$} & \multirow{4}{*}{$\begin{array}{l}\oplus \bigcirc \bigcirc \bigcirc \\
\text { Very low } 1,2\end{array}$} & \multirow{4}{*}{$\begin{array}{l}2 \text { further trials reported } \\
\text { combined results that } \\
\text { could not be included } \\
\text { in the analysis. } 25 \% \text { of } \\
\text { participants in the com- } \\
\text { bined intervention arms } \\
\text { and } 50 \% \text { in combined } \\
\text { controlarms had a least } \\
1 \text { clinically significant } \\
\text { bleeding episode }\end{array}$} \\
\hline & 50 per 1000 & $\begin{array}{l}21 \text { per } 1000 \\
(5 \text { to } 79)\end{array}$ & & & & \\
\hline & \multicolumn{2}{|l|}{ Moderate** } & & & & \\
\hline & 430 per 1000 & $\begin{array}{l}232 \text { per } 1000 \\
(70 \text { to } 550)\end{array}$ & & & & \\
\hline \multirow{2}{*}{$\begin{array}{l}\text { Number of participants } \\
\text { with severe or life- } \\
\text { threatening bleeding } \\
\text { follow-up: } 30 \text { days }\end{array}$} & Moderate** & & \multirow{2}{*}{$\begin{array}{l}\text { OR } 1.46 \\
(0.06 \text { to } 33.14)\end{array}$} & \multirow{2}{*}{$\begin{array}{l}209 \\
\text { (3 RCTs) }\end{array}$} & \multirow{2}{*}{$\begin{array}{l}\oplus \bigcirc \bigcirc \bigcirc \\
\text { Very low } 3,4\end{array}$} & \multirow{2}{*}{$\begin{array}{l}\text { No severe or life-threat- } \\
\text { ening bleeding events } \\
\text { occurred in the control } \\
\text { arms of these trials }\end{array}$} \\
\hline & 3 per 1000 & $\begin{array}{l}5 \text { per } 1000 \\
(0 \text { to } 102)\end{array}$ & & & & \\
\hline $\begin{array}{l}\text { Number of days on } \\
\text { which bleeding oc- } \\
\text { curred-not reported }\end{array}$ & Not estimable & & Not estimable & (No trials) & - & Outcome not reported \\
\hline $\begin{array}{l}\text { Time from randomisa- } \\
\text { tion to first bleeding } \\
\text { episode - not reported }\end{array}$ & Not estimable & & Not estimable & (No trials) & & Outcome not reported \\
\hline
\end{tabular}




\begin{tabular}{|c|c|c|c|c|c|c|c|}
\hline $\begin{array}{ll}0 \\
0 \\
0\end{array}$ & $\begin{array}{l}\text { All-cause mortality } \\
\text { follow-up: } 30 \text { days }\end{array}$ & Not estimable & Not estimable & $\begin{array}{l}120 \\
(1 \mathrm{RCT})\end{array}$ & $\begin{array}{l}\oplus \bigcirc \bigcirc \bigcirc \\
\text { Very low } 4,5\end{array}$ & $\begin{array}{l}\text { No deaths reported in } \\
\text { either arm of this trial. } \\
2 \text { further trials reported } \\
\text { combined results that } \\
\text { could not be included in } \\
\text { the analysis: all-cause } \\
\text { mortality } 0 \% \text { to } 8.3 \% \text { in } \\
\text { intervention arms and } \\
11.8 \% \text { in the combined } \\
\text { control arms }\end{array}$ & \\
\hline 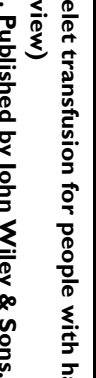 & $\begin{array}{l}\text { Number of platelet } \\
\text { transfusions } \\
\text { follow-up: } 30 \text { days }\end{array}$ & $\begin{array}{l}\text { The mean number } \\
\text { of platelet transfusions } \\
\text { was } 9 \text { units }\end{array}$ & $\begin{array}{l}\text { The mean number of } \\
\text { platelet transfusions in } \\
\text { the intervention group } \\
\text { was } 3 \text { units lower ( } 5.39 \\
\text { lower to } 0.61 \text { lower) }\end{array}$ & 更 & $\begin{array}{l}120 \\
(1 \mathrm{RCT})\end{array}$ & $\begin{array}{l}\oplus \bigcirc \bigcirc \bigcirc \\
\text { Very low } 1,2\end{array}$ & $\begin{array}{l}5 \text { other trials reported } \\
\text { in a manner that could } \\
\text { not be incorporated } \\
\text { into meta-analysis. Me- } \\
\text { dian platelet transfu- } \\
\text { sions were } 4 \text { to } 10 \text { units } \\
\text { in the intervention arms } \\
\text { and } 4 \text { to } 8 \text { units in the } \\
\text { control arms }\end{array}$ \\
\hline 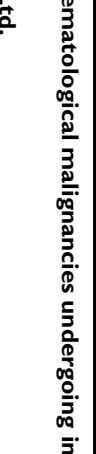 & $\begin{array}{l}\text { Thromboembolic } \\
\text { events } \\
\text { follow-up: } 30 \text { days }\end{array}$ & Not estimable & & Not estimable & $\begin{array}{l}209 \\
\text { (2 RCTs) }\end{array}$ & $\begin{array}{l}\oplus \bigcirc \bigcirc \bigcirc \\
\text { Very low } 4,5\end{array}$ & $\begin{array}{l}\text { No thromboembolic } \\
\text { events were reported in } \\
\text { any arm of these trials. } \\
5 \text { further trials reported } \\
\text { combined results that } \\
\text { could not be included } \\
\text { in the analysis: throm- } \\
\text { boembolic events } 0 \% \\
\text { to } 9.1 \% \text { in intervention } \\
\text { arms and } 5.6 \% \text { to } 15.8 \% \\
\text { in the control arms }\end{array}$ \\
\hline 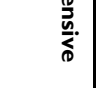 & $\begin{array}{l}\text { Quality of life - not re- } \\
\text { ported }\end{array}$ & Not estimable & & Not estimable & (No trials) & - & Outcome not reported \\
\hline
\end{tabular}


${ }^{*}$ The risk in the intervention group (and its $95 \%$ confidence interval) is based on the assumed risk in the comparison group and the relative effect of the intervention (and its $95 \% \mathrm{Cl})$.

** Background risk derived from the prophylactic transfusion arm of TOPPS trial (Stanworth 2013).

Cl: confidence interval; OR: odds ratio; RCT: randomised controlled trial.

\section{GRADE Working Group grades of evidence}

High quality: We are very confident that the true effect lies close to that of the estimate of the effect

Moderate quality: We are moderately confident in the effect estimate: The true effect is likely to be close to the estimate of the effect, but there is a possibility that it is substantially different

Low quality: Our confidence in the effect estimate is limited: The true effect may be substantially different from the estimate of the effect

Very low quality: We have very little confidence in the effect estimate: The true effect is likely to be substantially different from the estimate of effect

Downgraded one point due to imprecision (low event rate with confidence intervals including both absolute estimates of benefit and of harm).

Downgraded two points due to risk of performance and detection bias.

${ }^{3}$ Downgraded one point rather than two points due to risk of performance and detection bias, because the outcome had already been downgraded by two points due to imprecision.

${ }^{4}$ Downgraded two points due to imprecision (low event rate with confidence intervals including both absolute estimates of benefit and of harm).

Downgraded one point due to risk of performance bias. 


\section{B A C K G R O U N D}

\section{Description of the condition}

Haematological malignancies account for between $8 \%$ and $9 \%$ of all new cancers reported in the UK and USA (CDC 2012; ONS $2014)$, and their incidence is increasing (11\% to $14 \%$ increase in new cases of lymphoma and myeloma between 1991 and 2001, and 2008 and 2010) (Cancer Research UK 2013). The prevalence of these cancers is also increasing due to increased survival rates (Coleman 2004; Rachet 2009). These improved survival rates are due to the introduction of intensive chemotherapy treatments and use of stem cell transplantation (Burnett 2011; Fielding 2007; Patel 2009). Over 50,000 haematopoietic stem cell transplants (HSCT) are carried out annually worldwide (Gratwohl 2010), and are used to treat both malignant and non-malignant haematological disorders. Autologous HSCT is the most common type of HSCT (57\% to 59\%) (Gratwohl 2010; Passweg 2012). However, chemotherapy and stem cell transplantation can lead to prolonged periods of severe thrombocytopenia (De la Serna 2008; Heddle 2009a; Rysler 2010; Stanworth 2013; Wandt 2012).

Platelet transfusions are used in modern clinical practice to prevent and treat bleeding in people with thrombocytopenia with bone marrow failure secondary to chemotherapy or stem cell transplantation. Administration of platelet transfusions to people with haematological disorders now constitute a significant proportion (up to 67\%) of all platelets issued (Cameron 2007; Greeno 2007; Pendry 2011), and the majority of these (69\%) are given to prevent bleeding (Estcourt 2012a).

People can become refractory to platelet transfusions. In an analysis of the TRAP 1997 study data, there was a progressive decrease in the post-transfusion platelet count increments and time interval between transfusions as the number of preceding transfusions increased (Slichter 2005). This effect was seen irrespective of whether or not people had developed detectable human leukocyte antigen (HLA) antibodies (Slichter 2005).

Platelet transfusions are also associated with adverse events. Mild to moderate reactions to platelet transfusions include rigors, fever and urticaria (Heddle 2009b). These reactions are not life-threatening but can be extremely distressing for the person. Rarer, but more serious sequelae include: anaphylaxis, transfusion-transmitted infections, transfusion-related acute lung injury and immunomodulatory effects (Benson 2009; Blumberg 2009; Bolton-Maggs 2012; Heddle 2009b; Knowles 2011; Pearce 2011; Popovsky 1985; Silliman 2003; Taylor 2010).

Any strategy that can safely decrease the need for prophylactic platelet transfusions in people with haematological disorders will have significant logistical and financial implications as well as decreasing peoples' exposure to the risks of transfusion.

\section{Description of the intervention}

The standard practice in most haematology units across the developed world is to use prophylactic transfusions to prevent bleeding for people with thrombocytopenia due to intensive chemotherapy or stem cell transplantation in line with guidelines $(\mathrm{BCSH}$ 2003; BCSH 2004; Board 2009; NBA 2012; Schiffer 2001; Slichter 2007; Tinmouth 2007). The experimental intervention is to give an alternative treatment, such as artificial platelet substitutes, platelet-poor plasma (PPP), recombinant activated factor VII (rFVIIa), fibrinogen or TPO mimetics. This review does not include anti-fibrinolytics (lysine analogues) because they are the focus of another Cochrane Review (Estcourt 2016).

\section{How the intervention might work}

Alternatives to platelet transfusions for decreasing the incidence of thrombocytopenic bleeding have been suggested. These include the use of artificial substitutes for platelets, treatment with pharmacological agents that act at different parts of the clotting cascade (Estcourt 2016; Mannucci 1997), and growth factor agonists to stimulate the person's bone marrow to recover more rapidly and therefore decrease the duration of thrombocytopenia (Miao 2012).

\section{Artificial platelet substitutes}

Artificial platelet substitutes overcome some of the problems associated with prophylactic platelet transfusions derived from donors (limited supply and risk of infection). Various different forms have been suggested and studied, including liposomes, nanoparticles, nanosheets and hydrogels (Doshi 2012; Nishiya 2002; Okamura 2009a; Okamura 2009b). In vitro studies and animal models have been used to assess the efficacy of these agents (Doshi 2012; Nishiya 2002; Okamura 2009a; Okamura 2009b).

\section{Platelet-poor plasma (PPP)}

PPP is a source of clotting factor concentrates and fibrinogen ( Desborough 2012).

\section{Recombinant factor VIla}

rFVIIa is licensed for use in people with haemophilia and inhibitory allo-antibodies, and for prophylaxis and treatment of people with congenital factor VII deficiency. It is also used for offlicense indications to prevent bleeding in operations where blood loss is likely to be high, or to stop bleeding that is proving difficult to control by other means, or both. However, one systematic review showed that the effectiveness of rFVIIa outside its licensed indications remains unproven (Simpson 2012). 


\section{Fibrinogen}

Fibrinogen is the endogenous substrate for fibrin formation (Manco-Johnson 2009). The formation of a fibrin network, formed by activated platelets and cross-linked fibrin strings, is the endpoint of the coagulation process in vivo (Sørensen 2011). Multiple in vitro experiments, animal studies and non-randomised clinical trials have suggested that use of a fibrinogen concentrate may be efficient and safe in controlling perioperative bleeding (Solomon 2010; Sørensen 2011).

\section{Desmopressin}

Desmopressin (DDAVP), a derivative of the antidiuretic hormone, has been used since the 1970s to treat mild haemophilia A and von Willebrand's disease without the need for blood products (Mannucci 1997). DDAVP increases the plasma levels of factor VIII (FVIII) and von Willebrand factor (vWF) and enhances platelet adhesion to the vessel wall but has no effect on the platelet count (Barnhart 1983; Mannucci 1997; Sakariassen 1984). It has been shown to be effective at preventing bleeding in people who have normal levels of FVIII and vWF, for example, people with uraemia (Mannucci 1997).

\section{Thrombopoietin mimetics}

TPO is the major regulator of both megakaryopoiesis and thrombopoiesis, it promotes cell differentiation and prevents apoptosis of megakaryocyte colony-forming cells and early megakaryocyte progenitors (Kuter 2010). The two main TPO mimetics in current use are romiplostim (weekly injection) and eltrombopag (daily oral tablet). The National Institute for Health and Care Excellence (NICE) recommends both romiplostim and eltrombopag for use in adults with immune thrombocytopenia (ITP) who have severe disease and a high risk of bleeding (NICE 2011; NICE 2013). However, in one systematic review of TPO mimetics in chronic ITP there was no evidence to demonstrate that TPO mimetics improved significant bleeding events despite significantly increasing platelet response (Zeng 2011). PEG-rHuMGDF is a TPO mimetic that has now been withdrawn from development after the discovery that, in some cases, both participants and normal volunteers developed antiplatelet antibodies resulting in a prolonged thrombocytopenia (Li 2001). The efficacy of recombinant human thrombopoietin (rhTPO) (daily injection) is in under investigation in China (Han 2015; Miao 2012).

\section{Assessment of bleeding}

A bleeding assessment has been seen as a more clinically relevant measure of the effect of platelet transfusions than surrogate markers such as platelet increment.

Any review that uses bleeding as a primary outcome measure needs to assess the way that the trials have recorded bleeding. Unfortu- nately, the way bleeding has been recorded and assessed has varied markedly between trials (Cook 2004; Estcourt 2013; Heddle 2003).

Retrospective analysis of bleeding leads to a risk of bias because bleeding events may be missed, and only more severe bleeding is likely to have been documented. Prospective bleeding assessment forms provide more information and are less likely to miss bleeding events. However, different assessors may grade the same bleed differently and it is very difficult to blind the assessor to the intervention.

The majority of trials have used the World Health Organization (WHO) system, or a modification of it, for grading bleeding (Estcourt 2013; Koreth 2004; WHO 1979). One limitation of all the scoring systems that have been based on the WHO system is that the categories are relatively broad and subjective. This means that a small change in a person's bleeding risk may not be detected. Another limitation is that the modified WHO categories are partially defined by whether a bleeding person requires a blood transfusion. The threshold for intervention may vary between clinicians and institutions and so the same level of bleeding could be graded differently in different institutions.

The definition of what constitutes clinically significant bleeding has varied between trials. Although the majority of more recent platelet transfusion trials (Heddle 2009a; Slichter 2010; Stanworth 2010; Wandt 2012) now classify it as WHO grade 2 or above, there has been greater heterogeneity in the past (Cook 2004; Estcourt 2013; Koreth 2004). The difficulties with assessing and grading bleeding may limit the ability to compare results between trials and this needs to be kept in mind when reviewing the evidence for the effectiveness of prophylactic platelet transfusions.

\section{Why it is important to do this review}

This review focused on the additional question of whether alternative agents instead of prophylactic platelet transfusions can be used for the prevention or control (or both) of life-threatening thrombocytopenic bleeding. This review did not assess the evidence for antifibrinolytics (lysine analogues) as this is the focus of another review (Estcourt 2016).

Avoiding the need for unnecessary prophylactic platelet transfusions in people with haematological malignancies will have significant logistical and financial implications for national health services as well as decreasing people's exposure to the risks of transfusion. This knowledge is perhaps even more important in the development of platelet transfusion strategies in low and middle income countries where access to blood components is much more limited (Verma 2009).

This review did not assess whether there are any differences in the efficacy of apheresis versus whole-blood derived platelet products, the efficacy of pathogen-reduced platelet components, the efficacy of HLA-matched versus random donor platelets, or differences between $\mathrm{ABO}$ identical and $\mathrm{ABO}$ non-identical platelet transfusions. 
This is because these topics have been covered by other systematic reviews (Butler 2013; Heddle 2008; Pavenski 2013; Shehata 2009).

\section{O B J E C T IVES}

To determine whether agents that can be used as alternatives, or adjuncts, to platelet transfusions for people with haematological malignancies undergoing intensive chemotherapy or stem cell transplantation are safe and effective at preventing bleeding.

\section{METHODS}

\section{Criteria for considering studies for this review}

\section{Types of studies}

We included randomised controlled trials (RCTs). We applied no restrictions on language or publication status.

\section{Types of participants}

We included people with haematological malignancies receiving treatment with intensive chemotherapy or stem cell transplantation (or both). We included participants of all ages, and included both inpatients and outpatients.

When trials consisted of mixed populations of participants (e.g. people with diagnoses of solid tumours), we used only data from the haematological subgroups. If subgroup data for haematological participants were not provided (after contacting the authors of the trial), we excluded trials if less than $80 \%$ of participants had a haematological disorder. We excluded any participants that were not treated with intensive chemotherapy or a stem cell transplant as these participants are the focus of another review (Desborough 2016). We included participants with non-malignant haematological disorders (e.g. aplastic anaemia, congenital bone marrow failure syndromes) that were being treated with an allogeneic stem cell transplant. We also excluded people treated with non-intensive chemotherapy (such as azacitidine, decitabine and lenalidomide) because the degree of thrombocytopenia is much less profound with a lower risk of bleeding. Trials in people with chronic bone marrow failure using these agents are reported in another review (Desborough 2016).

\section{Types of interventions}

We included the two following comparisons:

- alternative agent versus prophylactic platelet transfusion;

- alternative agent and prophylactic platelet transfusion versus placebo or no treatment and prophylactic platelet transfusion.

We considered the following interventions:

- experimental intervention: alternative agents:
○ artificial platelet substitutes;
○ PPP;
$\circ$ rFVIIa;
- fibrinogen;
- TPO mimetics;
- DDAVP.

We placed no restrictions on the dose of alternative agents used.

- Comparator intervention:

○ comparison one: alternative agent versus prophylactic platelet transfusion. The comparator was prophylactic platelet transfusions. Transfusion of platelet concentrates, prepared either from individual units of whole blood or by apheresis, and given prophylactically to prevent bleeding. Prophylactic platelet transfusions are typically given when blood platelet counts fall below a given trigger level. There was no restriction on the dose or frequency of platelet transfusions, neither was there a restriction on the transfusion trigger level, although we took this information into account in the analysis where available;

- comparison two: alternative agent and prophylactic platelet transfusion versus placebo or no treatment and prophylactic platelet transfusion. The comparator was prophylactic platelet transfusions and placebo or no treatment. There was no restriction on the dose or frequency of platelet transfusions used in addition to the alternative agents, but the dose of prophylactic platelet transfusions received and the platelet transfusion threshold at which they were given was the same in both arms of the trial.

\section{Types of outcome measures}

\section{Primary outcomes}

- Number and severity of bleeding episodes within 30 days from the start of the trial: episode.

- Number of participants with at least one bleeding

- Total number of days on which bleeding occurred per participant.

- Number of participants with at least one episode of severe or life-threatening bleeding.

○ Time from randomisation to first bleeding episode. 


\section{Secondary outcomes}

- Mortality (all-causes, secondary to bleeding and secondary to infection) within 30 days and 90 days from the start of the trial.

- Overall survival within 30 days, 90 days and 180 days from the start of the trial.

- Proportion of participants requiring additional interventions to stop bleeding (surgical, medical e.g. tranexamic acid, other blood products e.g. fresh frozen plasma (FFP), cryoprecipitate) within 30 days from the start of the trial.

- Number of platelet transfusions per participant and number of platelet components per participant within 30 days from the start of the trial.

- Platelet transfusion interval within 30 days from the start of the trial.

- Duration of thrombocytopenia within 30 days from the start of the trial.

- Number of red cell transfusions per participant and number of red cell components per participant within 30 days from the start of the trial.

- Proportion of participants achieving complete remission within 30 days and 90 days from the start of the trial.

- Total time in hospital within 30 days from the start of the trial.

- Adverse effects of treatments (transfusion reactions, transfusion-transmitted infections, thromboembolism, development of platelet antibodies, development of platelet refractoriness, drug reactions) within 30 days and 90 days from the start of the trial.

- Quality of life, as defined by the individual trials.

We expressed all primary and secondary outcomes in the formats defined in the Measures of treatment effect section of this review when data were available. Quality of life used the trial's own measure as there is no definitive participant-reported outcome measure for this participant group (Estcourt 2014a). The platelet transfusion interval was calculated in many different ways and the exact methodology was not reported sufficiently to allow us to combine the data.

\section{Search methods for identification of studies}

The Systematic Review Initiative (SRI) Information Specialist (CD) formulated entirely new search strategies for this review in collaboration with the Cochrane Haematological Malignancies Review Group.

\section{Electronic searches}

\section{Bibliographic databases}

We searched the following databases:
- Cochrane Central Register of Controlled Trials

(CENTRAL, 2016, Issue 4) (Appendix 1);

- MEDLINE (OvidSP, 1946 to 19 May 2016) (Appendix 2);

- Embase (OvidSP, 1974 to 19 May 2016) (Appendix 3);

- PubMed (e-publications only, 19 May 2016) (Appendix 4);

- CINAHL (EBSCOhost, 1982 to 19 May 2016) (Appendix $5)$;

- UKBTS/SRI Transfusion Evidence Library ( www.transfusionevidencelibrary.com) (1950 to 19 May 2016) (Appendix 6);

- Web of Science: Conference Proceedings Citation IndexScience (CPCI-S) (Thomson Reuters, 1990 to 19 May 2016) (Appendix 7);

- LILACS (BIREME/PAHO/WHO, 1982 to 19 May 2016) (Appendix 8);

- IndMed (ICMR-NIC, 1985 to 19 May 2016) (Appendix 9);

- KoreaMed (KAMJE, 1997 to 19 May 2016) (Appendix 10);

- PakMediNet (2001 to 19 May 2016) (Appendix 10).

As we rewrote the search strategies, we ran searches from the earliest dates specified above and did not updated them from the original and updated searches in January 2002 (Stanworth 2004) and November 2011 (Estcourt 2012b). We combined searches in MEDLINE, Embase and CINAHL with adaptations of the Cochrane RCT search filters, as detailed in the Cochrane Handbook for Systematic Reviews of Interventions (Lefebvre 2011).

\section{Databases of ongoing trials}

In order to identify ongoing trials to 19 May 2016, we also searched ClinicalTrials.gov (clinicaltrials.gov/ct2/search) (Appendix 11), the WHO International Clinical Trials Registry (ICTRP) ( apps.who.int/trialsearch/) (Appendix 11), the ISRCTN Register (www.controlled-trials.com/isrctn/) (Appendix 12), the EU Clinical Trials Register (www.clinicaltrialsregister.eu/ctr-search) (Appendix 13) and the Hong Kong Clinical Trials Register ( www.hkclinicaltrials.com/) (Appendix 14).

\section{Searching other resources}

\section{Handsearching of references}

We checked references of all included trials, relevant review articles and current treatment guidelines for further literature. We limited these searches to the 'first generation' reference lists.

\section{Personal contacts}

We contacted authors of relevant trials, trial groups and experts worldwide known to be active in the field for unpublished material or further information on ongoing trials. 


\section{Data collection and analysis}

\section{Selection of studies}

We updated the selection of studies from that performed for the previous version of this review (Estcourt 2012b).

Two review authors (MD, LE) independently performed an initial screen of all electronically derived citations and abstracts of papers identified by the review search strategy for relevance. We excluded clearly irrelevant trials at this stage.

Two review authors (MD, LE) independently assessed the full texts of all potentially relevant trials formally for eligibility against the criteria. We resolved all disagreements by discussion with a third review author (SS). We sought further information from trial authors if the article contained insufficient data to make a decision about eligibility. We designed a trial eligibility form for trials of platelet transfusion to help in the assessment of relevance, which included ascertaining whether the participants had haematological malignancies, and whether the two groups could be defined in the trial on the basis of use of an alternative agent to prophylactic platelet transfusions. We recorded the reasons why potentially relevant trials did not meet the eligibility criteria.

\section{Data extraction and management}

The data extraction was updated from that performed for the previous version of this review (Estcourt 2012b). This included data extraction for all trials that were included since the previous review and also for all review outcomes that were not part of the previous review (e.g. platelet transfusion interval, quality of life). Two review authors (MD, LE) independently conducted data extraction according to the guidelines proposed in the Cochrane Handbook for Systematic Reviews of Interventions (Higgins 2011a). We resolved disagreements between the review authors by consensus without the need for a third review author. The review authors were not blinded to names of authors, institutions, journals or outcomes of the trials. The data extraction forms were piloted in the previous version of this review (Estcourt 2012b). Due to minor changes in the format, the forms were piloted on a further trial, thereafter the two review authors (MD, LE) extracted data independently for all the trials as follows.

\section{General information}

Review author's name, date of data extraction, trial identity number, first author of trial, author's contact address (if available), citation of paper and objectives of the trial.

\section{Trial details}

Trial design, location, setting, sample size, power calculation, treatment allocation, randomisation, blinding, inclusion and exclusion criteria, reasons for exclusion, comparability of groups, length of follow-up, stratification, stopping rules described, statistical analysis, results, conclusion and funding.

\section{Characteristics of participants}

Age, gender, ethnicity, total number recruited, total number randomised, total number analysed, types of haematological disease, lost to follow-up numbers, drop outs (percentage in each arm) with reasons, protocol violations, previous treatments, current treatment, prognostic factors.

\section{Interventions}

Experimental and control interventions, type of platelet given, timing of intervention, dosage of platelet given, compliance to interventions, additional interventions given especially in relation to red cell transfusions, any differences between interventions.

\section{Assessment of bias}

Sequence generation, allocation concealment, blinding (participants, personnel and outcome assessors), incomplete outcome data, selective outcome reporting, other sources of bias.

\section{Outcomes measured}

Number and severity of bleeding episodes, mortality (all causes). mortality due to infection, mortality due to bleeding, overall survival, proportion of participants requiring additional interventions to stop bleeding (surgical, medical e.g. tranexamic acid, other blood products e.g. FFP, cryoprecipitate), number of platelet transfusions and platelet components, platelet transfusion interval, duration of thrombocytopenia, number of red cell transfusions and red cell components, proportion of participants achieving complete remission, time in hospital, adverse effects of treatments (e.g. transfusion reactions, transfusion-transmitted infections, thromboembolism, development of platelet antibodies or platelet refractoriness) and quality of life.

We used both full-text versions and abstracts to retrieve the data. We extracted publications reporting on more than one trial using one data extraction form for each trial and trials reported in more than one publication on one form only. When these sources did not provide sufficient information, we contacted the authors, trial groups or companies for additional details.

One review author (MD) entered data entry into Review Manager 5 (RevMan 2012) and a second review author (LE) checked entries for accuracy.

\section{Assessment of risk of bias in included studies}

The 'Risk of bias' assessment was updated from that performed for the previous version of this review (Estcourt 2012b).

Two review authors (MD, LE) assessed all newly included trials for possible risk of bias (as described in the Cochrane Handbook for 
Systematic Reviews of Interventions, (Higgins 2011b). The assessment included information about the design, conduct and analysis of the trial. Each criterion was evaluated on a three-point scale: low risk of bias, high risk of bias, or unclear risk of bias. To assess risk of bias, we included the following questions in the 'Risk of bias' table for each included trial.

- Was the allocation sequence adequately generated?

- Was allocation adequately concealed?

- Was knowledge of the allocated intervention adequately prevented during the trial (including an assessment of blinding of participants, personnel and outcome assessors)?

- Were incomplete outcome data adequately addressed (for every outcome separately)?

- Were reports of the trial free of selective outcome reporting?

- Was the trial apparently free of other problems that could put it at risk of bias?

\section{Measures of treatment effect}

For dichotomous outcomes, we recorded the number of outcomes in the treatment and control groups and estimated the treatment effect measures across individual trials as the relative effect measures (odds ratio (OR) with 95\% confidence interval (CI)). If continuous outcomes had been reported in a way that permitted analysis, we intended to record the mean and standard deviations (SD). For continuous outcomes measured using the same scale, the effect measure would have been the mean difference (MD) with $95 \% \mathrm{CI}$, or for outcomes measured using different scales, the effect measure would have been the standardised mean difference (SMD). For time-to-event outcomes, we planned to extracted the hazard ratio (HR) from published data according to Parmar 1998 and Tierney 2007. When appropriate, we planned to assess the number needed to treat for an additional beneficial outcome (NNTB) with CIs and the number needed to treat for an additional harmful outcome (NNTH) with CIs.

\section{Unit of analysis issues}

We did not prespecify in the original protocol how we would deal with any unit of analysis issues. In one trial, there were unit of analysis issues as three participants were re-randomised; we used only data from one randomisation in the quantitative analysis (Higby 1974).

The trials by Geissler (Geissler 2003-T1; Geissler 2003-T2) included 47 participants who had previously been treated in the trials by Archimbaud (Archimbaud 1999-T1; Archimbaud 1999-T2), so we did not combine data from these trials in a meta-analysis. We did not prespecify in the original protocol how we would deal with multi-arm trials. For two outcomes that included multi-arm trials (duration of thrombocytopenia and proportion of participants in complete remission), we split participants from the control arm equally between the intervention arms.

\section{Dealing with missing data}

We dealt with missing data according to the recommendations in the Cochrane Handbook for Systematic Reviews of Interventions (Higgins 2011c). We contacted authors in order to obtain information that was missing or unclear in the published report.

In trials that included participants with haematological malignancies as well as participants with solid tumours or non-malignant haematological disorders, we extracted data for the malignant haematology subgroup from the general trial data. When this could not be done, we contacted the trial author.

Within an outcome, when there were missing data, the preferred analysis was intention-to-treat (ITT) analysis. We recorded the number of participants lost to follow-up for each trial.

\section{Assessment of heterogeneity}

If trials were sufficiently homogenous in their trial design, we planned to conduct meta-analysis and assess the statistical heterogeneity (Deeks 2011). However, due to problems with the way trials were reported, we performed no meta-analyses. We planned to assess statistical heterogeneity of treatment effects between trials using a $\mathrm{Chi}^{2}$ test with a significance level at $\mathrm{P}<0.1$. We planned to use the $\mathrm{I}^{2}$ statistic to quantify possible heterogeneity $\left(\mathrm{I}^{2}>50 \%\right.$ moderate heterogeneity, $\mathrm{I}^{2}>80 \%$ considerable heterogeneity). When necessary, we intended to explore potential causes of heterogeneity by sensitivity and subgroup analyses. This was not possible with the final data set that was obtained.

\section{Assessment of reporting biases}

We did not assess for potential publication bias (small-trial bias) by generating a funnel plot, and statistically test using a linear regression test because the search identified an insufficient number of adequately reported trials reporting the primary outcome. We will perform such testing in future updates of this review if the search identifies at least 10 trials reporting the primary outcome. If this is the case, we will consider a $\mathrm{P}<0.1$ significant for this test (Sterne 2011).

\section{Data synthesis}

We performed analyses according to the recommendations of Cochrane (Deeks 2011). For statistical analysis, we entered data into Review Manager 5 (RevMan 2012).

- We used the random-effects model for pooling the data, using the Mantel-Haenszel method for dichotomous outcomes, and the inverse variance method for continuous outcomes.

- We used the random-effects model for sensitivity analyses as part of the exploration of heterogeneity. When heterogeneity was above $80 \%$, we did not perform a meta-analysis and commented on the results as a narrative. 
We used GRADEprofiler to create 'Summary of findings' tables as suggested in the Cochrane Handbook for Systematic Reviews of Interventions (Schünemann 2011). We reported 'Summary of findings' tables that included the following outcomes.

- Number of participants with at least one bleeding episode.

- Total number of days on which bleeding occurred per participant.

- Number of participants with at least one episode of severe or life-threatening bleeding.

- Time from randomisation to first bleeding episode.

- All-cause mortality.

- Number of platelet transfusions per participant within 30 days from the start of the trial.

- Adverse effects: thromboembolic events.

- Quality of life.

For future updates, we will produce separate 'Summary of findings' tables for each type of alternative agent if the search identifies trials of these agents.

\section{Subgroup analysis and investigation of heterogeneity}

The studies did not report data in sufficient detail to perform subgroup analysis or to investigate heterogeneity. For future reviews, we intend to use the following methodology.

Two subgroup analyses: we will use fever and participants' diagnostic and treatment subgroups. We will consider performing subgroup analyses on the following characteristics:

- presence of fever (greater than $38^{\circ} \mathrm{C}$ );

- underlying disease;

- type of treatment (autologous HSCT, allogeneic HSCT, or chemotherapy alone);

- age of the participant (paediatric, adults, older adults (over 60 years)).

We did not perform meta-regression as no subgroup contained more than 10 trials (Deeks 2011). For future updates of this review, if the search identifies sufficient trials for subgroup analysis, we will compare differences between subgroups using a randomeffects model when the two subgroups are independent following the guidance in the Cochrane Handbook for Systematic Reviews of Interventions (Deeks 2011). If this is not possible, then we will comment on the differences as a narrative.

We did not perform as investigation of heterogeneity between trials but for future updates this will include:

- age of the trial (as the type of platelet component has changed since the mid-1970s);

- different platelet component doses;

- different prophylactic platelet transfusion thresholds.

\section{Sensitivity analysis}

We did not perform a sensitivity analysis due to an inadequate number of adequately reported trials. For future updates of this review, we will assess robustness of the overall results with sensitivity analysis with respect to those trials deemed to be at high risk of bias.

For dichotomous data, we will assess the influence of participant drop-out, analysing separately RCTs with less than 20\% dropout, RCTs with $20 \%$ to $50 \%$ drop-out and RCTs with greater than $50 \%$ drop-out. We will use the random-effects model for sensitivity analyses as part of the exploration of heterogeneity.

\section{R E S U L T S}

\section{Description of studies}

See Characteristics of included studies; Characteristics of excluded studies; and Characteristics of ongoing studies.

\section{Results of the search}

The database searches identified 7312 references and searching the references of included trials identified one additional reference. After removing duplicates, there were 3583. Two review authors (MD, LE) screened these references according to the Review criteria, and we excluded 3425 references as they were not an RCT or were clearly outside the scope of this review (see PRISMA diagram Figure 1). We obtained the full text of the remaining 157 references and excluded 144 (21 review articles, 35 not RCTs, 46 wrong participant group, 19 incorrect interventions and 23 secondary citations). We assessed 16 trials reported in 14 papers and deemed them eligible for inclusion (Archimbaud 1999-T1; Archimbaud 1999-T2; Geissler 2003-T1; Geissler 2003-T2; Han 2015; Higby 1974; Miao 2012; Moskowitz 2007-T1; Moskowitz 2007-T2; Schiffer 2000; EudraCT 2015-000929-37; NCT01397149; NCT01656252; NCT01890746; Popat 2015; Vadhan-Raj 2010). Six trials were ongoing and are expected to be reported (EudraCT 2015000929-37; NCT01397149; NCT01656252; NCT01890746; Popat 2015; Vadhan-Raj 2010). We included the remaining eight papers (reporting 10 trials) in the qualitative analysis (Archimbaud 1999-T1; Archimbaud 1999-T2; Geissler 2003-T1; Geissler 2003-T2; Han 2015; Higby 1974; Miao 2012; Moskowitz 2007-T1; Moskowitz 2007-T2; Schiffer 2000). 
Figure I. PRISMA flow diagram.

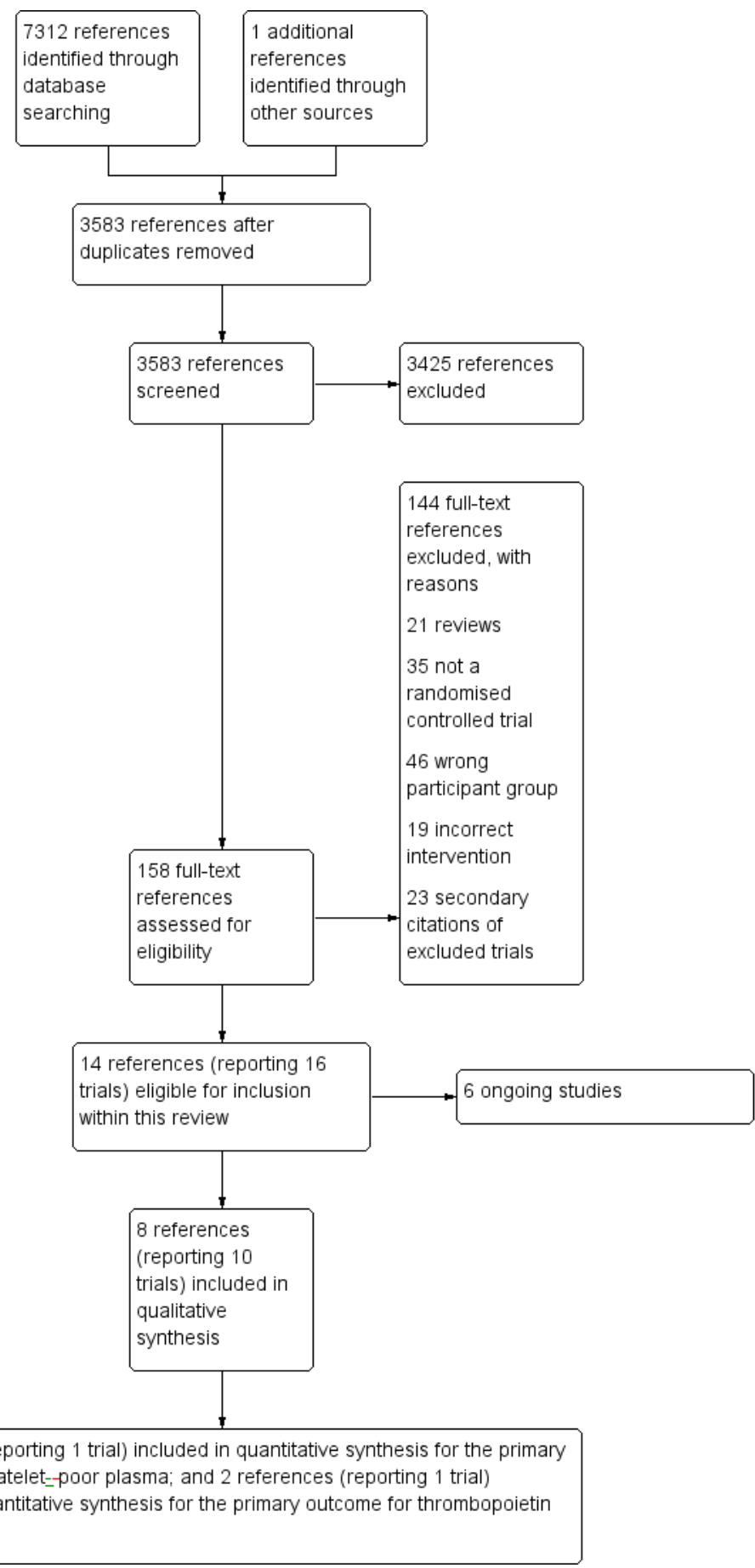

Alternatives, and adjuncts, to prophylactic platelet transfusion for people with haematological malignancies undergoing intensive 
We contacted the original authors and sponsors of the trials when possible but were unable to obtain any additional information.

\section{Included studies}

The analysis included 10 completed trials reported in seven papers (see Characteristics of included studies for full details of each trial).

\section{Design}

Ten trials were published as full-text articles (published in eight papers) between 1974 and 2015 (Archimbaud 1999-T1; Archimbaud 1999-T2; Geissler 2003-T1; Geissler 2003-T2; Han 2015; Higby 1974; Miao 2012; Moskowitz 2007-T1; Moskowitz 2007-T2; Schiffer 2000). Eight were published in English and two in Chinese (Miao 2012). Six trials were parallel-group two-arm trials (Geissler 2003-T1; Geissler 2003-T2; Han 2015; Higby 1974; Moskowitz 2007-T1; Moskowitz 2007-T2), three were threearm trials (Archimbaud 1999-T1; Archimbaud 1999-T2; Schiffer 2000), and one was a four-arm trial (Miao 2012).

\section{Sample sizes}

The trials included 554 participants with numbers ranging from 18 (Higby 1974) to 120 (Han 2015; Miao 2012).

\section{Setting}

Six trials were conducted in a single country, with four in the USA (Higby 1974; Moskowitz 2007-T1; Moskowitz 2007-T2; Schiffer 2000), and two in China (Han 2015; Miao 2012). The trials by Geissler were conducted in Europe and Australia (Geissler 2003-T1; Geissler 2003-T2), and the trials by Archimbaud did not specify which countries the trials were conducted in (Archimbaud 1999-T1; Archimbaud 1999-T2).

\section{Participants}

Six trials assessed participants undergoing chemotherapy for acute myeloid leukaemia (Archimbaud 1999-T1; Archimbaud 1999T2; Geissler 2003-T1; Geissler 2003-T2; Higby 1974; Schiffer 2000), two trials assessed participants undergoing intensive chemotherapy for lymphoma (Moskowitz 2007-T1; Moskowitz 2007-T2), and two trials assessed participants undergoing allogeneic stem cell transplantation (Han 2015; Miao 2012).

\section{Interventions}

Nine trials compared a TPO mimetic to placebo or standard care (Archimbaud 1999-T1; Archimbaud 1999-T2; Geissler 2003-T1;
Geissler 2003-T2; Han 2015; Miao 2012; Moskowitz 2007-T1; Moskowitz 2007-T2; Schiffer 2000).

One trial compared PPP to platelet transfusion (Higby 1974). No trials compared artificial platelet substitutes, rFVIIa, fibrinogen concentrate or DDAVP.

\section{Outcomes}

No trial reported all the outcomes of interest. Four trials reported data for our primary outcome of number and severity of bleeding episodes within 30 days from the start of the trial (Geissler 2003-T1; Geissler 2003-T2; Han 2015; Higby 1974). No trial reported total number of days on which bleeding occurred, time from randomisation to first bleeding episode, red cell transfusions, total time in hospital, transfusion reactions, transfusion-transmitted infections, platelet refractoriness or quality of life.

\section{Funding}

The manufacturer of the agent under investigation sponsored eight trials (Archimbaud 1999-T1; Archimbaud 1999-T2; Geissler 2003-T1; Geissler 2003-T2; Han 2015; Moskowitz 2007-T1; Moskowitz 2007-T2; Schiffer 2000), and two trials did not report their source of funding (Higby 1974; Miao 2012).

\section{Excluded studies}

We excluded 144 trials from the review (see Characteristics of excluded studies for further details).

- Twenty-one trials were review articles (ASH 2003; Basciano 2012; Basser 2002; Blajchman 2001; Blajchman 2003;

Catalá-López 2015; Corrales-Alvarez 2011; Drug news 2005; Drug news 2006; Franchini 2007; Hampton 2007; Johansson 2008; Levy 2008; Mizer 1998; Norris 2011; Peeters 2008; Prica 2014; Squizzato 2007; Vadhan-Raj 2000; Wang 2009; Wardrop 2013).

- Thirty-five trials were not RCTs (Bauman 2011; Berstein 2002; Castaman 1997; Dickinson 2014; Elinoff 2014; Frey 2012; Gerrits 2015; Knoefler 2013; Kristensen 1993; Liesveld 2013; Mittelman 2012; Nash 2000; NCT00358540;

NCT00472290; NCT00922883; NCT01194167;

NCT01328587; NCT01500538; NCT01516619;

NCT01550185; NCT01757145; NCT01791101;

NCT01957176; NCT01980030; NCT02046291;

NCT02323178; Olnes 2012; Palmblad 2008; Svensson 2014; Townsley 2015; Will 2009a; Will 2009b; Wolff 2001; Wu 2014; Xu 2008).

- Forty-six trials were on the wrong participant group (Bai 2004a; Bai 2004b; Basser 1996; Basser 1997; Bowen 2010; 
Bussel 2006; Bussel 2007; EudraCT number 2010-022890-33; Eudra CT number 2014-000174-19; Giagounidis 2014; Greenberg 2013; Höchsmann 2014; Jain 2013; Kantarjian 2010a; Kantarjian 2010b; Kellum 2010; Korte 2009; Malyszko 1990; Mannucci 1986; Natale 2009; NCT00102726; NCT00413283; NCT00614523; NCT00688272; NCT00903422; NCT01072162; NCT01147809; NCT01893372; NCT02052882; NCT02093325; NCT02094417; NCT02446145; Oliva 2013; Platzbecker 2015; Risitano 2014; Schuster 2002; Sekeres 2011; Seza 1997; Somlo 1999; Wang 2012; Wang 2013; Williams 2009; Winer 2015; Wire 2012; Wroblewski 2010). Seven of these trials were included in a separate review that included participants with bone marrow failure receiving no treatment or low-dose chemotherapy (Fricke 1991; Giagounidis 2014; Greenberg 2013; Kantarjian 2010a; Mannucci 1986; Platzbecker 2015; Wang 2012).

- Nineteen trials were incorrect interventions (Avvisati 1989; Basser 2000; Brenner 2004; Dunser 2004; Gallardo 1983; Glaspy 1991; Heddle 1995; Kruskemper 1966; Li 2012; Louis 1967; Matsumoto 2007; Nair 2006; Pihusch 2005; Rasche 1982; Rasche 1986; Shpilberg 1993; Takami 2002; Thompson 2000; Vannucchi 1996).

- Twenty-three trials were secondary citations for excluded trials.

\section{Ongoing studies}

We identified six ongoing trials (see Characteristics of ongoing studies table) (EudraCT 2015-000929-37; NCT01397149; NCT01656252; NCT01890746; Popat 2015; Vadhan-Raj 2010). We will monitor the progress of these trials and on publication (assuming eligibility), we will include them in future updates of this review. Two of these trials have been completed or closed but the results are not published (NCT01397149; Vadhan-Raj 2010). Three trials are due to be completed between August 2016 and February 2017 (NCT01656252; NCT01890746; Popat 2015). One trial commenced in December 2015 and is due to run for five years but the formal finish date has not been reported (EudraCT 2015-000929-37). Five of the ongoing trials are comparing eltrombopag to placebo in the following settings: poststem cell transplant (Popat 2015), newly diagnosed acute myeloid leukaemia (EudraCT 2015-000929-37; NCT01890746), acute myeloid leukaemia in complete remission before consolidation therapy (NCT01656252), and in participants with chronic lymphocytic leukaemia (NCT01397149). One trial is comparing romiplostim (AMG531) to placebo for participants undergoing intensive chemotherapy for non-Hodgkin's lymphoma (VadhanRaj 2010). One of these trials is already completed and the final publication is awaited (Vadhan-Raj 2000). We contacted Prof Vadhan-Raj, the lead investigator for this trial, on 13 July 2015 and 7 August 2015, who replied on 23 August 2015 reporting that this trial will be published as a full-text article. The preliminary results of this trial were published in 2010 in abstract format and the lack of a full-text publication of this trial is a potential source of publication bias. This trial has a factorial design and there is insufficient information provided in the published conference abstract for it to be incorporated into this review. Overall, the six ongoing trials are expected to contribute another 424 potential participants to the systematic review.

\section{Risk of bias in included studies}

See the 'Risk of bias' table within the Characteristics of included studies table for details of our assessment for each trial and Figure 2 for a tabular summary. 
Figure 2. Risk of bias summary: review authors' judgements about each risk of bias item for each included study.

\begin{tabular}{|c|c|c|c|c|c|c|c|c|}
\hline & 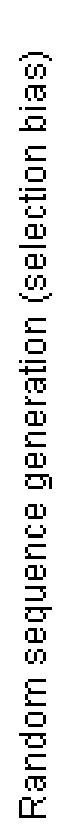 & 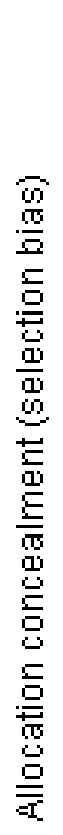 & 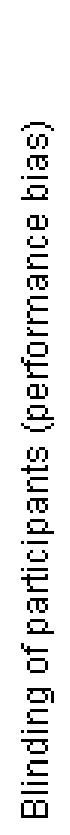 & 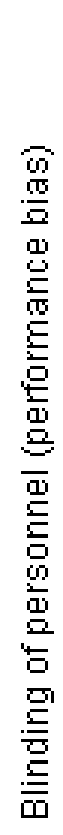 & 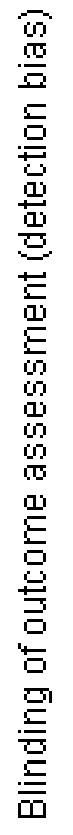 & 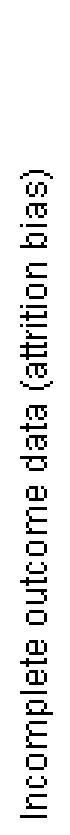 & 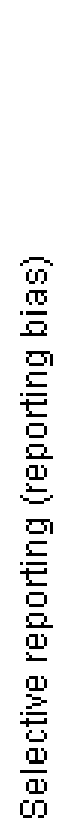 & 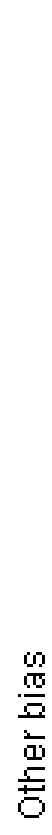 \\
\hline Archimbaud 1999-T1 & $?$ & $?$ & + & + & + & + & $?$ & \\
\hline Archimbaud 1999-T2 & $?$ & $?$ & + & $A$ & + & $A$ & ? & \\
\hline Geissler 2003-T1 & $?$ & $?$ & + & & + & & $?$ & \\
\hline Geissler 2003-T2 & $?$ & $?$ & + & & + & & $?$ & \\
\hline Han 2015 & $?$ & $?$ & & & & & $?$ & \\
\hline Higby 1974 & $?$ & + & + & $?$ & $?$ & & $?$ & \\
\hline Miao 2012 & $?$ & ? & & & & & ? & \\
\hline Moskowitz 2007-T1 & $?$ & + & + & & + & & & \\
\hline Moskowitz 2007-T2 & $?$ & + & + & & + & & & \\
\hline Schiffer 2000 & $?$ & $?$ & + & 1 & + & & $?$ & \\
\hline
\end{tabular}

Alternatives, and adjuncts, to prophylactic platelet transfusion for people with haematological malignancies undergoing intensive 


\section{Allocation}

\section{Sequence generation}

No trial reported details of the randomisation sequence and consequently all 10 trials were at unclear risk of bias.

\section{Concealment of treatment allocation}

Three trials reported details of concealment of treatment allocation (Higby 1974; Moskowitz 2007-T1; Moskowitz 2007-T2). All three trials were at low risk of bias with two trials reporting that all participants, trial staff and staff from the trial sponsors were blinded to the outcomes in the trial (Moskowitz 2007-T1; Moskowitz 2007-T2), and one trial reporting that participants were randomised in the hospital blood bank without the knowledge of the participants' physicians (Higby 1974). The remaining seven trials did not give sufficient detail for risk of bias to be assessed and were at unclear risk of bias (Archimbaud 1999-T1; Archimbaud 1999-T2; Geissler 2003-T1; Geissler 2003-T2; Han 2015; Miao 2012; Schiffer 2000).

\section{Blinding}

\section{Performance bias}

\section{Participants}

All trials provided adequate information to assess risk of bias from blinding of participants and eight of these trials were double-blind placebo-controlled trials and were at low risk of bias (Archimbaud 1999-T1; Archimbaud 1999-T2; Geissler 2003-T1; Geissler 2003-T2; Higby 1974; Moskowitz 2007-T1; Moskowitz 2007-T2; Schiffer 2000). Two trials did not blind participants and were at high risk of bias (Han 2015; Miao 2012).

\section{Trial personnel}

Nine trials provided adequate information to assess risk of bias from blinding of trial personnel and seven of these trials were double-blind placebo-controlled trials and were at low risk of bias (Archimbaud 1999-T1; Archimbaud 1999-T2; Geissler 2003-T1; Geissler 2003-T2; Moskowitz 2007-T1; Moskowitz 2007-T2; Schiffer 2000). Two trials did not blind trial personnel and were at high risk of bias (Han 2015; Miao 2012). There was insufficient information provided to assess the risk of bias for one trial (Higby 1974).

\section{Blinding of trial analysts}

Nine trials provided adequate information to assess risk of bias from blinding of trial analysts and seven of these trials were double-blind placebo-controlled trials and were at low risk of bias (Archimbaud 1999-T1; Archimbaud 1999-T2; Geissler 2003-T1; Geissler 2003-T2; Moskowitz 2007-T1; Moskowitz 2007-T2; Schiffer 2000). Two trials did not blind trial analysts and were at high risk of bias (Han 2015; Miao 2012). There was insufficient information provided to assess the risk of bias for one trial (Higby 1974).

\section{Incomplete outcome data}

Nine trials were at low risk of bias from incomplete outcome data (Archimbaud 1999-T1; Archimbaud 1999-T2; Geissler 2003-T1; Geissler 2003-T2; Han 2015; Higby 1974; Moskowitz 2007-T1; Moskowitz 2007-T2; Schiffer 2000). In the two trials by Archimbaud, three participants were withdrawn from the trial before they received the intervention and all other participants were accounted for (Archimbaud 1999-T1; Archimbaud 1999-T2). It was unclear from the reporting of these trials which of the two trials the participants were due to enter before they were withdrawn. Three participants were also withdrawn from the trials by Geissler as one was not in remission at trial entry and two withdrew early (Geissler 2003-T1; Geissler 2003-T2). One of the participants that was withdrawn had been randomised to PEG-rHuMGDF $30 \mu \mathrm{g} / \mathrm{kg}$ (Geissler 2003-T1), but it was unclear which trial the two other participants were in. Three participants were also excluded from the trials by Moskowitz, although it was unclear which arms or trials they had been allocated to (Moskowitz 2007-T1; Moskowitz 2007-T2). Two trials accounted for all the participants (Higby 1974; Schiffer 2000). One trial was at high risk from incomplete outcome data. Of 120 participants enrolled, only 89 were studied and reasons for exclusion of the remaining 31 participants were not given (Miao 2012).

\section{Selective reporting}

Two trials were at high risk of selective reporting. These trials did not have a prospectively registered protocol or trial registration but prespecified outcomes in the methods section of the paper that were not included in the results (Moskowitz 2007-T1; Moskowitz 2007-T2). Eight trials were at unclear risk of bias because no protocol or trial registration was published (Archimbaud 1999-T1; Archimbaud 1999-T2; Geissler 2003-T1; Geissler 2003-T2; Higby 1974; Miao 2012; Schiffer 2000), or because the trial registration was retrospective (Han 2015). 


\section{Other potential sources of bias}

Nine trials were had other threats to validity resulting in high risk of bias (Archimbaud 1999-T1; Archimbaud 1999-T2; Higby 1974; Moskowitz 2007-T1; Moskowitz 2007-T2; Schiffer 2000). Four of these trials were directly sponsored by AMGEN (Archimbaud 1999-T1; Archimbaud 1999-T2; Moskowitz 2007-T1; Moskowitz 2007-T2; Schiffer 2000) and one by the SUNSHINE pharmaceutical limited company (Han 2015). In one trial there was a significant difference between the ages of participants in the two groups (mean \pm SD $53.3 \pm 18.5$ years in arm one versus $43.8 \pm 19.4$ years in arm two; $\mathrm{P}<0.05$ (t-test)) (Higby 1974). For two trials (Geissler 2003-T1; Geissler 2003-T2) participants were included who had previously been included in the trials by Archimbaud (Archimbaud 1999-T1; Archimbaud 1999-T2) leading to potential bias with particularly good responders being selected. There was insufficient information from one trial to assess other threats to validity (Miao 2012).

\section{Effects of interventions}

See: Summary of findings for the main comparison Thrombopoietin mimetics versus placebo or standard care; Summary of findings 2 Platelet-poor plasma

The search identified no trials of artificial platelet substitutes, rFVIIa, fibrinogen concentrate or DDAVP. There were nine trials of TPO mimetics (Archimbaud 1999-T1; Archimbaud 1999-T2; Geissler 2003-T1; Geissler 2003-T2; Han 2015; Miao 2012; Moskowitz 2007-T1; Moskowitz 2007-T2; Schiffer 2000) and one of PPP (Higby 1974).

\section{Thrombopoietin mimetics}

Nine trials with 536 participants compared TPO mimetics to placebo or standard care (Archimbaud 1999-T1; Archimbaud 1999-T2; Geissler 2003-T1; Geissler 2003-T2; Han 2015; Miao 2012; Moskowitz 2007-T1; Moskowitz 2007-T2; Schiffer 2000). The timing of administration, dose and type of TPO mimetic varied between trials.

\section{Type of thrombopoietin mimetic}

Seven trials compared PEG-rHuMGDF (manufactured by AMGEN) to placebo (Archimbaud 1999-T1; Archimbaud 1999T2; Geissler 2003-T1; Geissler 2003-T2; Moskowitz 2007-T1; Moskowitz 2007-T2; Schiffer 2000), and two trials compared rhTPO (manufactured by Sansei Shenyang Pharmaceutical Company) to placebo (Han 2015) or standard care (Miao 2012).

\section{Dose and timing}

Doses ranged from $2.5 \mu \mathrm{g} / \mathrm{kg}$ (Archimbaud 1999-T1; Archimbaud 1999-T2; Moskowitz 2007-T1; Schiffer 2000) to $30 \mu \mathrm{g} / \mathrm{kg}$ (Geissler 2003-T2) for PEG-rHuMGDF. Participants treated with rhTPO received 300 units $/ \mathrm{kg}$ in one trial (Miao 2012) and 15,000 units in one trial (Han 2015). There was heterogeneity in the duration of treatment, ranging from trials administering a single dose (Archimbaud 1999-T2; Geissler 2003-T1) to trials administering 28 days of treatment (Schiffer 2000). The timing of treatment also ranged between trials with a range from six days before chemotherapy started (Geissler 2003-T1; Geissler 2003-T2) to 11 days after chemotherapy started (Schiffer 2000). A summary of the dose and timing of the trial drug for each trial is reported in Figure 3. 
Figure 3. Trial characteristics and outcomes. No trial reported: time from randomisation to first bleeding episode; mortality due to infection; platelet transfusion interval; number of red cell transfusions per participant; proportion of participants requiring additional interventions to stop bleeding; total time in hospital; or quality of life.C: control arm; HLA: human leukocyte antigen; I: intervention arm; max: maximum; N/A: not applicable; PEG-rHuMGDF: pegylated recombinant human megakaryocyte growth and differentiation factor; PIt: platelet; rhTPO: recombinant human thrombopoietin; T: trial when more than one reported per paper; yr: year.* dose was $30 \mu \mathrm{g} / \mathrm{kg}$ for first dose then $10 \mu \mathrm{g} / \mathrm{kg}$ daily thereafter; **day I was first day of chemotherapy; ***day 0 was day of stem cell infusion; $\checkmark$ : outcome reported; $\boldsymbol{x}$ : outcome not reported; (1): intervention groups combined together and not reported individually; (: control group reported together and not reported individually; ?: reported but too unclear to extract data.

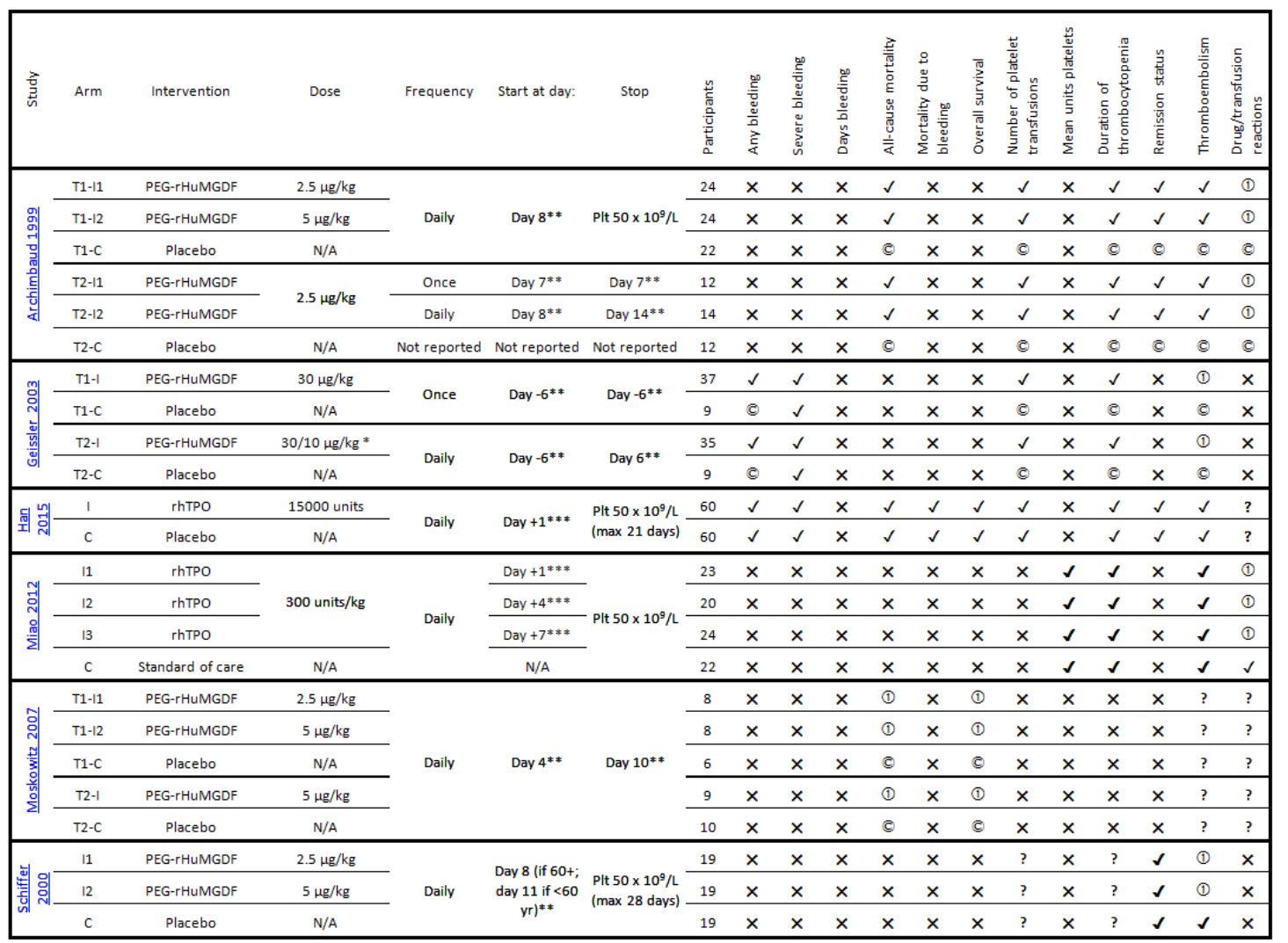

Other important information when interpreting results

Forty-seven participants randomised in the Geissler trials (Geissler 2003-T1; Geissler 2003-T2) had also been randomised in the Archimbaud trials (Archimbaud 1999-T1; Archimbaud 1999T2), and consequently could not be combined for meta-analysis. Six trials did not report individual arms and they either combined control groups or combined intervention arms making analysis of individual doses impossible (Archimbaud 1999-T1; Archimbaud 1999-T2; Geissler 2003-T1; Geissler 2003-T2;
Moskowitz 2007-T1; Moskowitz 2007-T2). We requested additional information from AMGEN (the sponsor) but received no further information.

Bleeding

Number of participants with at least one bleeding episode Three trials (210 participants) reported the number of participants with at least one bleeding episode (Geissler 2003-T1; Geissler 
2003-T2; Han 2015). One trial (120 participants) reported this outcome in a way that could be analysed (Han 2015). Data from the two trials by Geissler could not be included in a meta-analysis because the control groups and intervention groups from two trials were reported together (Geissler 2003-T1; Geissler 2003-T2). The results are summarised in Figure 4. There was no evidence of a difference in the risk of bleeding between participants treated with a TPO mimetic or placebo (OR $0.40,95 \%$ CI 0.10 to 1.62 , one trial, 120 participants, very low quality evidence) (Analysis 1.1). The two trials that could not be included in the meta-analysis reported $22.5 \%$ of participants treated with a TPO mimetic and $50 \%$ of participants treated with placebo had at least one bleeding episode (Geissler 2003-T1; Geissler 2003-T2).

Figure 4. Bleeding. C: control arm; I: intervention arm; max: maximum; n: number; PEG-rHuMGDF: pegylated recombinant human megakaryocyte growth and differentiation factor; rhTPO: recombinant human thrombopoietin; T: trial when more than one reported per paper.

\begin{tabular}{|c|c|c|c|c|c|c|c|}
\hline Study & Arm & Intervention & $\begin{array}{c}\text { Timing of } \\
\text { assessment }\end{array}$ & $\begin{array}{l}\text { Number of } \\
\text { participants }\end{array}$ & $\begin{array}{c}\text { Total } \\
\text { contributing to } \\
\text { outcome }\end{array}$ & $\begin{array}{l}\text { All bleeding events } n \\
\qquad \%)\end{array}$ & $\begin{array}{c}\text { Serious or life-threatening } \\
\text { bleeding } \mathrm{n}(\%)\end{array}$ \\
\hline \multirow{3}{*}{ 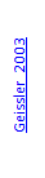 } & $\mathrm{T} 1-1$ & PEG-rHUMGDF $30 \mu \mathrm{g} / \mathrm{kg}$ (day -6 ) & \multirow{3}{*}{28 days } & 37 & \multirow{2}{*}{71} & \multirow{2}{*}{$16(22.5)$} & 0 \\
\hline & $\mathrm{T} 2-1$ & PEG-rHuMGDF $30 \mu \mathrm{g} / \mathrm{kg}$ (day -6 ) then $10 \mu \mathrm{g} / \mathrm{kg}$ (days -5 to 6 ) & & 34 & & & $2(6)$ \\
\hline & $\mathrm{T} 1-\mathrm{c}$ & Placebo (day -6) & & 9 & & & 0 \\
\hline \multirow{4}{*}{ 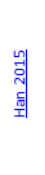 } & \multirow{2}{*}{1} & \multirow{2}{*}{$\begin{array}{l}\text { rhTPO } 15000 \text { units } \\
\text { (day }+1 \text { until platelets } 50 \times 10^{9} / L: 21 \text { days max) }\end{array}$} & & \multirow{2}{*}{60} & \multirow{2}{*}{60} & \multirow{2}{*}{$3(5)$} & 0 at 21 days \\
\hline & & & & & & & $1(1.7)$ at 60 days \\
\hline & \multirow[b]{2}{*}{ c } & \multirow{2}{*}{$\begin{array}{l}\text { Placebo } \\
\text { (day }+1 \text { until platelets } 50 \times 10^{9} / \text { L: } 21 \text { days } \max \text { ) }\end{array}$} & & \multirow{2}{*}{60} & \multirow{2}{*}{60} & \multirow{2}{*}{$7(11.7)$} & 0 at 21 days \\
\hline & & & & & & & $1(1.7)$ at 60 days \\
\hline
\end{tabular}

\section{Number of participants with at least one episode of severe or life-threatening bleeding}

Three trials (209 participants) reported the number of participants with at least one episode of severe or life-threatening bleeding (Geissler 2003-T1; Geissler 2003-T2; Han 2015). The results are summarised in Figure 4. There was no evidence of a difference in the risk of a life-threatening bleed between participants treated with TPO mimetics compared to participants treated with control after 30 days (OR 1.46, 95\% CI 0.06 to 33.14, 209 participants, three trials, very low quality evidence) or after 90 days (OR 1.00, 95\% CI 0.06 to 16.37 , one trial, 120 participants, very low quality evidence) (Analysis 1.2).

Total number of days on which bleeding occurred per participant
No trial reported the total number of days on which bleeding occurred per participant.

Time from randomisation to first bleeding episode

No trial reported time from randomisation to first bleeding episode.

\section{Mortality}

\section{All-cause mortality}

Five trials (266 participants) reported all-cause mortality ( Archimbaud 1999-T1; Archimbaud 1999-T2; Han 2015; Moskowitz 2007-T1; Moskowitz 2007-T2). Data could not be included in meta-analysis in four trials, as the control groups were 
reported together (Archimbaud 1999-T1; Archimbaud 1999-T2; Moskowitz 2007-T1; Moskowitz 2007-T2), and in addition to this in two trials, the intervention groups were reported in combination (Moskowitz 2007-T1; Moskowitz 2007-T2). The results are summarised in Figure 5. There was no evidence of a difference in all-cause mortality for participants treated with TPO mimetics or control at 30 days (OR not estimable as no deaths, one trial, 120 participants, very low quality evidence) or at 90 days (OR $1.00,95 \%$ CI 0.24 to 4.20 , one trial, 120 participants, very low quality evidence (Analysis 1.4). Two additional trials reported allcause mortality at 30 days that could not be included in metaanalysis with all-cause mortality of $0 \%$ to $9.3 \%$ in the combined TPO mimetic arms and $11.8 \%$ in the combined control arms (Archimbaud 1999-T1; Archimbaud 1999-T2). Two further trials reported all-cause mortality at 90 days in a manner that could not be used for meta-analysis with an all-cause mortality of $13.6 \%$ in the combined intervention arms and $25 \%$ in the combined control arms (Moskowitz 2007-T1; Moskowitz 2007-T2).

Figure 5. All-cause mortality. C: control arm; I: intervention arm; max: maximum; n: number; PEGrHUMGDF: pegylated recombinant human megakaryocyte growth and differentiation factor; rhTPO:

recombinant human thrombopoietin; T: trial when more than one reported per paper; $(1):=$ after one cycle of chemotherapy; $\mathrm{O}$ : up to $\mathbf{9 0}$ days (data extracted from survival curves).

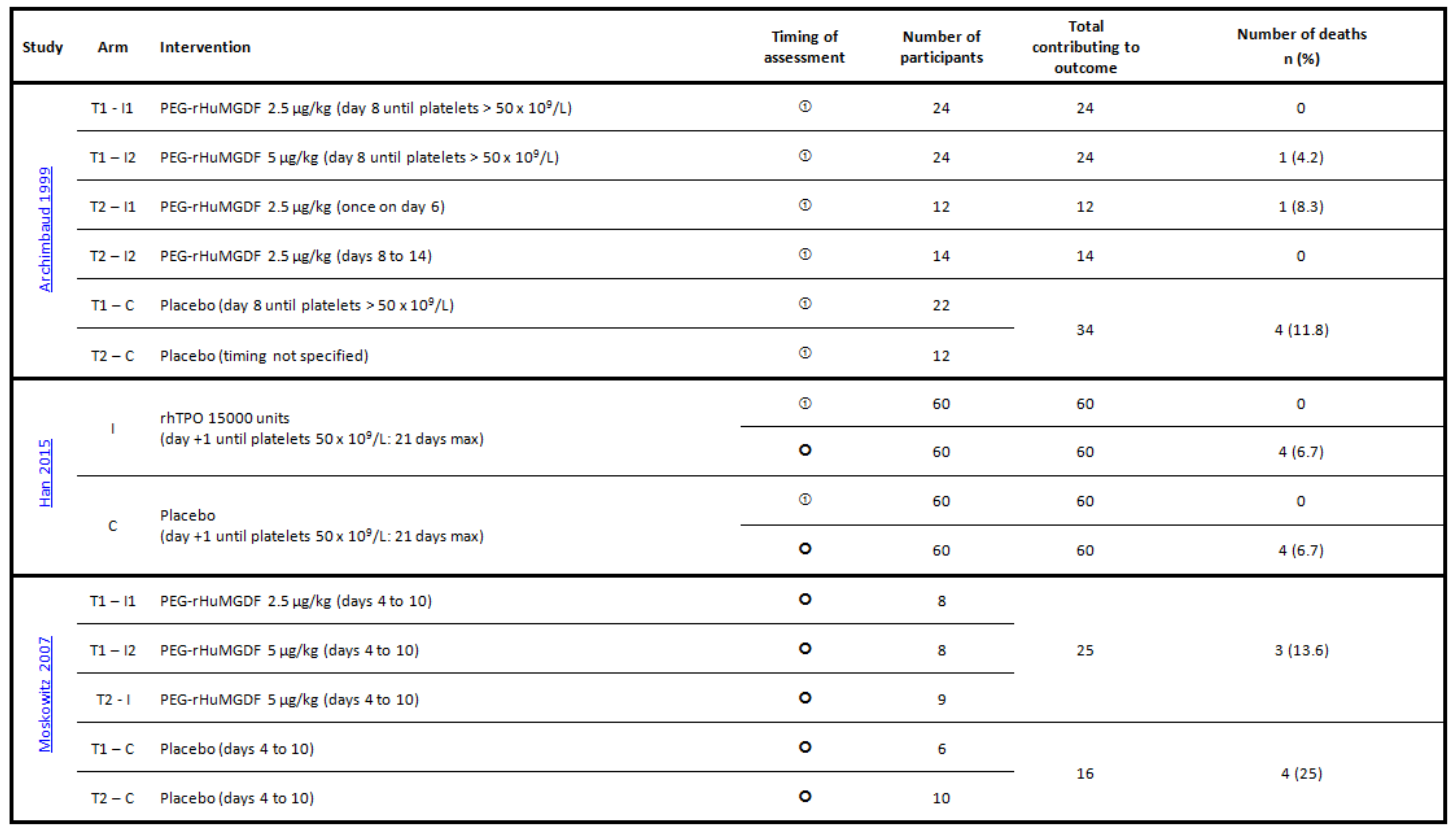

Mortality secondary to bleeding

No trial reported mortality due to bleeding.

\section{Mortality secondary to infection}

No trial reported mortality due to infection.

\section{Overall survival}

Three trials (158 participants) reported overall survival with no trials reporting data in a way that could be analysed (Han 2015;
Moskowitz 2007-T1; Moskowitz 2007-T2). There was no evidence of a difference in overall survival in the trial that reported this outcome, with a P value of 0.368 , no HR or CI reported (one trial, 120 participants) (Han 2015). In the remaining two trials, data could not be pooled, as the control arms and intervention arms were combined (Moskowitz 2007-T1; Moskowitz 2007-T2). HRs in these two trials were not reported but at 8.5 years' median follow-up, Kaplan-Meier estimates for overall survival were reported as 59\% for the combined group of participants treated with a TPO mimetic and $31 \%$ for the combined group of par- 
ticipants treated with placebo (Moskowitz 2007-T1; Moskowitz 2007-T2).

Proportion of participants requiring additional interventions to stop bleeding

No trial reported additional interventions to stop bleeding.

\section{Platelet transfusions}

\section{Number of platelet transfusions per participant}

Six trials (378 participants) reported platelet transfusions per participant (Archimbaud 1999-T1; Archimbaud 1999-T2; Geissler 2003-T1; Geissler 2003-T2; Han 2015; Schiffer 2000). One trial presented data in a way that permitted meta-analysis (Han 2015). There was a significant reduction in platelet transfusion requirements between participants treated with TPO mimetics and participants treated with control (mean difference -3 units, 95\% CI
-5.39 to -0.61 , one trial, 120 participants, very low quality evidence (Analysis 1.3). Data could not be combined in the remaining five trials, as in four trials, the control arms had been combined and data were presented as medians (Archimbaud 1999-T1; Archimbaud 1999-T2; Geissler 2003-T1; Geissler 2003-T2), and in one trial participants were divided into those aged under 60 years and those aged over 60 years and presented as medians preventing combined analysis. There was considerable clinical heterogeneity between these trials. Additionally, 47 participants from the trials by Geissler (Geissler 2003-T1; Geissler 2003-T2) had previously been included in the trials by Archimbaud (Archimbaud 1999-T1; Archimbaud 1999-T2). The results are summarised in Figure 6. Platelet transfusions per participant were presented as medians for five of the trials assessing TPO mimetics (Archimbaud 1999-T1; Archimbaud 1999-T2; Geissler 2003-T1; Geissler 2003-T2; Schiffer 2000. The range of medians presented was 4 to 10 platelet transfusions for participants receiving TPO mimetics and 4 to 8 transfusions for participants treated with placebo.

Figure 6. Mean number of platelet transfusions. C: control arm; I: intervention arm; max: maximum; PEGrHuMGDF: pegylated recombinant human megakaryocyte growth and differentiation factor; rhTPO: recombinant human thrombopoietin; SD: standard deviation; T: trial when more than one reported per paper;

yr: year.(1) : after one cycle of chemotherapy; 0 : until 28 days after last cycle of chemotherapy; (2): until 60 days of treatment.

\begin{tabular}{|c|c|c|c|c|c|c|c|}
\hline \multirow{5}{*}{ 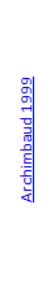 } & & T1 - 11 & PEG-rHuMGDF $2.5 \mu \mathrm{\mu g} / \mathrm{kg}$ (day 8 until platelets $>50 \times 10^{9} / \mathrm{L}$ ) & (1) & 24 & \multirow{2}{*}{48} & \multirow{2}{*}{$\begin{array}{l}4 \text { (unclear measure) } \\
\text { (range not reported) }\end{array}$} \\
\hline & & $11-12$ & PEG-rHuMGDF $5 \mu \mathrm{\mu g} / \mathrm{kg}$ (day 8 until platelets $>50 \times 10^{9} / \mathrm{L}$ ) & (1) & 24 & & \\
\hline & & $12-11$ & PEG-rHUMGDF $2.5 \mu \mathrm{g} / \mathrm{kg}$ (once on day 6) & (1) & 12 & 26 & $\begin{array}{l}5 \text { (unclear measure) } \\
\text { (range not reported) }\end{array}$ \\
\hline & & $\mathrm{T} 1-\mathrm{c}$ & Placebo (day 8 until platelets $>50 \times 10^{9} / L$ ) & (1) & 22 & \multirow{2}{*}{34} & \multirow{2}{*}{$\begin{array}{l}5.5 \text { (unclear measure) } \\
\text { (range not reported) }\end{array}$} \\
\hline & & $\mathrm{T} 2-\mathrm{c}$ & Placebo (timing not specified) & (1) & 12 & & \\
\hline \multirow{2}{*}{ 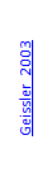 } & & $\mathrm{T} 1-1$ & PEG-rHUMGDF $30 \mu \mathrm{g} / \mathrm{kg}$ (day -6) & $\circ$ & 37 & 37 & Median 4 (range 1 to 15 ) \\
\hline & & $\mathrm{T} 2-1$ & PEG-rHuMGDF $30 \mu \mathrm{g} / \mathrm{kg}$ (day -6 ) then $10 \mu \mathrm{g} / \mathrm{kg}$ (days -5 to 6 ) & $\circ$ & 34 & 34 & Median 5 (range 1 to 18 ) \\
\hline \multirow{2}{*}{ 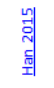 } & & 1 & rhTPO 15000 units (day +1 until platelets $50 \times 10^{9} / L: 21$ days max) & (2) & 60 & 60 & Mean 6 (SD 5) \\
\hline & & c & Placebo (day +1 until platelets $50 \times 10^{9} /$ L: 21 days $\max$ ) & (2) & 60 & 60 & Mean 9 (SD 8 ) \\
\hline \multirow{5}{*}{ 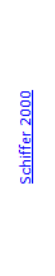 } & \multirow{3}{*}{ 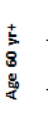 } & 11 & PEG-rHuMGDF $2.5 \mu \mathrm{g} / \mathrm{kg}$ (days 8 to 35 or when platelets $50 \times 10^{9} / \mathrm{L}$ ) & (1) & 7 & 7 & Median 5 (range not reported) \\
\hline & & 12 & PEG-rHuMGDF $5 \mu \mathrm{gg} / \mathrm{kg}$ (days 8 to 35 or when platelets $50 \times 10^{9} / \mathrm{L}$ ) & (1) & 7 & 7 & Median 6 (range not reported) \\
\hline & & c & Placebo (days 8 to 35 or when platelets $50 \times 10^{9} / \mathrm{L}$ ) & (1) & 8 & 8 & Median 5 (range not reported) \\
\hline & \multirow{2}{*}{ 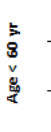 } & 11 & PEG-rHuMGDF $2.5 \mu \mathrm{g} / \mathrm{kg}$ (days 11 to 38 or when platelets $50 \times 10^{9} / \mathrm{L}$ ) & (1) & 12 & 12 & Median 7 (range not reported) \\
\hline & & 12 & PEG-rHuMGDF $5 \mu \mathrm{g} / \mathrm{kg}$ (days 11 to 38 or when platelets $50 \times 10^{9} / \mathrm{L}$ ) & (1) & 12 & 12 & Median 10 (range not reported) \\
\hline
\end{tabular}




\section{Platelet transfusion interval}

No trial reported platelet transfusion interval.

\section{Duration of thrombocytopenia}

Seven trials (598 participants) reported duration of thrombocytopenia (Archimbaud 1999-T1; Archimbaud 1999-T2; Geissler 2003-T1; Geissler 2003-T2; Han 2015; Miao 2012; Schiffer 2000). One trial reported data in a way that could be analysed (Miao 2012). This was a four-arm multiple group trial where we compared the control group against each intervention but did not perform meta-analysis to avoid counting the control group on more than one occasion. When rhTPO was started on day +1 after stem cell transplantation, there was no evidence of a difference in the duration of thrombocytopenia (mean difference -1.65 days, $95 \%$ CI -4.07 to 0.77 , one trial, 45 participants). There was a significant decrease in the duration of thrombocytopenia when rhTPO was started at day 4 after stem cell transplantation (mean difference -2.67 days, $95 \%$ CI -4.97 to -0.37 , one trial, 42 participants) or at day +7 after stem cell transplantation (mean difference -2.49 days; $95 \%$ CI -4.71 to -0.27 , one trial, 46 participants) (Analysis 1.5). Data could not be combined together for the remaining six trials. In all six trials data were presented as medians and ranges (Archimbaud 1999-T1; Archimbaud 1999-T2; Geissler 2003-T1; Geissler 2003-T2; Han 2015; Schiffer 2000). In four trials, the control arms had been combined (Archimbaud 1999-T1; Archimbaud 1999-T2; Geissler 2003-T1; Geissler 2003-T2), and in one trial, participants were divided into those aged under 60 years and those aged 60 years or more preventing combined analysis (Schiffer 2000). There was considerable clinical heterogeneity between these trials. Lastly, 47 participants from the trials by Geissler (Geissler 2003-T1; Geissler 2003-T2) had previously been included in the trials by Archimbaud (Archimbaud 1999-T1; Archimbaud 1999-T2). The results are summarised in Figure 7. For the trials presenting their results as medians, duration of thrombocytopenia was similar between participants treated with TPO mimetics (range 14 to 30 days) and participants treated with placebo (range 14 to 28 days). 
Figure 7. Time to platelet count recovery (defined a platelet count of $20 \times 109 / \mathrm{L}$ in all trials). C: control arm; I: intervention arm; max: maximum; PEG-rHuMGDF: pegylated recombinant human megakaryocyte growth and differentiation factor; rhTPO: recombinant human thrombopoietin; SD: standard deviation; T: trial when more than one reported per paper; yr: year.

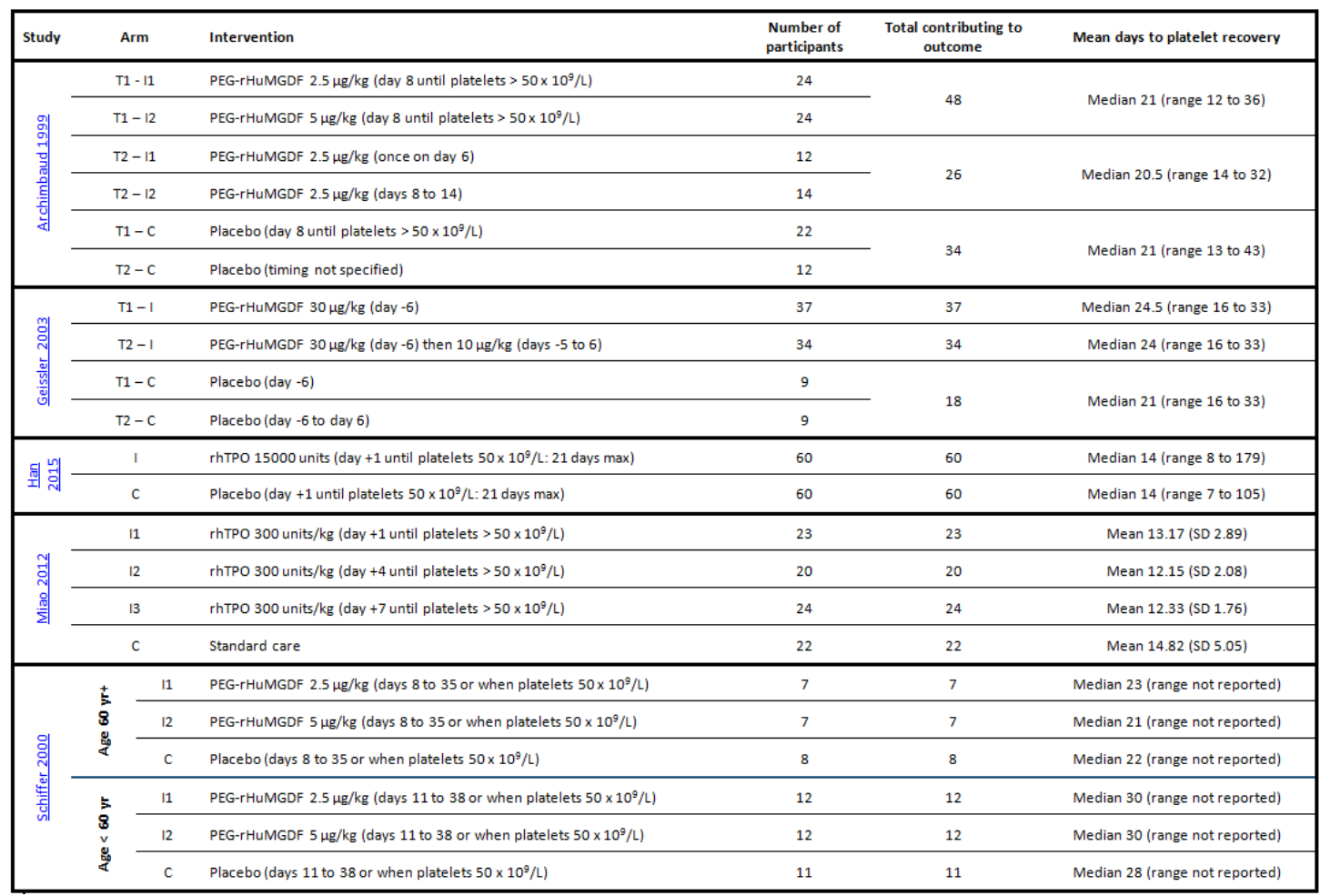

\section{Number of red cell transfusions}

No trial reported the number of red cell transfusions per participant or the number of red cell components per participant.

\section{Proportion of participants achieving complete remission}

Four trials (288 participants) reported remission status ( Archimbaud 1999-T1; Archimbaud 1999-T2; Han 2015; Schiffer 2000). Two trials presented data in a way that could be included in meta-analysis (Han 2015; Schiffer 2000). The trial by Schiffer presented results for participants aged under 60 years and 60 years or more of age separately. There was no evidence of a difference in the number of participants in complete remission at 30 days (OR 0.99, 95\% CI 0.30 to 3.29, two trials, 177 participants) or at 90 days (OR 1.00, 95\% CI 0.06 to 16.37 , one trial, 120 participants) (Analysis 1.6). Data from two trials could not be used for meta-analysis, as their control arms were combined (Archimbaud 1999-T1; Archimbaud 1999-T2). Proportion of participants in complete remission at 30 days was $50 \%$ to $66.7 \%$ in the TPO mimetic groups and $61.8 \%$ in the combined control groups. The results are summarised in Figure 8. 
Figure 8. Remission status. C: control arm; I: intervention arm; max: maximum; n: number; PEGrHuMGDF: pegylated recombinant human megakaryocyte growth and differentiation factor; rhTPO: recombinant human thrombopoietin; T: trial when more than one reported per paper

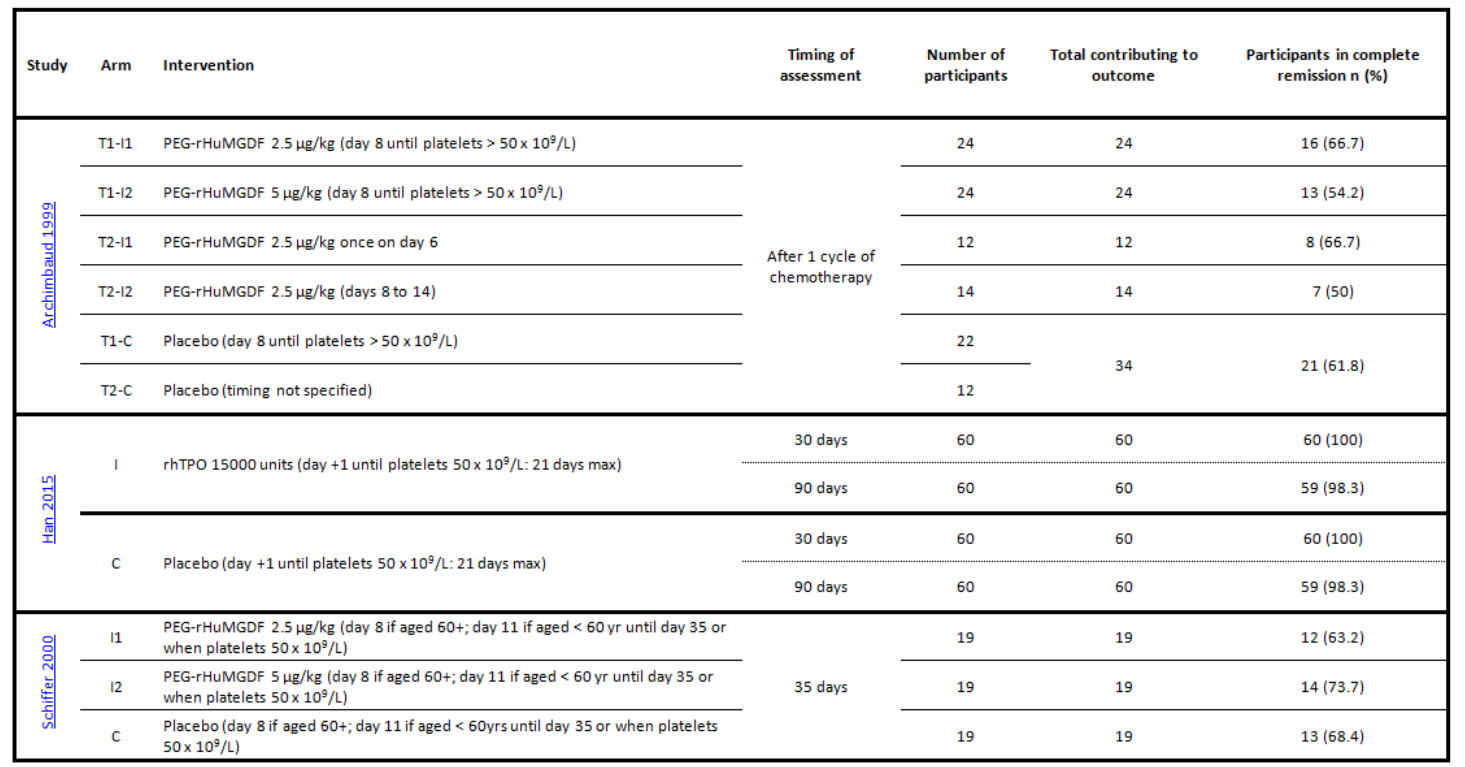

\section{Total time in hospital}

No trial reported total time in hospital.

\section{Adverse events}

\section{Transfusion reactions}

No trial reported transfusion reactions.

\section{Transfusion-transmitted infections}

No trial reported transfusion-transmitted infection.

\section{Thromboembolism}

Seven trials (498 participants) reported thromboembolic events (Archimbaud 1999-T1; Archimbaud 1999-T2; Geissler 2003-T1;
Geissler 2003-T2; Han 2015; Miao 2012; Schiffer 2000). Two trials reported thromboembolic events in a manner that allowed meta-analysis. No participants in either trial had a thromboembolic event (Han 2015; Miao 2012). Data could not be combined for meta-analysis in the remaining five trials (Archimbaud 1999-T1; Archimbaud 1999-T2; Geissler 2003-T1; Geissler 2003-T2; Schiffer 2000), as in four trials, the control arms and intervention arms had been combined (Archimbaud 1999-T1; Archimbaud 1999-T2; Geissler 2003-T1; Geissler 2003-T2). One trial reported its control arm individually but combined data for the intervention arms (Schiffer 2000). There was considerable clinical heterogeneity and 47 participants from the trials by Geissler (Geissler 2003-T1; Geissler 2003-T2) had previously been included in the trials by Archimbaud (Archimbaud 1999-T1; Archimbaud 1999-T2). Rates of thromboembolism ranged from $0 \%$ to $9.1 \%$ for participants treated with TPO mimetics to $5.9 \%$ to $15.8 \%$ for participants treated with control. The results are summarised in Figure 9. 
Figure 9. Thromboembolic events. C: control arm; I: intervention arm; max: maximum; PEG-rHuMGDF: pegylated recombinant human megakaryocyte growth and differentiation factor; rhTPO: recombinant human thrombopoietin; T: trial when more than one reported per paper; yr: year.

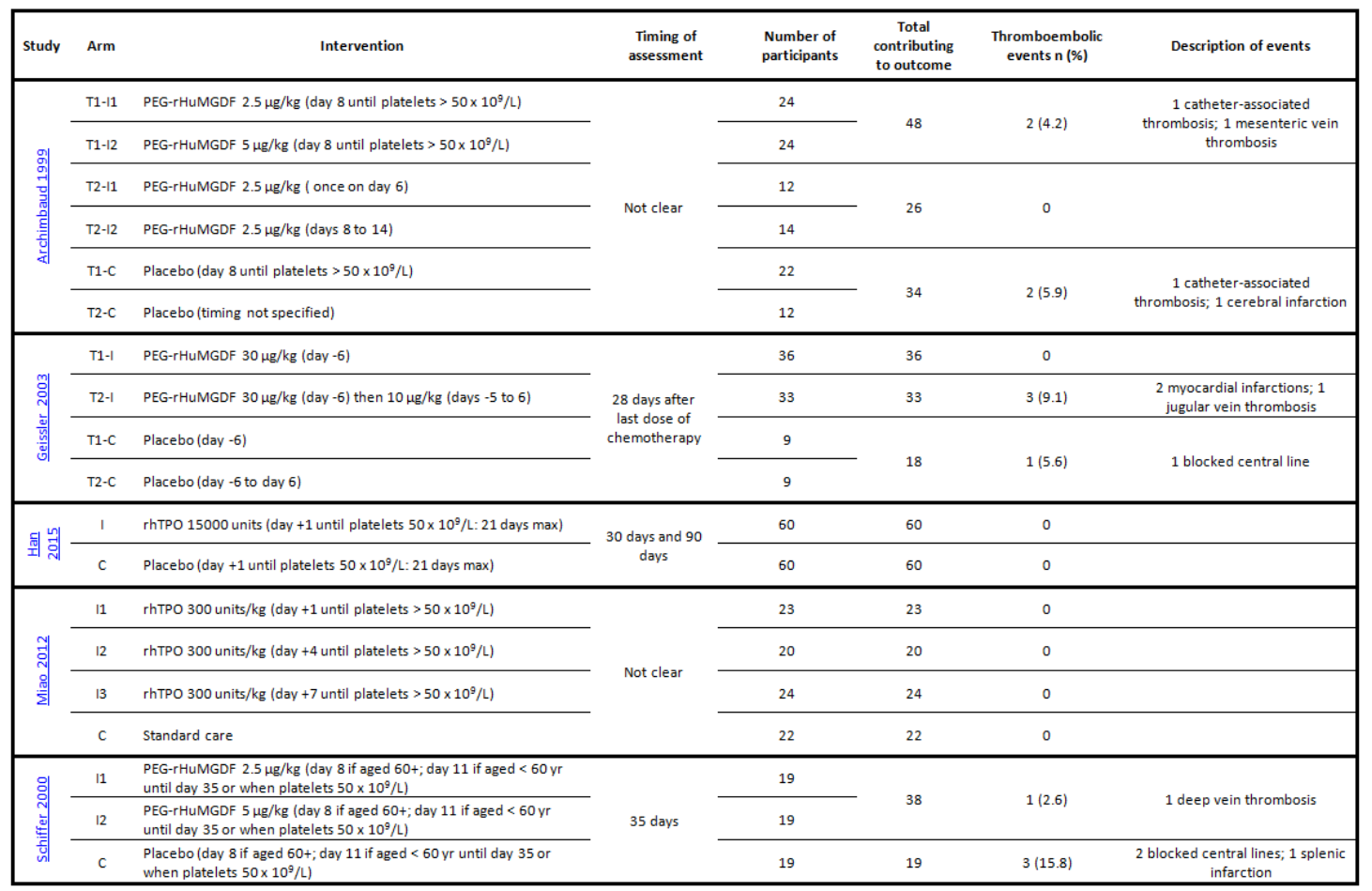

\section{Development of platelet antibodies}

No trial reported formation of anti-HLA antibodies.

\section{Development of platelet refractoriness}

No trial reported platelet refractoriness.

\section{Drug reactions}

Six trials (385 participants) reported drug reactions (Archimbaud 1999-T1; Archimbaud 1999-T2; Miao 2012; Moskowitz $2007-$ T1; Moskowitz 2007-T2). Data could not be combined, as two trials reported their control arms and intervention arms in combination (Archimbaud 1999-T1; Archimbaud 1999-T2), one trial reported its control arm individually and its intervention arms in combination (Miao 2012), and in three trials the number of events were not reported sufficiently clearly for data extraction to be possible (Han 2015; Moskowitz 2007-T1; Moskowitz 2007-T2). The results are summarised in Figure 10. Drug reactions were reported more commonly among participants receiving TPO mimetics ( $1.5 \%$ to $17.1 \%)$ than placebo $(0 \%)$, but the types of adverse events were not consistent between trials with no two trials reporting the same types of adverse event (with the exception of thromboembolism as reported above). 
Figure 10. Drug reactions. C: control arm; I: intervention arm; max: maximum; PEG-rHuMGDF: pegylated recombinant human megakaryocyte growth and differentiation factor; rhTPO: recombinant human

thrombopoietin; T: trial when more than one reported per paper; yr: year.

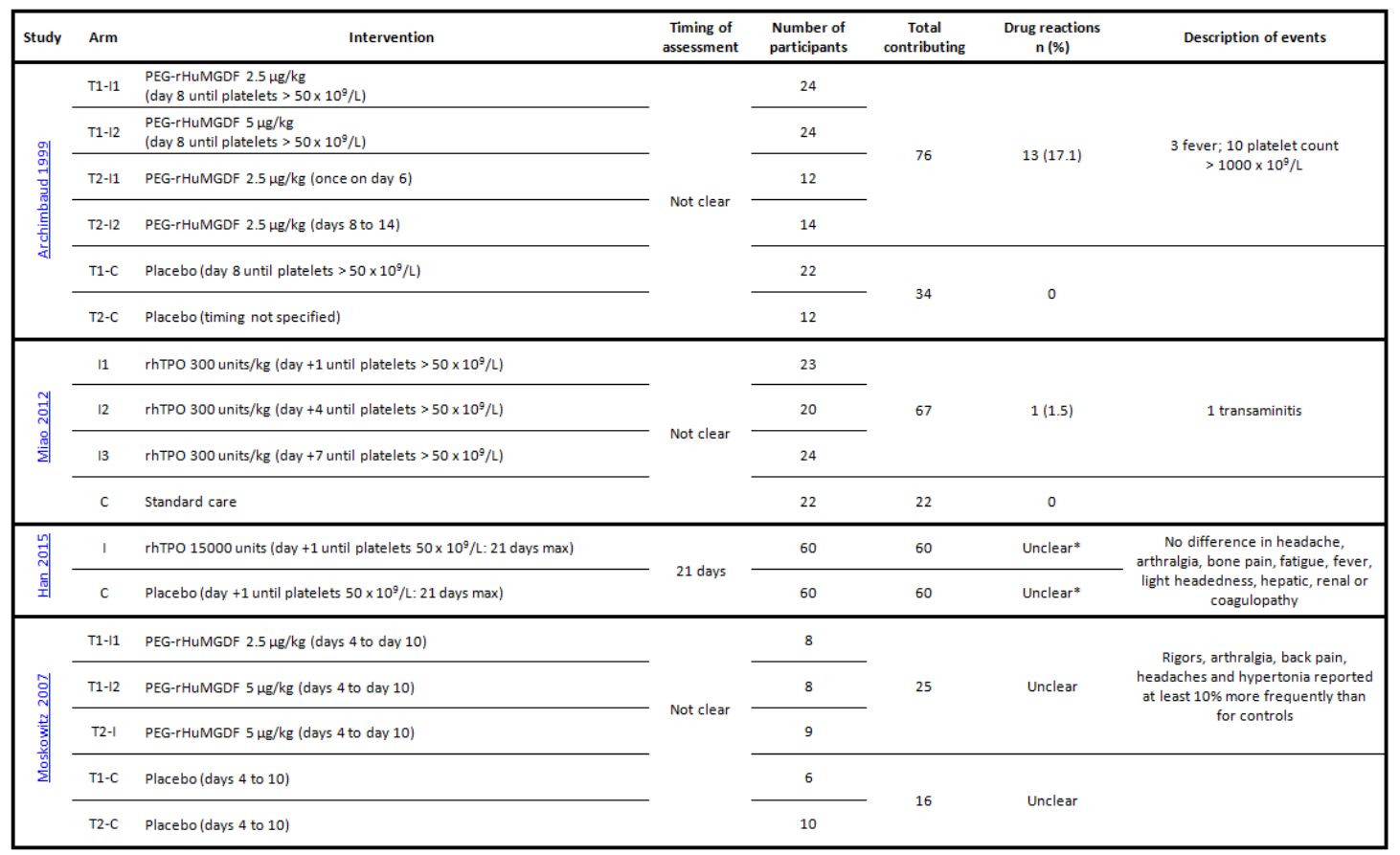

\section{Quality of life}

No trial reported quality of life.

\section{Platelet-poor plasma}

One trial with 18 participants (who could be assessed) compared PPP and platelet transfusions (Higby 1974). The intervention or comparator was transfused twice weekly starting when the platelet count fell below $30 \times 10^{9} / \mathrm{L}$ and continuing until the platelet count rose above $30 \times 10^{9} / \mathrm{L}$ and remained in this range for at least two days without platelet support.

\section{Bleeding}

\section{Number of participants with at least one bleeding episode}

There were more bleeding events among participants transfused with PPP than platelets (OR 16.00, 95\% CI 1.32 to 194.62, one trial, 18 participants, very low quality evidence) (Analysis 2.1) (Higby 1974).
Number of participants with at least one episode of severe or life-threatening bleeding

There was no evidence of a difference in the risk of severe or lifethreatening bleeding events among participants transfused with PPP compared to platelets (OR 4.00, 95\% CI 0.56 to 28.40, one trial, 18 participants, very low quality evidence) (Analysis 2.2) (Higby 1974).

Total number of days on which bleeding occurred per participant

Higby 1974 did not report the number of days on which bleeding occurred per participant.

Time from randomisation to first bleeding episode

Higby 1974 did not report the time from randomisation to first bleeding episode.

\section{Mortality}




\section{All-cause mortality}

Higby 1974 did not report all-cause mortality.

\section{Mortality secondary to bleeding}

There was no evidence of a difference in mortality due to bleeding in the group treated with PPP and platelet transfusions (OR 0.30, 95\% CI 0.01 to 8.35 , one trial, 18 participants) (Analysis 2.3) (Higby 1974).

\section{Mortality secondary to infection}

Higby 1974 did not report mortality due to infection.

\section{Overall survival}

Higby 1974 did not report overall survival.

Proportion of participants requiring additional interventions to stop bleeding

Higby 1974 did not report any additional interventions to stop bleedings.

\section{Platelet transfusions}

\section{Number of platelet transfusions per participant}

Higby 1974 did not report the number of platelet transfusions per participant or the number of platelet components per participant.

\section{Platelet transfusion interval}

Higby 1974 did not report the platelet transfusion intervals.

\section{Duration of thrombocytopenia}

Higby 1974 did not report the duration of thrombocytopenia.

\section{Number of red cell transfusions}

Higby 1974 did not report the number of red cell transfusions per participant or the number of red cell components per participant.

\section{Proportion of participants achieving complete remission}

Higby 1974 did not report the remission status.

\section{Total time in hospital}

Higby 1974 did not report the total time in hospitals.

\section{Adverse events}

\section{Transfusion reactions}

Higby 1974 did not report transfusion reactions.

\section{Transfusion-transmitted infections}

Higby 1974 did not report transfusion-transmitted infections.

\section{Thromboembolism}

Higby 1974 did not report the number of thromboembolic events.

\section{Development of platelet antibodies}

Higby 1974 reported formation of anti-HLA antibodies but it was unclear if participants had anti-HLA antibodies before the trial or if they were formed during the trial. The time period over which the outcome was reported was also unclear. There was no evidence of a difference in anti-HLA antibody formation among participants treated with PPP and platelet transfusions (OR 6.40, 95\% CI 0.55 to 74.89 , one study, 18 participants) (Analysis 2.4 ).

\section{Development of platelet refractoriness}

Higby 1974 did not report platelet refractoriness.

\section{Drug reactions}

Higby 1974 did not report the number of drug or transfusion reactions.

\section{Quality of life}

Higby 1974 did not report quality of life. 
ADDITIONAL SUMMARYOF FINDINGS [Explanation]

Platelet-poor plasma

Population: people with haematological disorders undergoing intensive chemotherapy or stem cell transplantation

Intervention: platelet-poor plasma transfusion

Comparison: platelet transfusion

\begin{tabular}{|c|c|c|c|c|c|c|}
\hline \multirow[t]{2}{*}{ Outcomes } & \multicolumn{2}{|c|}{ Anticipated absolute effects* $(95 \% \mathrm{Cl})$} & \multirow{2}{*}{$\begin{array}{l}\text { Relative effect } \\
(95 \% \mathrm{Cl})\end{array}$} & \multirow{2}{*}{$\begin{array}{l}\text { No of participants } \\
\text { (trials) }\end{array}$} & \multirow{2}{*}{$\begin{array}{l}\text { Quality of the evidence } \\
\text { (GRADE) }\end{array}$} & \multirow{2}{*}{ Comments } \\
\hline & $\begin{array}{l}\text { Risk with platelet } \\
\text { transfusion }\end{array}$ & $\begin{array}{l}\text { Risk with platelet-poor } \\
\text { plasma }\end{array}$ & & & & \\
\hline \multirow{4}{*}{$\begin{array}{l}\text { Number of participants } \\
\text { with at least } 1 \text { bleeding } \\
\text { episode } \\
\text { follow-up: } 30 \text { days }\end{array}$} & \multicolumn{2}{|l|}{ Trial population } & \multirow{4}{*}{$\begin{array}{l}\text { OR } 16.00 \\
(1.32 \text { to } 194.62)\end{array}$} & \multirow{4}{*}{$\begin{array}{l}18 \\
(1 \mathrm{RCT})\end{array}$} & \multirow{4}{*}{$\begin{array}{l}\oplus \bigcirc \bigcirc \bigcirc \\
\text { Very low } 1,2\end{array}$} & \multirow[t]{4}{*}{-} \\
\hline & 333 per 1000 & $\begin{array}{l}889 \text { per } 1000 \\
(398 \text { to } 990)\end{array}$ & & & & \\
\hline & \multicolumn{2}{|l|}{ Moderate ${ }^{* *}$} & & & & \\
\hline & 430 per 1000 & $\begin{array}{l}923 \text { per } 1000 \\
(499 \text { to } 993)\end{array}$ & & & & \\
\hline \multirow{4}{*}{$\begin{array}{l}\text { Number of participants } \\
\text { with severe or life- } \\
\text { threatening bleeding } \\
\text { follow-up: } 30 \text { days }\end{array}$} & Trial population & & \multirow{4}{*}{$\begin{array}{l}\text { OR } 4.00 \\
(0.56 \text { to } 28.40)\end{array}$} & \multirow{4}{*}{$\begin{array}{l}18 \\
(1 \mathrm{RCT})\end{array}$} & \multirow{4}{*}{$\begin{array}{l}\oplus \bigcirc \bigcirc \bigcirc \\
\text { VERY LOW } 1,2\end{array}$} & \multirow[t]{4}{*}{-} \\
\hline & 333 per 1000 & $\begin{array}{l}667 \text { per } 1000 \\
(219 \text { to } 934)\end{array}$ & & & & \\
\hline & \multicolumn{2}{|l|}{ Moderate ${ }^{* *}$} & & & & \\
\hline & 3 per 1000 & $\begin{array}{l}13 \text { per } 1000 \\
(2 \text { to } 88)\end{array}$ & & & & \\
\hline $\begin{array}{l}\text { Number of days on } \\
\text { which bleeding oc- } \\
\text { curred-not reported }\end{array}$ & Not estimable & & Not estimable & (No trials) & - & Outcome not reported \\
\hline
\end{tabular}




\begin{tabular}{|c|c|c|c|c|c|}
\hline $\begin{array}{l}\text { Time from randomisa- } \\
\text { tion to first bleeding } \\
\text { episode - not reported }\end{array}$ & Not estimable & Not estimable & (No trials) & - & Outcome not reported \\
\hline $\begin{array}{l}\text { Number of platelet } \\
\text { transfusions - not re- } \\
\text { ported }\end{array}$ & Not estimable & Not estimable & (No trials) & - & Outcome not reported \\
\hline $\begin{array}{l}\text { All-cause mortality - not } \\
\text { reported }\end{array}$ & Not estimable & Not estimable & (No trials) & - & Outcome not reported \\
\hline $\begin{array}{l}\text { Thromboembolic } \\
\text { events - not reported }\end{array}$ & Not estimable & Not estimable & (No trials) & - & Outcome not reported \\
\hline $\begin{array}{l}\text { Quality of life - not re- } \\
\text { ported }\end{array}$ & Not estimable & Not estimable & (No trials) & - & Outcome not reported \\
\hline
\end{tabular}

\section{GRADE Working Group grades of evidence}

High quality: We are very confident that the true effect lies close to that of the estimate of the effect

Moderate quality: We are moderately confident in the effect estimate: The true effect is likely to be close to the estimate of the effect, but there is a possibility that it is substantially different

Low quality: Our confidence in the effect estimate is limited: The true effect may be substantially different from the estimate of the effect

Very low quality: We have very little confidence in the effect estimate: The true effect is likely to be substantially different from the estimate of effect

${ }^{1}$ Downgraded one point for risk of bias due to risk of performance bias.

2 Downgraded two points for imprecision (low event rate with confidence intervals including both absolute estimates of

benefit and of harm). 


\section{DISCUSSION}

\section{Summary of main results}

\section{Thrombopoietin mimetics}

Nine trials (seven papers) reported the use of TPO mimetics ( Archimbaud 1999-T1; Archimbaud 1999-T2; Geissler 2003-T1; Geissler 2003-T2; Han 2015; Miao 2012; Moskowitz 2007-T1; Moskowitz 2007-T2; Schiffer 2000). Across all the outcomes, the trials included 41 possible sets of outcome data. Of these, 29/ $41(70.7 \%)$ were reported in a form that rendered meta-analysis impossible due to combination of intervention or control (or both) groups. Additionally, the trials by Geissler (Geissler 2003-T1; Geissler 2003-T2) included participants that had already been randomised in the trials by Archimbaud (Archimbaud 1999-T1; Archimbaud 1999-T2), and it was not possible to determine which participants these were. Consequently, although these trials have been performed, accurate assessment and meta-analysis of most outcomes was not possible.

The evidence was of very low quality for number of participants with at least one bleeding episode, number of platelet transfusions within 30 days from the start of the trial and 30-day all-cause mortality.

We are very uncertain whether TPO mimetics reduce the number of participants with any bleeding episode (OR 0.40, 95\% CI 0.10 to 1.62 , one trial, 120 participants, very low quality evidence). We downgraded the quality of evidence for this outcome was downgraded two points for risk of performance and detection bias and one point for imprecision.

We are very uncertain whether TPO mimetics reduce the risk of a life-threatening bleed after 30 days (OR 1.46, 95\% CI 0.06 to 33.14, three trials, 209 participants, very low quality evidence), or after 90 days (OR 1.00, 95\% CI 0.06 to 16.37, one trial, 120 participants, very low quality evidence). We downgraded the quality of evidence for this outcome one point for risk of performance and detection bias and two points for imprecision.

We are very uncertain whether TPO mimetics reduce the platelet transfusion requirements after 30 days (mean difference -3 units, 95\% CI -5.39 to -0.61 , one trial, 120 participants, very low quality evidence). We downgraded the quality of evidence for this outcome two points for risk of performance and detection bias and one point for imprecision.

No deaths occurred at 30 days (one trial, 120 participants, very low quality evidence), and we are uncertain if there is a difference in allcause mortality at 90 days (OR 1.00, 95\% CI 0.24 to 4.20 , one trial, 120 participants, very low quality evidence). We downgraded the quality of evidence for this outcome one point for risk of performance bias and two points for imprecision.

No thromboembolic events occurred at 30 days (two trials, 209 participants, very low quality evidence). We downgraded the quality of evidence for this outcome one point for risk of performance bias and two points for imprecision.

We found no trials looking at: number of days on which bleeding occurred, time from randomisation to first bleeding episode or quality of life (Summary of findings for the main comparison).

\section{Platelet-poor plasma}

One trial compared PPP transfusion twice weekly with platelet transfusion twice weekly. It was at risk of bias due to differences in the baseline characteristics of the participants as well as lack of clarity on the method of randomisation (Higby 1974).

We are very uncertain whether PPP reduces the number of participants with any bleeding episode (OR 16.00, 95\% CI 1.32 to 194.62, one trial, 18 participants, very low quality evidence). We downgraded the quality of evidence for this outcome one point due to risk of performance bias and two points due to imprecision. We are very uncertain whether PPP reduces the number of participants with severe of life-threatening bleeding (OR 4.00, 95\% CI 0.56 to 28.40 , one trial, 18 participants, very low quality evidence). We downgraded the quality of evidence for this outcome one point due to risk of performance bias and two points due to imprecision.

We found no trials looking at: number of days on which bleeding occurred, time from randomisation to first bleeding episode, number of platelet transfusions, all-cause mortality, thromboembolic events or quality of life (Summary of findings 2).

\section{Overall completeness and applicability of evidence}

Six trials (336 participants) only included participants with acute myeloid leukaemia undergoing intensive chemotherapy, two trials (38 participants) included participants with lymphoma undergoing intensive chemotherapy and two trials (180 participants) reported participants undergoing allogeneic stem cell transplantation. None of the trials included children. No trials assessed artificial platelet substitutes, fibrinogen concentrate, recombinant rFVIIa or DDAVP. One trial compared PPP to platelet transfusion (Higby 1974), and nine trials compared a TPO mimetic to placebo or standard care (Archimbaud 1999-T1; Archimbaud 1999-T2; Geissler 2003-T1; Geissler 2003-T2; Han 2015; Miao 2012; Moskowitz 2007-T1; Moskowitz 2007-T2; Schiffer 2000).

\section{Thrombopoietin mimetics}

We found nine trials (reported in seven papers) but due to problems with the reporting of results, it was not possible to interpret the majority of the outcomes reported. Only three of the trials (reported in three papers) reported bleeding limiting the applicability of the results, even if it was possible to interpret them. To detect a decrease in the proportion of participants with clinically 
significant bleeding from 12 in 100 to 6 in 100 would require a trial containing at least 708 participants $(80 \%$ power, $5 \%$ significance). This estimate is based on the incidence of clinically significant bleeding in the trial by Han 2015. Larger trials assessing bleeding have reported higher bleeding rates, with a baseline risk of $43 \%$ in one large trial (Stanworth 2013). Detection of a decrease from 43 in 100 to 22 in 100 would require a trial containing at least 150 participants ( $80 \%$ power, $5 \%$ significance). Consequently, we are unable to answer this question without further evidence or improved reporting of the original data. Seven of the nine trials of TPO mimetics used PEG-rHuMGDF. This TPO mimetic was withdrawn from development after the discovery that in some cases for both participants and healthy volunteers, antiplatelet antibodies developed, resulting in a prolonged thrombocytopenia ( $\mathrm{Li} 2001$ ). Consequently, caution must be used when extrapolating results of trials with PEG-rHuMGDF to other TPO mimetics. The withdrawal of PEG-rHuMGDF occurred during the recruitment phase of several of the trials in this review. No trial assessing TPO mimetics assessed number of days on which bleeding occurred, time from randomisation to first bleeding episode or quality of life.

\section{Platelet-poor plasma}

One small trial that compared platelet transfusions to PPP was conducted in the early 1970s (Higby 1974). There is concern over the ability to generalise the findings from this trial to the present day. This is due to potential differences in the quality of the platelets and changes in the management of participants with haematological malignancies. It is very unlikely that a similar trial will be performed again due to the fact that the control arm was still exposing participants to a transfusion product that might harm the participant but was not expected to benefit the participant and hence would be ethically unacceptable. Newer trials instead compare a therapeutic versus prophylactic platelet transfusion policy. Therefore, we are unable to answer this question at the moment. In this trial, fever was associated with an increased risk of bleeding. However, aspirin was still used in the 1970 s as an antipyretic drug (because its antiplatelet effects were unknown at that time) and, therefore, this may have been a confounding factor in this trial. This trial did not include any data on time from randomisation to first bleeding episode, number of platelet transfusions, all-cause mortality or quality of life.

\section{Quality of the evidence}

\section{Thrombopoietin mimetics}

Overall, the quality of evidence was very low using the GRADE approach (Summary of findings for the main comparison). The majority of the outcome data for trials of TPO mimetics could not be combined for meta-analysis. All trials were RCTs but were prone to bias and had threats to validity. Risk of bias is summarised in Figure 2 with individual information about risk of bias in the Characteristics of included studies table. Two trials were open-label trials, which is a potential problem for assessing subjective outcomes such as bleeding (Han 2015; Miao 2012). It may also lead to bias for clinicians deciding whether to administer platelet transfusion. The manufacturer of the TPO mimetic under evaluation sponsored eight trials and so were at high risk of sponsorship bias (Archimbaud 1999-T1; Archimbaud 1999-T2; Geissler 2003-T1; Geissler 2003-T2; Han 2015; Moskowitz 2007-T1; Moskowitz 2007-T2; Schiffer 2000). There were particular problems with reporting random sequence generation where all trials did not provide sufficient data for a judgement to be made, and allocation concealment where only two trials assessing TPO mimetics provided sufficient information for a judgement to be made on risk of bias (Moskowitz 2007-T1; Moskowitz 2007-T2).

We assessed the GRADE quality of evidence as very low for:

- number of participants with at least one bleeding episode;

- number of participants with life-threatening bleeding;

- all-cause mortality;

- number of platelet transfusions;

- thromboembolic events.

The quality of the evidence was rated as very low due to risk of bias in the included trials and imprecision due to the small numbers of participants, events or both. We did not perform a GRADE assessment of quality of the evidence for number of days on which bleeding occurred, time from randomisation to first bleeding episode or quality of life because no trial reported these outcomes.

\section{Platelet-poor plasma}

Overall the quality of evidence was very low using the GRADE approach (Summary of findings 2). Interpretation of the quality of evidence was limited by inadequate detail in methodological reporting. Risk of bias is summarised in Figure 2 with individual information about risk of bias in the Characteristics of included studies table. The single trial of PPP compared to platelet transfusion did not report sufficient information to assess sequence generation, blinding of clinicians, blinding of outcome assessors or selective reporting. It was at high risk of bias due to an imbalance in the ages of the participants in each arm of the trial and re-randomisation of three participants.

We assessed the GRADE quality of evidence as very low for:

- number of participants with at least one bleeding episode;

- number of participants with life-threatening bleeding.

The quality of the evidence was rated as very low due to risk of bias in the included trial and imprecision due to the small number of participants and events. We did not perform a GRADE assessment of quality of the evidence for number of days on which bleeding occurred, time from randomisation to first bleeding episode, 
number of platelet transfusions, all-cause mortality, thromboembolic events or quality of life because the trial did not report these outcomes.

\section{Potential biases in the review process}

We conducted a wide search, carefully assessed the relevance of each paper identified and applied no restrictions for the language in which the paper was originally published. We gave the original authors and sponsors the opportunity to provide additional data to clarify the results of their trials but none put forward any new information. We could not formally assess publication bias, as our primary outcome was reported in only one paper assessing TPO mimetics and one paper assessing PPP. We identified one trial published as a conference abstract from a trial that was completed in April 2012 and has still not been published. This may represent publication bias (Vadhan-Raj 2010).

\section{Agreements and disagreements with other studies or reviews}

The results of further trials, including those of eltrombopag versus placebo, will be necessary to determine if there is any value in considering TPO mimetics to prevent bleeding for this group of participants.

\section{A U THORS' CONCLUSIONS}

\section{Implications for practice}

We are uncertain if thrombopoietin (TPO) mimetics or plateletpoor plasma reduce bleeding compared to placebo (or standard care) for people with haematological malignancies undergoing intensive chemotherapy. Pegylated recombinant human megakaryocyte growth and differentiation factor (PEG-rHuMGDF), which accounted for seven of the nine trials of TPO mimetics, has been withdrawn by its manufacturer, AMGEN. There is no randomised controlled trial evidence to assess artificial platelets, fibrinogen concentrate, recombinant activated factor VIIa (rFVIIa) or desmopressin (DDAVP) in this setting.

\section{Implications for research}

Our search strategy identified five further trials of TPO mimetics (eltrombopag) that are presently underway for participants undergoing intensive chemotherapy and one further trial of AMG531 (romiplostim) that was completed but the results have not yet been reported. The problems with reporting outcomes of the trials in this systematic review make it difficult to interpret the value of additional trials of TPO mimetics and without further data, a recommendation cannot be made. To detect a decrease in the proportion of participants with clinically significant bleeding from 12 in 100 to 6 in 100 would require a trial containing at least 708 participants (80\% power, $5 \%$ significance). Detection of a decrease from 43 in 100 to 22 in 100 would require a trial containing at least 150 participants ( $80 \%$ power, $5 \%$ significance). The search identified no trials of other alternative agents such as artificial platelets, fibrinogen concentrate, rFVIIa or DDAVP and further research will be necessary to determine whether these agents have a role in preventing bleeding for people with thrombocytopenia undergoing intensive chemotherapy.

\section{ACKNOWLEDGEMENTS}

We thank the editorial base of the Cochrane Haematological Malignancies Review Group.

We thank the National Institute of Health Research (NIHR). This review is part of a series of reviews that have been funded by the NIHR Cochrane Programme Grant - Safe and Appropriate Use of Blood Components. This research was also supported by the NIHR Oxford Biomedical Research Centre Programme. The views expressed are those of the review authors and not necessarily those of the National Health System (NHS), the NIHR or the Department of Health.

We thank the authors of the previous reviews (Stanworth 2004): S Brunskill, N Heddle, C Hyde, P Rebulla and Estcourt 2012b: A Tinmouth.

We thank an author of the protocol (Estcourt 2014b): R Gregg.

We thank Hoi-Pat Tsang for his translation of Miao 2012 from Chinese into English. 


\section{R E F E R E N C E S}

\section{References to studies included in this review}

Archimbaud 1999-T1 \{published data only\}

Archimbaud E, Ottmann OG, Yin JA, Lechner K, Dombret $\mathrm{H}$, Sanz MA, et al. A randomized, double-blind, placebocontrolled study with pegylated recombinant human megakaryocyte growth and development factor (PEGrHuMGDF) as an adjunct to chemotherapy for adults with de novo acute myeloid leukemia. Blood 1999;94(11): 3694-701.

Archimbaud 1999-T2 \{published data only\} Archimbaud E, Ottmann OG, Yin JA, Lechner K, Dombret $\mathrm{H}$, Sanz MA, et al. A randomized, double-blind, placebocontrolled study with pegylated recombinant human megakaryocyte growth and development factor (PEGrHuMGDF) as an adjunct to chemotherapy for adults with de novo acute myeloid leukemia. Blood 1999;94(11): 3694-701.

\section{Geissler 2003-T1 \{published data only\}}

Geissler K, Yin JA, Ganser A, Sanz MA, Szer J, Raghavachar A, et al. Prior and concurrent administration of recombinant human megakaryocyte growth and development factor in patients receiving consolidation chemotherapy for de novo acute myeloid leukemia - a randomized, placebo-controlled, double-blind safety and efficacy study. Annals of Hematology 2003;82(11):677-83.

\section{Geissler 2003-T2 \{published data only\}}

Geissler K, Yin JA, Ganser A, Sanz MA, Szer J, Raghavachar $A$, et al. Prior and concurrent administration of recombinant human megakaryocyte growth and development factor in patients receiving consolidation chemotherapy for de novo acute myeloid leukemia - a randomized, placebo-controlled, double-blind safety and efficacy study. Annals of Hematology 2003;82(11):677-83.

Han 2015 \{published data only\}

A compare study on human recombinant thrombopoietin (TPIAO) promote platelet recovery in haploidentical hematopoietic stem cell transplantation recipients. Chinese clinical trial registry number: ChiCTR-TRC-11001774.

* Han TT, Xu LP, Liu DH, Liu KY, Wang FR, Wang Y, et al. Recombinant human thrombopoietin promotes platelet engraftment after haploidentical hematopoietic stem cell transplantation: a prospective randomized controlled trial. Annals of Hematology 2015;94:117-28.

Higby 1974 \{published data only\}

Higby DJ, Cohen E, Holland JF, Sinks L. The prophylactic treatment of thrombocytopenic leukemic patients with platelets: a double blind study. Transfusion 1974;14:440-5.

Miao 2012 \{published data only\}

Miao M, Wu DP, Cao XS, Dong WM, Wang B, Ou $\mathrm{YJ}$, et al. Clinical study on platelet engraftment by thrombopoietin in patients with hematological malignancies after allogeneic hematopoietic stem cell transplantation
[血小板生成素在异基因 造血干细胞移植后促进血小板植入的临床研究]. Zhonghua Xue Ye Xue Za Zhi 2012;37(5):231-5.

Moskowitz 2007-T1 \{published data only\}

Moskowitz CH, Hamlin PA, Gabrilove J, Bertino JR, Portlock CS, Straus DJ, et al. Maintaining the dose intensity of ICE chemotherapy with a thrombopoietic agent, PEGrHuMGDF, may confer a survival advantage in relapsed and refractory aggressive non-Hodgkin lymphoma. Annals of Oncology 2007;18(11):1842-50.

Moskowitz 2007-T2 \{published data only\} Moskowitz CH, Hamlin PA, Gabrilove J, Bertino JR, Portlock CS, Straus DJ, et al. Maintaining the dose intensity of ICE chemotherapy with a thrombopoietic agent, PEGrHuMGDF, may confer a survival advantage in relapsed and refractory aggressive non-Hodgkin lymphoma. Annals of Oncology 2007;18(11):1842-50.

Schiffer 2000 \{published data only\} Schiffer CA, Miller K, Larson RA, Amrein PC, Antin JH, Zani VJ, et al. A double-blind, placebo-controlled trial of pegylated recombinant human megakaryocyte growth and development factor as an adjunct to induction and consolidation therapy for patients with acute myeloid leukemia. Blood 2000;95(8):2530-5.

\section{References to studies excluded from this review}

\section{ASH 2003 \{published data only\}}

American Society of Hematology. Meeting highlights from 45th annual meeting of the American Society of Hematology. Clinical Lymphoma 2003; Vol. 4:141-8.

Avvisati 1989 \{published data only\} Avvisati G, Cate JW, Büller HR, Mandelli F. Tranexamic acid for control of haemorrhage in acute promyelocytic leukaemia. Lancet 1989;2:122-4.

Bai 2004a \{published data only\}

Bai CM, Xu GX, Zhao YQ, Han SM, Shan YD. A multi-centre clinical trial of recombinant human thrombopoietin in the treatment of chemotherapy-induced thrombocytopenia in patients with solid tumor. Zhongguo Yi Xue Ke Xue Yuan Xue Bao Acta Academiae Medicinae Sinicae 2004;26(4):437-41.

Bai 2004b \{published data only\} Bai CM, Zou XY, Zhao YQ, Han SM, Shan YD. The clinical study of recombinant human thrombopoietin in the treatment of chemotherapy-induced severe thrombocytopenia. Zhonghua yi xue za zhi 2004;84(5): $397-400$.

Basciano 2012 \{published data only\} Basciano PA, Bussel JB. Thrombopoietin-receptor agonists. Current Opinion in Hematology 2012;19:392-8.

Basser 1996 \{published data only\} Basser RL, Rasko JE, Clarke K, Cebon J, Green MD, Hussein S, et al. Thrombopoietic effects of pegylated 
recombinant human megakaryocyte growth and development factor (PEG-rHuMGDF) in patients with advanced cancer. Lancet 1996;348:1279-81.

Basser 1997 \{published data only\}

Basser RL, Rasko JE, Clarke K, Cebon J, Green MD, Grigg AP, et al. Randomized, blinded, placebo-controlled phase I trial of pegylated recombinant human megakaryocyte growth and development factor with filgrastim after doseintensive chemotherapy in patients with advanced cancer. Blood 1997;89:3118-28.

Basser 2000 \{published data only\} Basser RL, Underhill C, Davis I, Green MD, Cebon J, Zalcberg J, et al. Enhancement of platelet recovery after myelosuppressive chemotherapy by recombinant human megakaryocyte growth and development factor in patients with advanced cancer. Journal of Clinical Oncology 2000;18: 2852-61.

Basser 2002 \{published data only\}

Basser R. The impact of thrombopoietin on clinical practice. Current Pharmaceutical Design 2002;8:369-77.

Bauman 2011 \{published data only\} Bauman JW, Vincent CT, Peng B, Wire MB, Williams DD, Park JW. Effect of hepatic or renal impairment on eltrombopag pharmacokinetics. Journal of Clinical Pharmacology 2011;51:739-50.

Berstein 2002 \{published data only\} Bernstein SH, Jusko WJ, Krzyzanski W, Nichol J, Wetzler M. Pharmacodynamic modeling of thrombopoietin, platelet, and megakaryocyte dynamics in patients with acute myeloid leukemia undergoing dose intensive chemotherapy. Journal of Clinical Pharmacology 2002;42:501-11.

Blajchman 2001 \{published data only\} Blajchman MA. Novel platelet products, substitutes and alternatives. Transfusion Clinique et Biologique 2001;8: 267-71.

Blajchman 2003 \{published data only\} Blajchman MA. Substitutes and alternatives to platelet transfusions in thrombocytopenic patients. Journal of Thrombosis and Haemostasis 2003;1:1637-41.

Bowen 2010 \{published data only\} Bowen CJ, Lobb KM, Park JW, Sanderson B, Ferguson J. Eltrombopag $(75 \mathrm{mg})$ does not induce photosensitivity: results of a clinical pharmacology trial. Photodermatology, Photoimmunology \& Photomedicine 2010;26:243-9.

Brenner 2004 \{published data only\}

Brenner B, Pihusch M, Bacigalupo A, Szer J, Prondzinkski MD, Gaspar-Blaudschun B, et al. Activated recombinant factor VII (rFVIIa/NovoSeven $\left.{ }^{\circledR}\right)$ in the treatment of bleeding complications following hematopoietic stem cell transplantation (HSCT). Blood 2004; 104:321-2a.

Bussel 2006 \{published data only\}

Bussel J, Saleh M, Provan D, Stone N, Hamilton JM, Hassani H, et al. Eltrombopag, a novel, oral platelet growth factor, increases platelet counts in thrombocytopenic patients and healthy subjects. Journal of Clinical Oncology: Asco Annual Meeting Proceedings 2006;24:493.
Bussel 2007 \{published data only\}

Bussel JB, McHutchison J, Provan D, Jagiello-Gruzfeld A, Rafi R, Goodison S. Safety of eltrombopag, an oral non-peptide platelet growth factor, in the treatment of thrombocytopenia: results of four randomized, placebocontrolled studies. Blood 2007;110:Abstract 1299.

\section{Castaman 1997 \{published data only\}}

Castaman G, Bona ED, Schiavotto C, Trentin L, Emilio $\mathrm{AD}$, Rodeghiero F. Pilot study on the safety and efficacy of desmopressin for the treatment or prevention of bleeding in patients with hematologic malignancies. Haematologica 1997;82:584-7.

Catalá-López 2015 \{published data only\} Catalá-López F, Corrales I, de la Fuente-Honrubia C, González-Bermejo D, Martín-Serrano G, Montero G, et al. Risk of thromboembolism with thrombopoietin receptor agonists in adult patients with thrombocytopenia: an updated systematic review and meta-analysis of randomized controlled trials. Medicina Clinica 2015;145:511-9.

Corrales-Alvarez 2011 \{published data only\} Corrales-Alvarez I, Catala-Lopez F, MartinSerrano G, Montero-Corominas D, Calvo-Rojas G. Thromboembolisms with thrombopoietin receptor agonists: systematic review and meta-analysis of randomized controlled trials. Value in Health 2011;14:A364-5.

Dickinson 2014 \{published data only\} Dickinson DJ, Herbert K, Sardjono C, Le T, Zannino D, Wood C, et al. 4657 final analysis of a Phase II study of intrapatient dose-escalation of eltrombopag in patients receiving azacitidine for myelodysplasia/AML. Blood 2014; 124:Abstract 4657.

Drug news 2005 \{published data only\} New drugs - drug news. P\&T: Journal for Formulary Management 2005; Vol. 30:624-69.

Drug news 2006 \{published data only\} New drugs/drug news. P\&T: Journal for Formulary Management 2006; Vol. 31:638.

Dunser 2004 \{published data only\} Dunser MW, Fries DR, Schobersberger W, Ulmer H, Wenzel V, Friesenecker B, et al. Does arginine vasopressin influence the coagulation system in advanced vasodilatory shock with severe multiorgan dysfunction syndrome?. Anesthesia \& Analgesia 2004;99:201-6.

Elinoff 2014 \{published data only\} Elinoff JM, Bagci U, Moriyama B, Dreiling JL, Foster B, Gormley NJ, et al. Recombinant human factor VIIa for alveolar hemorrhage following allogeneic stem cell transplantation. Biology of Blood and Marrow Transplantation 2014;20:969-78.

EudraCT number 2010-022890-33 \{published data only\} EudraCT number 2010-022890-33. Eltrombopag for the treatment of thrombocytopenia due to low- and intermediate risk myelodysplastic syndromes. EudraCT number 2010-022890-33. 
Eudra CT number 2014-000174-19 \{published data only\} EudraCT number 2014-000174-19. Efficacy and safety of eltrombopag in patients with acquired moderate aplastic anemia (EMAA) who are treated with ciclosporin A. EudraCT number 2014-000174-19.

Franchini 2007 \{published data only\} Franchini M, Veneri D, Lippi G. The potential role of recombinant activated FVII in the management of critical hemato-oncological bleeding: a systematic review. Bone Marrow Transplantation 2007;39:729-35.

Frey 2012 \{published data only\}

Frey NV, Hexner EO, Porter DL, Mangan JK, Loren AW, Hatem J, et al. A phase I clinical trial using eltrombopag in patients with acute myelogenous leukemia. Blood 2012; 120:Abstract 3576.

Fricke 1991 \{published data only\} Fricke W, Alling D, Kimball J, Griffith P, Klein H. Lack of efficacy of tranexamic acid in thrombocytopenic bleeding. Transfusion 1991;31(4):345-8.

Gallardo 1983 \{published data only\} Gallardo RL, Gardner FH. Antifibrinolytic therapy for bleeding control during remission induction for acute leukemia. Blood 1983;62:202a.

Gerrits 2015 \{published data only\}

Gerrits AJ, Leven EA, Frelinger III AL, Brigstocke SL, Berny-Lang MA, Mitchell WB, et al. Effects of eltrombopag on platelet count and platelet activation in Wiskott-Aldrich syndrome/X-linked thrombocytopenia. Blood 2015;126: 1367-78.

Giagounidis 2014 \{published data only\}

* Giagounidis A, Mufti GF, Fenaux P, Sekeres MA, Szer J, Platzbecker U, et al. Results of a randomized, doubleblind study of romiplostim versus placebo in patients with low/intermediate-1-risk myelodysplastic syndrome and thrombocytopenia. Cancer 2014;120:1838-46. Giagounidis A, Mufti GF, Kantarjian HM, Fenaux P, Sekeres MA, Szer J, et al. Treatment with the thrombopoietin (TPO)-receptor agonist romiplostim in thrombocytopenic patients (Pts) with low or intermediate-1 (Int-1) risk myelodysplastic syndrome (MDS): results of a randomized, double-blind, placebo(PBO)-controlled study. Blood 2011; 118:Abstract 117.

Sekeres MA, Giagounidis A, Kantarjian H, Mufti GJ, Fenaux P, Jia C, et al. Development and validation of a model to predict platelet response to romiplostim in patients with lower-risk myelodysplastic syndromes. British Journal of Haematology 2014;167:337-45.

Glaspy 1991 \{published data only\}

Glaspy J, Bleecker G, Crawford J, Stoller R, Strauss M. The impact of therapy with recombinant granulocyte colony stimulated factor (GCSF) on the health care costs associated with cancer chemotherapy. Blood 1991;78:7a.

Greenberg 2013 \{published data only\} Greenberg PL, Garcia-Manero G, Moore M, Damon L, Roboz G, Hu K, et al. A randomized controlled trial of romiplostim in patients with low- or intermediate-risk myelodysplastic syndrome receiving decitabine. Leukemia ¿ Lymphoma 2013;54:321-8.

Hampton 2007 \{published data only\}

Hampton T. Agents to control bleeding show promise. JAMA 2007;297:349-50.

\section{Heddle 1995 \{published data only\}}

Heddle NM, Klama L, Kelton JG, Meyer R, Walker I, Dickson L, et al. The use of anti-D to improve posttransfusion platelet response: a randomized trial. British Journal of Haematology 1995;89:163.

\section{Höchsmann 2014 \{published data only\}}

Ho chsmann B, Schrezenmeier H, on behalf of SAAWP. Efficiency and safety of thrombopoietin in moderate aplastic anemia-EMAA trial. Bone Marrow Transplantation 2014; 49:Abstract WP-O010.

\section{Jain 2013 \{published data only\}}

* Jain N, Keating MJ, Burger JA, Ferrajoli A, Borthakur G, Koller C, et al. A phase II trial of eltrombopag for patients with chronic lymphocytic leukemia (CLL) and thrombocytopenia. Blood 2013;122:Abstract.

NCT01168921. Phase II eltrombopag in chronic lymphocytic leukemia (CLL). clinicaltrials.gov/ct2/show/ NCT01168921 (accessed 24 July 2016).

Johansson 2008 \{published data only\}

Johansson PI. Off-label use of recombinant factor VIIa for treatment of haemorrhage: results from randomized clinical trials. Vox Sanguinis 2008;95:1-7.

\section{Kantarjian 2010a \{published data only\}}

Fenaux P, Kantarjian H, Lyons RM, Larson RA, Sekeres MA, Becker P, et al. Update from an open-label extension study evaluating the long-term safety and efficacy of romiplostim in thrombocytopenic patients (pts) with myelodysplastic syndromes (MDS). Blood 2010;116:Abstract 1885. Fenaux P, Kantarjian H, Lyons RM, Larson RA, Sekeres MA, Becker P, et al. Update of an open-label extension study evaluating the long-term safety and efficacy of romiplostim in thrombocytopenic patients with myelodysplastic syndromes (MDS). Blood 2011;118:Abstract 2772. Fenaux P, Kantarjian H, Lyons RM, Larson RA, Sekeres MA, Becker P, et al. Update of open-label extension study evaluating the long-term safety and efficacy of romiplostim in thrombocytopenic patients with myelodysplastic syndromes (MDS). Leukemia Research 2011;35:Abstract 2772.

Fenaux P, Muus P, Kantarjian H, Lyons RM, Larson RA, Sekeres MA, et al. Characteristics of romiplostim-treated MDS patients with hematologic improvement in platelets (HI-P). Leukaemia Research 2015;S1:Abstract 97.

Kantarjian H, Fenaux P, Sekeres MA, Becker PS, Boruchov A, Bowen D, et al. Phase 1/2 study of AMG 531 in thrombocytopenic patients (pts) with low-risk myelodysplastic syndrome (MDS): update including extended treatment. Blood 2007;110:81a.

* Kantarjian H, Fenaux P, Sekeres MA, Becker PS, Boruchov A, Bowen D, et al. Safety and efficacy of romiplostim in patients with lower-risk myelodysplastic syndrome and

Alternatives, and adjuncts, to prophylactic platelet transfusion for people with haematological malignancies undergoing intensive 
thrombocytopenia. Journal of Clinical Oncology 2010;28: 437-44.

Kantarjian H, Mufti GJ, Fenaux P, Sekeres MA, Szer U, Platzbecker A, et al. Treatment with romiplostim, a thrombopoietin-receptor agonist, in thrombocytopenic patients with low or intermediate-1 risk myelodysplastic syndrome: Updated follow-up results for acute myeloid leukemia and survival from a randomized, double-blind, placebo-controlled study. Blood 2013;122:1553.

Kantarjian H, Mufti GJ, Fenaux P, Sekeres MA, Szer U, Platzbecker A, et al. Treatment with the thrombopoietin (TPO)-receptor agonist romiplostim in thrombocytopenic patients (PTS) with low or intermediate-1 (INT-1) risk myelodysplastic syndrome (MDS): follow-up AML and survival results of a randomized, double-blind, placebo (PBO)-controlled study. Blood 2012;120:Abstract 421. Kantarjian HM, MuIi G, Fenaux P, Sekeres M, Szer J, Platzbecker U, et al. Treatment with romiplostim, a thrombopoietin-receptor agonist, in thrombocytopenic patients (Pts) with low or intermediate-1 (Int-1) risk myelodysplastic syndrome (MDS): updated follow-up results for acute myeloid leukemia (AML) and survival from a randomized, double-blind, placebo (PBO)-controlled study. Blood 2014;124:Abstract 3276.

NCT00303472. Determination of safe dose of romiplostim (AMG 531) in patients with myelodysplastic syndromes (MDS). clinicaltrials.gov/ct2/show/NCT00303472 (accessed 24 July 2016).

Platzbecker U, Sekeres MA, Kantarjian H, Giagounidis A, Mufti GJ, Jia C, et al. Relationship of different platelet response criteria and patient outcomes in a romiplostim myelodysplastic syndromes trial. Leukemia 2014;28: 2418-21.

Kantarjian 2010b \{published data only\}

Kantarjian HM, Giles FJ, Greenberg PL, Paquette RL, Wang ES, Gabrilove JL, et al. Phase 2 study of romiplostim in patients with low- or intermediate-risk myelodysplastic syndrome receiving azacitidine therapy. Blood 2010;116: 3163-70.

Kellum 2010 \{published data only\} Kellum A, Jagiello-Gruszfeld A, Bondarenko IN, Patwardhan R, Messam C, Mostafa Kamel Y. A randomized, double-blind, placebo-controlled, dose ranging study to assess the efficacy and safety of eltrombopag in patients receiving carboplatin/paclitaxel for advanced solid tumors. Current Medical Research \& Opinion 2010;26:2339-46.

Knoefler 2013 \{published data only\} Knoefler R, Gneub A, Franke D, Kentouche K, Koscielny J, Krammer-Steiner B, et al. Evaluation of laboratory desmopressin testing and clinical effects in patients with hereditary and acquired thrombocytopathies: results of a retrospective multicenter study. Journal of Thrombosis and Haemostasis 2013;11:Abstract 348 .

Korte 2009 \{published data only\}

Korte WC, Szadkowski C, Gahler A, Gabi K, Kownacki E, Eder M, et al. Factor XIII substitution in surgical cancer patients at high risk for intraoperative bleeding. Anesthesiology 2009;110:239-45.

Kristensen 1993 \{published data only\}

Kristensen J, Killander A, Hippe E, Ellegaard J Hedner U. Recombinant factor VIIa (rFVIIa) reduces the bleeding time in patients with thrombocytopenia. Blood 1993;82:155a.

\section{Kruskemper 1966 \{published data only\}}

Kruskemper HL. Effect of testosterone propionate and 1methyl-1-androstenolone on blood coagulation factors, bromsulphalein retention and serum enzymes as parameters of liver function. Klinische Wochenschrift 1966;44:1127-32.

Levy 2008 \{published data only\}

Levy B, Arnason JE, Bussel JB. The use of secondgeneration thrombopoietic agents for chemotherapyinduced thrombocytopenia. Current Opinion in Oncology 2008;20:690-6.

Li 2012 \{published data only\}

Li Q, Ye M, Xiao W, Zhu J, Zhang S. Prophylactic recombinant human thrombopoietin treatment alleviates chemotherapy-induced thrombocytopenia in tumor patients. Nan Fang Yi Ke Da Xue Xue Bao 2012;32:1064-6.

Liesveld 2013 \{published data only\}

* Liesveld JL, Phillips GL 2nd, Becker MW, Constine L, Friedberg J, Andolina J, et al. A phase 1 trial of eltrombopag in patients undergoing stem cell transplantation after total body irradiation. Biology of Blood \& Marrow Transplantation 2013;19:1745-52.

Liesveld JL, Phillips GL, Becker MW, Constine L, Friedberg J, Andolina J, et al. Phase I study of eltrombopag for promoting thrombopoiesis in patients undergoing stem cell transplantation after total body irradiation. Blood 2011;

118:Abstract 3295.

Liesveld JL, Phillips GL, Becker MW, Constine L, Friedberg J, Andolina J, et al. Phase I study of eltrombopag for promoting thrombopoiesis in patients undergoing stem cell transplantation after total body irradiation. Blood 2012; 120:Abstract 219.

Louis 1967 \{published data only\} Louis J, Paulus JM. Trial of a new hemostatic: dicynone. Revue Médicale de Liège 1967;22:649-51.

Malyszko 1990 \{published data only\} Malyszko J, Pietraszek M, Buczko W, Mysliwiec M. Study on mechanisms of a haemostatic effect of 1 deamino-8-Darginine vasopressin (desmopressin) in uraemic patients. Folia Haematologica 1990;117:319-24.

Mannucci 1986 \{published data only\}

Mannucci PM, Vicente V, Vianello L, Cattaneo M, Alberca I, Coccato MP, et al. Controlled trial of desmopressin in liver cirrhosis and other conditions associated with a prolonged bleeding time. Blood 1986;67:1148-53.

Matsumoto 2007 \{published data only\} Matsumoto M, Kawa K, Uemura M, Kato S, Ishizashi $\mathrm{H}$, Isonishi A, et al. Prophylactic fresh frozen plasma may prevent development of hepatic VOD after stem cell transplantation via ADAMTS13-mediated restoration

Alternatives, and adjuncts, to prophylactic platelet transfusion for people with haematological malignancies undergoing intensive 
of von Willebrand factor plasma levels. Bone Marrow

Transplantation 2007;40:251.

\section{Mittelman 2012 \{published data only\}}

Mittelman M, Assouline S, Briasoulis E, Alonso A, Delgado RG, Gorman PO, et al. Eltrombopag treatment of thrombocytopenia in advanced myelodysplastic syndromes and acute myeloid leukemia: results of the 8-week openlabel part of an ongoing study. Archivos de Cardiologia de Mexico 2012;82:105-11.

\section{Mizer 1998 \{published data only\}}

Mizer JC, Ichim TE, Alexandrescu DT, Dasanu CA, Ramos F, Turner A, et al. Exogenous endothelial cells as accelerators of hematopoietic reconstitution. Critical Care Medicine 1998;26:149-56.

Nair 2006 \{published data only\}

Nair V, Mishra DK, Sharma A, Das SN, Kotwal J, Mukerjee $\mathrm{B}$, et al. Erythropoietin (EPO) and granulocyte colony stimulating factor (GCS-F) based therapy in patients with low risk MDS: a single centre experience from India. Blood 2006; 108:Abstract 4869.

Nash 2000 \{published data only\}

Nash RA, Kurzrock R, DiPersio J, Vose J, Linker C, Maharaj D, et al. A phase I trial of recombinant human thrombopoietin in patients with delayed platelet recovery after hematopoietic stem cell transplantation. Biology of Blood \& Marrow Transplantation 2000;6:25-34.

Natale 2009 \{published data only\}

Natale R, Charu V, Schutte W, Albert I, Tehenes S, McCoy J, et al. Safety of romiplostim for treatment of chemotherapy-induced thrombocytopenia (CIT) in patients with advanced non-small cell lung cancer (NSCLC). European Journal of Cancer 2009;7:574.

\section{NCT00102726 \{published data only\}}

NCT00102726. SB-497115 (oral thrombopoietin receptor agonist) versus placebo in adult cancer patients receiving chemotherapy. clinicaltrials.gov/ct2/show/NCT00102726 (accessed 24 July 2016).

\section{NCT00358540 \{published data only\}}

NCT00358540. Dose finding study of oral eltrombopag in patients with sarcoma receiving adriamycin and ifosfamide. clinicaltrials.gov/ct2/show/NCT00358540 (accessed 24 July 2016).

\section{NCT00413283 \{published data only\}}

NCT00413283. Dose/schedule finding trial of romiplostim for chemotherapy-induced thrombocytopenia (CIT) in non-small cell lung cancer (NSCLC). clinicaltrials.gov/ct2/ show/NCT00413283 (accessed 24 July 2016).

NCT00472290 \{published data only\}

NCT00472290. An open label extension study evaluating the safety of long term dosing of romiplostim in thrombocytopenic subjects with myelodysplastic syndromes (MDS). clinicaltrials.gov/ct2/show/NCT00472290 (accessed 24 July 2016).

\section{NCT00614523 \{published data only\}}

NCT00614523. Romiplostim treatment of thrombocytopenia in subjects with low or intermediate-1 risk myelodysplastic syndrome (MDS). clinicaltrials.gov/ ct2/show/NCT00614523 (accessed 24 July 2016).

NCT00688272 \{published data only\} NCT00688272. Study in healthy subjects to evaluate the photo-irritant potential of eltrombopag. clinicaltrials.gov/ ct2/show/NCT00688272 (accessed 24 July 2016).

\section{NCT00903422 \{published data only\}}

NCT00903422. Eltrombopag treatment of thrombocytopenia in subjects with advanced myelodysplastic syndrome (MDS) or secondary acute myeloid leukemia after MDS (sAML/MDS). clinicaltrials.gov/ct2/show/ NCT00903422 (accessed 24 July 2016).

NCT00922883 \{published data only\} NCT00922883. A pilot study of a thrombopoietinreceptor agonist (TPO-R agonist), eltrombopag, in aplastic anemia patients with immunosuppressive-therapy refractory thrombocytopenia. clinicaltrials.gov/ct2/show/ NCT00922883 (accessed 24 July 2016).

NCT01072162 \{published data only\} NCT01072162. Relative bioavailibility for pediatric powder for suspension (PfOS) formulation and food effect. clinicaltrials.gov/ct2/show/NCT01072162 (accessed 24 July 2016).

\section{NCT01147809 \{published data only\}} NCT01147809. Safety and efficacy study for solid tumor patients treated with eltrombopag. clinicaltrials.gov/ct2/ show/NCT01147809 (accessed 24 July 2016).

\section{NCT01194167 \{published data only\}} NCT01194167. Study of eltrombopag in platelet refractory thrombocytopenia. clinicaltrials.gov/ct $2 /$ show/ NCT01194167 (accessed 24 July 2016).

\section{NCT01328587 \{published data only\}} NCT01328587. A pilot study of a thrombopoietinreceptor agonist (TPO-R agonist), eltrombopag, in moderate aplastic anemia patients. clinicaltrials.gov/ct2/ show/NCT01328587 (accessed 24 July 2016).

\section{NCT01500538 \{published data only\}} NCT01500538. A pilot study of oral vorinostat plus oral eltrombopag support in patients with lymphoma (VEIL). clinicaltrials.gov/ct2/show/NCT01500538 (accessed 24 July 2016).

\section{NCT01516619 \{published data only\}} NCT01516619. Secondary prophylaxis in nonHodgkin lymphoma (NHL) and chemotherapy-induced thrombocytopenia (ProRom). clinicaltrials.gov/ct2/show/ NCT01516619 (accessed 24 July 2016).

\section{NCT01550185 \{published data only\}} NCT01550185. Eltrombopag olamine in treating patients with relapsed/refractory acute myeloid leukemia. clinicaltrials.gov/ct2/show/NCT01550185 (accessed 24 July 2016). 
NCT01757145 \{published data only\}

NCT01757145. Eltrombopag for enhancing platelet engraftment in adult patients undergoing cord blood transplantation. clinicaltrials.gov/ct2/show/NCT01757145 (accessed 24 July 2016).

NCT01791101 \{published data only\} NCT01791101. Eltrombopag in patients with delayed post transplant thrombocytopenia (ITP0511). clinicaltrials.gov/ ct2/show/NCT01791101 (accessed 24 July 2016).

NCT01893372 \{published data only\} NCT01893372. Eltrombopag with or without hypomethylating agent after hypomethylating agent failure for patients with myelodysplastic syndrome (MDS). clinicaltrials.gov/ct2/show/NCT01893372 (accessed 24 July 2016).

NCT01957176 \{published data only\} NCT01957176. A rollover study to provide continued treatment with eltrombopag. clinicaltrials.gov/ct2/show/ NCT01957176 (accessed 24 July 2016).

NCT01980030 \{published data only\} NCT01980030. Using ROMIPLOSTINE for persistent thrombocytopenia with transfusion-dependent patients who received allogeneic hematopoietic stem cell (AGRAH003). clinicaltrials.gov/ct2/show/NCT01980030 (accessed 24 July 2016).

NCT02046291 \{published data only\} NCT02046291. Safety of romiplostim (Nplate $\left.{ }^{\circledR}\right)$ following UCBT. clinicaltrials.gov/ct2/show/NCT02046291 (accessed 24 July 2016).

\section{NCT02052882 \{published data only\}} NCT02052882. Study of romiplostim versus observation for chemotherapy induced thrombocytopenia. clinicaltrials.gov/ct2/show/NCT02052882 (accessed 24 July 2016).

NCT02093325 \{published data only\} NCT02093325. A randomized, double blind, placebocontrolled study to assess the efficacy and safety of eltrombopag as a rescue of isolated chemotherapy-induced thrombocytopenia in patients with gynecologic cancer. clinicaltrials.gov/ct2/show/NCT02093325 (accessed 24 July 2016).

NCT02094417 \{published data only\} NCT02094417. A phase 2 study to evaluate the efficacy and safety of AMG531 in aplastic anemia. clinicaltrials.gov/ ct2/show/NCT02094417 (accessed 24 July 2016).

NCT02323178 \{published data only\}

NCT02323178. A study of eltrombopag in patients with CMML and thrombocytopenia. clinicaltrials.gov/ct2/show/ NCT02323178 (accessed 24 July 2016).

NCT02446145 \{published data only\}

NCT02446145. A randomized placebo-controlled phase 2 study of decitabine with or without eltrombopag in AML patients (DELTA). clinicaltrials.gov/ct2/show/ NCT02446145 (accessed 24 July 2016).
Norris 2011 \{published data only\}

Norris L, Qureshi Z, Barnato S, Lai S, Bennett C. Serious adverse drug reactions (sADRS) associated with hematopoietic growth factors: a systematic review from the southern network on adverse reactions (SONAR) program. Journal of Oncology Pharmacy Practice 2011;17:20-1.

Oliva 2013 \{published data only\}

Oliva E, Latagliata R, Santini V, Palumbo GA, Poloni A, Cortelezzi A, et al. Efficacy and safety of eltrombopag for the treatment of thrombocytopenia of low and int-1 risk MDS: preliminary results of a prospective, randomized, single-blind placebo-controlled trial. Haematologica 2012; S1:Abstract 1138.

* Oliva E, Santini V, Zini G, Palumbo G, Poloni A, Cortelezzi A, et al. Eltrombopag for the treatment of thrombocytopenia of low and intermediate-1 IPSS risk myelodysplastic syndromes: results of a prospective, randomized, trial. Haematologica 2013;98:Abstract S1110. Oliva EN, Santini V, Zini G, Palumbo GA, Poloni A, Cortelezzi A, et al. Efficacy and safety of eltrombopag for the treatment of thrombocytopenia of low and intermediate1 IPSS risk myelodysplastic syndromes: interim analysis of a prospective, randomized, single-blind, placebo-controlled trial (EQOL-MDS). Blood 2012;120:Abstract 923.

Olnes 2012 \{published data only\}

Olnes MJ, Scheinberg P, Calvo K, Tang Y, Soto S, Feng X, et al. Eltrombopag can stimulate trilineage hematopoiesis with transfusion independence in patients with refractory severe aplastic anemia: results from a phase II trial. Blood 2011;118:Abstract 54.

Olnes MJ, Scheinberg P, Calvo KR, Desmond R, Tang Y, Dumitriu B, et al. Eltrombopag and improved hematopoiesis in refractory aplastic anemia. New England Journal of Medicine 2012;367:11-9.

Palmblad 2008 \{published data only\} Palmblad J, Björkholm M, Kutti J, Lärfars G, Löfvenberg E, Markevärn B, et al. TPO, but not soluble-IL-6 receptor, levels increase after anagrelide treatment of thrombocythemia in chronic myeloproliferative disorders. International Journal of Medical Sciences 2008;5:87-91.

Peeters 2008 \{published data only\}

Peeters K, Stassen JM, Collen D, Geet CV, Freson K. Emerging treatments for thrombocytopenia: increasing platelet production. Drug Discovery Today 2008;13: 798-806.

Pihusch 2005 \{published data only\}

Pihusch M, Bacigalupo A, Szer J, von Depka Prondzinski M, Gaspar-Blaudschun B, Hyveled L, et al. Recombinant activated factor VII in treatment of bleeding complications following hematopoietic stem cell transplantation. Journal of Thrombosis \& Haemostasis 2005;3:1935-44.

Platzbecker 2015 \{published data only\} Platzbecker U, Wong R, Verma A, Abboud C, Araujo S, Chiou T, et al. Placebo-controlled, randomized, phase I/II trial of the thrombopoietin receptor agonist eltrombopag in thrombocytopenic patients with advanced myelodysplastic 
syndromes or acute myeloid leukemia. Haematologica 2013; 98:Abstract S1108.

Platzbecker U, Wong RS, Araujo S, Feigert J, Bennett J, Messam C, et al. Randomized, placebo (PBO)-controlled, phase I/II trial of the thrombopoietin receptor agonist eltrombopag (EPAG) in thrombocytopenic patients with advanced myelodysplastic syndromes (MDS). Haematologica 2014;100(S1):Abstract P241.

* Platzbecker U, Wong RSM, Verma A, Abboud C, Araujo S, Chiou T-J, et al. Safety and tolerability of eltrombopag versus placebo for the treatment of thrombocytopenia in patients with advanced myelodysplastic syndromes or acute myeloid leukaemia: a multicentre, randomised, placebo-controlled, double-blind, phase 1/2 trial. Lancet Haematology 2015;2:e417-26.

Prica 2014 \{published data only\}

* Prica A, Sholzberg M, Buckstein R. Safety and efficacy of thrombopoietin-receptor agonists in myelodysplastic syndromes: a systematic review and meta-analysis of randomized controlled trials. British Journal of Haematology 2014;167:626-38.

Prica A, Sholzberg M, Buckstein R. Thrombopoietin (TPO)-receptor agonists in myelodysplastic syndromes (MDS): a systematic review and meta-analysis. Blood 2013; 122: Abstract 2806.

Rasche 1982 \{published data only\}

Rasche H, Haghou F, Gaus W, Dietrich M, Hoelzer D, Pflieger $\mathrm{H}$, et al. Blood clotting factor XIII substitution in acute leukaemia: result of a randomized and controlled study. Deutsche Medizinische Wochenschrift 1982;107: 1882-6.

Rasche 1986 \{published data only\}

Rasche H. Substitution with blood coagulation factor XIII concentrates in patients with acute leukemia. Beitrage $Z u$ Infusionstherapie und Klinische Ernahrung 1986;15:179-86.

Risitano 2014 \{published data only\}

Risitano AM, Peffault de Latour R, Dufour C, Marsh $\mathrm{J}$ on behalf of SAAWP. The RACE study: a SAAWP prospective randomized multicenter study comparing horse antithymocyte globulin (HATG) + cyclosporine A (CSA) with or without eltrombopag as front-line therapy for severe aplastic anaemia patients. Bone Marrow Transplantation 2014;49:Abstract WPO-005.

\section{Schuster 2002 \{published data only\}}

Schuster MW, Beveridge R, Frei-Lahr D, Abboud $\mathrm{CN}$, Cruickshank S, Macri M, et al. The effects of pegylated recombinant human megakaryocyte growth and development factor (PEG-rHuMGDF) on platelet recovery in breast cancer patients undergoing autologous bone marrow transplantation. Experimental Hematology 2002;30: $1044-50$.

Sekeres 2011 \{published data only\}

Sekeres MA, Kantarjian H, Fenaux P, Becker P, Boruchov A, Guerci-Bresler A, et al. Subcutaneous or intravenous administration of romiplostim in thrombocytopenic patients with lower risk myelodysplastic syndromes. Cancer 2011;117:992-1000.

\section{Seza 1997 \{published data only\}}

Seza O, Saatci U, Bakkaloglu A, Ozdemir S, Besbas N. Low-dose intranasal desmopressin (DDAVP) for uremic bleeding. Nephron 1997;75:119-20.

Shpilberg 1993 \{published data only\} Shpilberg O, Blumenthal R, Sofer O, Eldor A, Ben-Bassat I. A controlled trial of tranexamic acid (TA) treatment for reduction of bleeding during acute myeloid leukemia (AML) induction and consolidation. Blood 1993;82:547a.

Somlo 1999 \{published data only\}

Somlo G, Sniecinski I, ter Veer A, Longmate J, Knutson G, Vuk-Pavlovic $S$, et al. Recombinant human thrombopoietin in combination with granulocyte colony-stimulating factor enhances mobilization of peripheral blood progenitor cells, increases peripheral blood platelet concentration, and accelerates hematopoietic recovery following high-dose chemotherapy. Blood 1999;93:2798-806.

Squizzato 2007 \{published data only\} Squizzato A, Ageno W. Recombinant activated factor VII as a general haemostatic agent: evidence-based efficacy and safety. Current Drug Safety 2007;2:155-61.

Svensson 2014 \{published data only\} Svensson T, Chowdhury O, Garelius H, Lorenz F, Saft L, Jacobsen SE, et al. A pilot phase I dose finding safety study of the thrombopoietin-receptor agonist, eltrombopag, in patients with myelodysplastic syndrome treated with azacitidine. European Journal of Haematology 2014;93: $439-45$.

Takami 2002 \{published data only\} Takami A, Asakura H, Nakao S. Menatetrenone, a vitamin $\mathrm{K} 2$ analog, ameliorates cytopenia in patients with refractory anemia of myelodysplastic syndrome. Annals of Hematology 2002;81:16-9.

\section{Thompson 2000 \{published data only\}} Thompson JA, Gilliland DG, Prchal JT, Bennett JM, Larholt K, Nelson RA, et al. Effect of recombinant human erythropoietin combined with granulocyte/ macrophage colony-stimulating factor in the treatment of patients with myelodysplastic syndrome. GM/EPO MDS Study Group. Blood 2000;95:1175.

Townsley 2015 \{published data only\} Townsley D, Desmond R, Weinstein B, Perikh A, Valdez J, Dumitriu B, et al. Eltrombopag for low to intermediate-2 risk myelodysplastic syndrome. Leukemia Research 2015;39 (S1):Abstract 56.

\section{Vadhan-Raj 2000 \{published data only\}} Vadhan-Raj S. Clinical experience with recombinant human thrombopoietin in chemotherapy-induced thrombocytopenia. Seminars in Hematology 2000;37: 28-34.

Vannucchi 1996 \{published data only\} Vannucchi AM, Bosi A, Ieri A, Guidi S, Saccardi R, Lombardini L, et al. Combination therapy with GCSF and erythropoietin after autologous bone marrow transplantation for lymphoid malignancies: a randomized trial. Bone Marrow Transplantation 1996;17:527. 
Wang 2009 \{published data only\}

Wang J, An L, Chen S, Ouyang J, Zhou R, Chen B, et al. Prophylactic use of granulocyte colony-stimulating factor after chemotherapy does not affect survival rate in acute myeloid leukemia: a meta-analysis. Acta Haematologica 2009;121:223-6.

Wang 2012 \{published data only\}

Wang ES, Lyons RM, Larson RA, Gandhi S, Liu D, Matei C, et al. A randomized, double-blind, placebocontrolled phase 2 study evaluating the efficacy and safety of romiplostim treatment of patients with low or intermediate1 risk myelodysplastic syndrome receiving lenalidomide. Journal of Hematology \& Oncology 2012;5:71.

Wang 2013 \{published data only\}

Wang Y, Wang Z, Wu L, Zhang J, Wang J, Yan L. Recombinant human thrombopoietin is an effective treatment for thrombocytopenia in hemophagocytic lymphohistiocytosis. Annals of Hematology 2013;92: 1695-9.

Wardrop 2013 \{published data only\} Wardrop D, Estcourt LJ, Brunskill SJ, Doree C, Trivella M, Stanworth S, et al. Antifibrinolytics (lysine analogues) for the prevention of bleeding in patients with haematological disorders. Cochrane Database of Systematic Reviews 2013, Issue 7. [DOI: 10.1002/14651858.CD009733.pub2]

Will 2009a \{published data only\}

Will B, Luciano J, Kawahara M, Erickson-Miller C, Verma A, Aivado M, et al. The non-peptide thrombopoietin receptor agonist eltrombopag (SB-497115, Promacta/ Revolade) does not stimulate malignant growth of bone marrow cells from patients with acute myeloid leukemia or myelodysplastic syndromes. Leukemia Research 2009;33: Abstract C026.

Will 2009b \{published data only\}

Will B, Luciano J, Kawahara M, Erickson-Miller C, Verma A, Aivado M, et al. Effect of the non-peptide Thrombopoietin receptor agonist eltrombopag (promacta/ revoladetm) on bone marrow cells from patients with acute myeloid leukemia and myelodysplastic syndromes. Haematologica 2009;94:Abstract 0185.

Williams 2009 \{published data only\} Williams DD, Peng B, Bailey CK, Wire MB, Deng Y, Park JW, et al. Effects of food and antacids on the pharmacokinetics of eltrombopag in healthy adult subjects: two single-dose, open-label, randomized-sequence, crossover studies. Clinical Therapeutics 2009;31:764-76.

Winer 2015 \{published data only\}

* Winer ES, Safran H, Karaszewska B, Richards DA, Hartner L, Forget F, et al. Eltrombopag with gemcitabinebased chemotherapy in patients with advanced solid tumors: a randomized phase I study. Cancer Medicine 2015;4: 16-26.

Winer ES, Safran H, Karaszewska B, Richards DA, Hartner L, Forget F, et al. Safety and efficacy of eltrombopag (epag) versus placebo (pbo) for the treatment (tx) of chemotherapyinduced thrombocytopenia (CIT) in patients with solid tumors receiving gemcitabine (gem)-based chemotherapy (ctx): a phase I study. Journal of Clinical Oncology 2012;30 Abstract 9117.

Wire 2012 \{published data only\}

Wire MB, Bruce J, Gauvin J, Pendry CJ, McGuire S, Qian $\mathrm{Y}$, et al. A randomized, open-label, 5-period, balanced crossover study to evaluate the relative bioavailability of eltrombopag powder for oral suspension (PfOS) and tablet formulations and the effect of a high-calcium meal on eltrombopag pharmacokinetics when administered with or 2 hours before or after PfOS. Clinical Therapeutics 2012;34: 699-709.

\section{Wolff 2001 \{published data only\}}

Wolff SN, Herzig R, Lynch J, Ericson SG, Greer JP, Stein $\mathrm{R}$, et al. Recombinant human thrombopoietin (rhTPO) after autologous bone marrow transplantation: a phase I pharmacokinetic and pharmacodynamic study. Bone Marrow Transplantation 2001;27:261-8.

Wroblewski 2010 \{published data only\}

Wroblewski S, Shi W, Mudd P, Aivado M. Eltrombopag in thrombocytopenic patients with advanced myelodysplastic syndromes (MDS) or secondary acute myeloid leukemia after MDS: a phase I/II study. Journal of Clinical Oncology 2010;28:Abstract TPS184.

Wu 2014 \{published data only\}

Wu Q, Ren J, Wu X, Wang G, Gu G, Liu S, et al. Recombinant human thrombopoietin improves platelet counts and reduces platelet transfusion possibility among patients with severe sepsis and thrombocytopenia: a prospective study. Journal of Critical Care 2014;29:362-6.

Xu 2008 \{published data only\}

$\mathrm{Xu}$ YH, Chen ZW, Ye XY, Lu S. Evaluation of recombinant human thrombopoietin in the treatment of chemotherapyinduced thrombocytopenia in lung cancer patients. ChungHua Chung Liu Tsa Chih 2008;30:716-9.

\section{References to ongoing studies}

\section{EudraCT 2015-000929-37 \{published data only\}} EudraCT number 2015-000929-37. EPAG 2015: a phase II randomized placebo-controlled study to assess the impact on outcome of eltrombopag administered to elderly patients with acute myeloid leukemia receiving induction chemotherapy [EPAG 2015 "Etude de phase II randomisée versus placebo de l'impact sur le devenir de l'administration d'Eltrombopag àdes patients agés atteints d'une Leucemie Aigue Myeloblastique qui recoivent une chimiotherapie d'induction"]. EudraCT number 2015-000929-37.

\section{NCT01397149 \{published data only\}}

NCT01397149. Eltrombopag in thrombocytopenic chronic lymphocytic leukemia (CLL) patients (CLL2S study of GCLLSG). clinicaltrials.gov/ct2/show/NCT01397149 (accessed 24 July 2016).

\section{NCT01656252 \{published data only\}} NCT01656252. Trial of eltrombopag during consolidation therapy in adults with AML in complete remission. 
clinicaltrials.gov/ct2/show/NCT01656252 (accessed 24 July 2016).

\section{NCT01890746 \{published data only\}}

NCT01890746. A safety and efficacy Sstudy of eltrombopag in subjects with AML. clinicaltrials.gov/ct2/ show/NCT01890746 (accessed 24 July 2016).

Popat 2015 \{published data only\}

NCT01000051. Eltrombopag for post transplant thrombocytopenia. clinicaltrials.gov/ct2/show/ NCT01000051 (accessed 24 July 2016).

* Popat UR, Ray G, Bassett RL Jr, Poon M-YC, Valdez BC, Konoplev S, et al. Eltrombopag for post-transplant thrombocytopenia: results of phase II randomized double blind placebo controlled trial. Blood 2015;126:Abstract.

\section{Vadhan-Raj 2010 \{published data only\}}

NCT00299182. Study of AMG 531 to evaluate the safety $\&$ efficacy in patients with non-Hodgkin's lymphoma. clinicaltrials.gov/ct2/show/NCT00299182 (accessed 24 July 2016).

* Vadhan-Raj S, Hagemeister F, Fayad LE, Zhou X, ORoark SS, Ames K, et al. Randomized, double-blind, placebocontrolled, dose and schedule-finding study of AMG 531 in chemotherapy-induced thrombocytopenia (CIT): results of a phase I/II study. Blood 2010;116:Abstract 1544.

\section{Additional references}

\section{Barnhart 1983}

Barnhart MI, Chen S, Lusher JM. DDAVP: does the drug have a direct effect on the vessel wall?. Thrombosis Research 1983;31(2):239-52.

\section{BCSH 2003}

British Committee for Standards in Haematology (BCSH). Guidelines for the use of platelet transfusions. British Journal of Haematology 2003;122:10-23.

\section{BCSH 2004}

British Committee for Standards in Haematology (BCSH). Transfusion guidelines for neonates and older children. British Journal of Haematology 2004;124(4):433-53.

\section{Benson 2009}

Benson AB, Moss M, Silliman CC. Transfusion-related acute lung injury (TRALI): a clinical review with emphasis on the critically ill. British Journal of Haematology 2009;147 (4):431-43.

\section{Blumberg 2009}

Blumberg N, Spinelli SL, Francis CW, Taubman MB, Phipps RP. The platelet as an immune cell - CD40 ligand and transfusion immune modulation. Immunology Research 2009;45:251-60.

Board 2009

Board of the German Medical Association on the Recommendation of the Scientific Advisory Board. Platelet concentrates. Cross-sectional guidelines for therapy with blood components and plasma derivatives. Transfusion Medicine and Hemotherapy 2009;36:372-82.
Bolton-Maggs 2012

Bolton-Maggs PHB (editor) and $\mathrm{H}$ Cohen on behalf of the Serious Hazards of Transfusion (SHOT) Steering Group. The 2011 Annual SHOT Report. www.shotuk.org/shotreports/shot-annual-report-summary-2011/ (accessed 24 July 2016).

\section{Burnett 2011}

Burnett AK, Hills RK, Milligan D, Kjeldsen L, Kell J, Russell $\mathrm{NH}$, et al. Identification of patients with acute myeloblastic leukemia who benefit from the addition of gemtuzumab ozogamicin: results of the MRC AML15 trial. Journal of Clinical Oncology 2011;29(4):369-77.

Butler 2013

Butler C, Doree C, Estcourt LJ, Trivella M, Hopewell S, Brunskill SJ, et al. Pathogen-reduced platelets for the prevention of bleeding. Cochrane Database of Systematic Reviews 2013, Issue 3. [DOI: 10.1002/ 14651858.CD009072]

\section{Cameron 2007}

Cameron B, Rock G, Olberg B, Neurath D. Evaluation of platelet transfusion triggers in a tertiary-care hospital. Transfusion 2007;47(2):206-11.

\section{Cancer Research UK 2013}

Cancer Research UK. Percentage change in European agestandardised three year average incidence rates, males, UK, 1991-2001 and 2008-2010. www.cancerresearchuk.org/ cancer-info/cancerstats/ (accessed 14 February 2013).

\section{CDC 2012}

CDC (Center for Disease Control and Prevention). United States Cancer Statistics. nccd.cdc.gov/uscs/ (accessed 14 February 2013).

\section{Coleman 2004}

Coleman MP, Rachet B, Woods LM, Mitry E, Riga M, Cooper N, et al. Trends and socioeconomic inequalities in cancer survival in England and Wales up to 2001. British Journal of Cancer 2004;90(7):1367-73.

\section{Cook 2004}

Cook RJ, Heddle NM, Rebulla P, Sigouin CS, Webert KE. Methods for the analysis of bleeding outcomes in randomized trials of platelet transfusion triggers. Transfusion 2004;44:1135-42.

\section{De la Serna 2008}

De la Serna J, Montesinos P, Vellenga E, Rayon C, Parody $\mathrm{R}$, Leon $\mathrm{A}$, et al. Causes and prognostic factors of remission induction failure in patients with acute promyelocytic leukemia treated with all-trans retinoic acid and idarubicin. Blood 2008;111(7):3395-402.

\section{Deeks 2011}

Deeks JJ, Higgins JPT, Altman DG. Chapter 9: Analysing data and undertaking meta-analyses. In: Higgins JPT, Green S (editors). Cochrane Handbook for Systematic Reviews of Interventions Version 5.1.0 [updated March 2011]. The Cochrane Collaboration, 2011. Available from www.cochrane-handbook.org. 


\section{Desborough 2012}

Desborough M, Stanworth S. Plasma transfusion for bedside, radiologically guided, and operating room invasive procedures. Transfusion 2012;52(Suppl 1):20S-9S.

\section{Desborough 2016}

Desborough M, Estcourt LJ, Chaimani A, Doree C, Hopewell S, Trivella M, et al. Alternative agents versus prophylactic platelet transfusion for preventing bleeding in patients with thrombocytopenia due to chronic bone marrow failure: a network meta-analysis and systematic review. Cochrane Database of Systematic Reviews 2016, Issue 1. [DOI: 10.1002/14651858.CD012055]

\section{Doshi 2012}

Doshi, N, Orje JN, Molins B, Smith JW, Mitragotri $S$, Ruggeri ZM. Platelet mimetic particles for targeting thrombi in flowing blood. Advanced Materials 2012;24 (28):3864-9.

\section{Estcourt 2012a}

Estcourt LJ, Birchall J, Lowe D, Grant-Casey J, Rowley M, Murphy MF. Platelet transfusions in haematology patients: are we using them appropriately?. Vox Sanguinis 2012;103 (4):284-93.

Estcourt 2013

Estcourt LJ, Heddle N, Kaufman RM, McCullough J, Murphy MF, Slichter S, et al. On behalf of the BEST (Biomedical Excellence for Safer Transfusion) Collaborative. Differences in the methods of assessing and analysing bleeding outcomes in platelet transfusion trials. Transfusion 2013;53(7):1531-43.

\section{Estcourt 2014a}

Estcourt LJ, Pinchon D, Symington E, Kelly AM, Doree C, Brunskill S, et al. Does bleeding affect patient reported outcome measures in patients with myelodysplasia or hematologic malignancies: a systematic review. Transfusion 2014;54(4):1166-79. [DOI: 10.1111/trf.12441]

\section{Estcourt 2014c}

Estcourt LJ, Stanworth S, Doree C, Trivella M, Hopewell S, Murphy MF, et al. Comparison of different platelet count thresholds to guide administration of prophylactic platelet transfusion for preventing bleeding in patients with haematological disorders after chemotherapy or stem cell transplantation. Cochrane Database of Systematic Reviews 2014, Issue 3. [DOI: 10.1002/14651858.CD010983]

\section{Estcourt 2014d}

Estcourt LJ, Crighton GL, Wood EM, Stanworth S, Trivella M, Doree C, et al. A therapeutic-only versus prophylactic platelet transfusion strategy for preventing bleeding in patients with haematological disorders after chemotherapy or stem cell transplantation. Cochrane Database of Systematic Reviews 2014, Issue 3. [DOI: 10.1002/14651858.CD010981]

\section{Estcourt 2014e}

Estcourt LJ, Stanworth S, Doree C, Trivella M, Hopewell S, Murphy MF, et al. Different doses of prophylactic platelet transfusion for preventing bleeding in patients with haematological disorders after chemotherapy or stem cell transplantation. Cochrane Database of Systematic Reviews 2014, Issue 3. [DOI: 10.1002/14651858.CD010984]

\section{Estcourt 2016}

Estcourt LJ, Desborough M, Brunskill SJ, Doree C, Hopewell S, Murphy MF, et al. Antifibrinolytics (lysine analogues) for the prevention of bleeding in people with haematological disorders. Cochrane Database of Systematic Reviews 2016, Issue 3. [DOI: 10.1002/ 14651858.CD009733.pub3]

Fielding 2007

Fielding AK, Richards SM, Chopra R, Lazarus HM, Litzow MR, Buck G, et al. Outcome of 609 adults after relapse of acute lymphoblastic leukemia (ALL); an MRC UKALL12/ECOG 2993 study. Blood 2007;109(3):944-50. [PUBMED: 17032921]

\section{Gratwohl 2010}

Gratwohl A, Baldomero H, Aljurf M, Pasquini MC, Bouzas LF, Yoshimi A, et al. Hematopoietic stem cell transplantation: a global perspective. JAMA 2010;303(16): 1617-24. [DOI: 10.1001/jama.2010.491]

\section{Greeno 2007}

Greeno E, McCullough J, Weisdorf D. Platelet utilisation and the transfusion trigger: a prospective analysis. Transfusion 2007:72(2):201-5.

\section{Heddle 2003}

Heddle NM, Cook RJ, Webert KE, Sigouin C, Rebulla P. Methodologic issues in the use of bleeding as an outcome in transfusion medicine studies. Transfusion 2003;43:742-52.

\section{Heddle 2008}

Heddle NM, Arnold DM, Boye D, Webert KE, Resz I, Dumont LJ. Comparing the efficacy and safety of apheresis and whole blood-derived platelet transfusions: a systematic review. Transfusion 2008;48(7):1447-58.

\section{Heddle 2009a}

Heddle NM, Cook RJ, Tinmouth A, Kouroukis CT, Hervig T, Klapper E, et al. A randomized controlled trial comparing standard and low dose strategies for transfusion of platelets (SToP) to patients with thrombocytopenia. Blood 2009;113(7):1564-73.

\section{Heddle 2009b}

Heddle NM, Webbert K. Investigation of acute transfusion reactions. In: Murphy MF, Pamphilion DH editor(s). Practical Transfusion Medicine. 4th Edition. Blackwell, 2009:63-89.

\section{Higgins 2011a}

Higgins JPT, Deeks JJ. Chapter 7: Selecting studies and collecting data. In: Higgins JPT, Green S (editors). Cochrane Handbook for Systematic Reviews of Interventions Version 5.1.0 [updated March 2011]. The Cochrane Collaboration, 2011. Available from www.cochrane-handbook.org.

\section{Higgins 2011b}

Higgins JPT, Altman DG, Sterne JAC. Chapter 8: Assessing risk of bias in included studies. In: Higgins JPT, Green $S$ (editors). Cochrane Handbook for Systematic Reviews 
of Interventions Version 5.1.0 [updated March 2011]. The Cochrane Collaboration, 2011. Available from www.cochrane-handbook.org.

\section{Higgins 2011c}

Higgins JPT, Deeks JJ, Altman DG (editors). Chapter 16: Special topics in Statistics. In: Higgins JPT, Green S (editors), Cochrane Handbook for Systematic Reviews of Interventions Version 5.1.0 (updated March 2011). The Cochrane Collaboration, 2011. Available from www.cochrane-handbook.org.

\section{Knowles 2011}

Knowles $\mathrm{S}$ (editor), Cohen $\mathrm{H}$, on behalf of the Serious Hazards of Transfusion (SHOT) Steering Group. The 2010 Annual SHOT Report. www.shotuk.org/shot-reports/ report-and-summary-2010-2/ (accessed 24 July 2016).

\section{Koreth 2004}

Koreth R, Weinert C, Weisdorf DJ, Key NS. Measurement of bleeding severity: a critical review. Transfusion 2004;44: 605-17.

\section{Kuter 2010}

Kuter DJ. Biology and chemistry of thrombopoietic agents. Seminars in Hematology 2010;47(3):243-8.

\section{Lefebvre 2011}

Lefebvre C, Manheimer E, Glanville J. Chapter 6: Searching for studies. In: Higgins JPT, Green S (editors). Cochrane Handbook for Systematic Reviews of Interventions Version 5.1.0 [updated March 2011]. The Cochrane Collaboration, 2011. Available from www.cochrane-handbook.org.

\section{Li 2001}

Li J, Yang C, Xia Y, Bertino A, Glaspy J, Roberts M, et

al. Thrombocytopenia caused by the development of antibodies to thrombopoietin. Blood 2001;98(12):3241-8.

\section{Manco-Johnson 2009}

Manco-Johnson MJ, Dimichele D, Castaman G, Fremann S, Knaub S, Kalina U, et al. Pharmacokinetics and safety of fibrinogen concentrate. Journal of Thrombosis and Haemostasis 2009;7(12):2064-9.

\section{Mannucci 1997}

Mannucci PM. Desmopressin (DDAVP) in the treatment of bleeding disorders: the first 20 years. Blood 1997;90(7): 2515-21.

\section{NBA 2012}

National Blood Authority (NBA). The National Blood Authority's Patient Blood Management Guideline: Module 3 Medical. National Blood Authority, 2012.

\section{NICE 2011}

National Institute for Health and Care Excellence (NICE). Romiplostim for the treatment of chronic immune (idiopathic) thrombocytopenic purpura TA221. www.nice.org.uk/Guidance/TA221 (accessed 24 July 2016).

\section{NICE 2013}

National Institute for Health and Care Excellence (NICE). Eltrombopag for treating chronic immune (idiopathic) thrombocytopenic purpura TA293. National Institute for Health and Care Excellence 2013.

\section{Nishiya 2002}

Nishiya T, Kainoh M, Murata M, Handa M, Ikeda Y. Reconstitution of adhesive properties of human platelets in liposomes carrying both recombinant glycoproteins Ia/IIa and Iba under flow conditions: specific synergy of receptorligand interactions. Blood 2002;100(1):136-42.

\section{Okamura 2009a}

Okamura Y, Fukui Y, Kabata K, Suzuki H, Handa M, Ikeda Y, et al. Novel platelet substitutes: disk-shaped biodegradable nanosheets and their enhanced effects on platelet aggregation. Bioconjugate Chemistry 2009;20: 1958-65.

\section{Okamura 2009b}

Okamura Y, Takeoka S, Eto K, Maekawa I, Fujie T, Maruyama $\mathrm{H}$, et al. Development of fibrinogen gammachain peptide-coated, adenosine diphosphate-encapsulated liposomes as a synthetic platelet substitute. Journal of Thrombosis and Haemostasis 2009;7(3):470-7.

\section{ONS 2014}

Office of National Statistics (ONS). Cancer Statistics Registrations, England: 2012. www.ons.gov.uk/peoplepopulationandcommunity/ healthandsocialcare/conditionsanddiseases/bulletins/ cancerregistrationstatisticsengland/2014-06-19 (accessed 3 August 2016).

\section{Parmar 1998}

Parmar MK, Torri V, Stewart L. Extracting summary statistics to perform meta-analyses of the published literature for survival endpoints. Statistics in Medicine 1998;17(24): 2815-34.

\section{Passweg 2012}

Passweg JR, Baldomero H, Gratwohl A, Bregni M, Cesaro S, Dreger P, et al. The EBMT activity survey: 1990-2010. Bone Marrow Transplant 2012;47(7):906-23.

Patel 2009

Patel B, Kirkland K, Szydlo R, Pearce R, Clark R, Craddock $\mathrm{C}$, et al. Favorable outcomes with alemtuzumabconditioned unrelated donor stem cell transplantation in adults with high-risk Philadelphia chromosome-negative acute lymphoblastic leukemia in first complete remission. Haematologica 2009;94:1399-406.

\section{Pavenski 2013}

Pavenski K, Rebulla P, Duquesnoy R, Saw CL, Slichter SJ, Tanael S, et al. International Collaboration for Guideline Development, Implementation. Evaluation for Transfusion Therapies, Collaborators. Efficacy of HLA-matched platelet transfusions for patients with hypoproliferative thrombocytopenia: a systematic review. Transfusion 2013; 53(10):2230-42. [DOI: 10.1111/trf.12175]

Pearce 2011

Pearce S, Rowe GP, Field SP. Screening of platelet for bacterial contamination at the Welsh Blood Service. Transfusion Medicine 2011;21(1):25-32.

\section{Pendry 2011}

Pendry K, Davies T. An audit of use and wastage in the north west of England and North Wales: where have all 
the platelets gone?. Blood and Transplant Matters 2011;34: 17-9.

\section{Popovsky 1985}

Popovsky MA, Moore SB. Diagnostic and pathogenetic considerations in transfusion-related acute lung injury. Transfusion 1985;25:573-7.

\section{Rachet 2009}

Rachet B, Maringe C, Nur U, Quaresma M, Shah A, Woods LM, et al. Population-based cancer survival trends in England and Wales up to 2007: an assessment of the NHS cancer plan for England. Lancet Oncology 2009;10 (4):351-69.

RevMan 2012 [Computer program]

The Nordic Cochrane Centre. Review Manager (RevMan). Version 5.2. Copenhagen: The Cochrane Collaboration, 2012.

\section{Rysler 2010}

Rysler C, Stoffel N, Buser A, Gratwohl A, Tsakiris DA, Stern M. Effect of beta-blockers, Ca2+antagonists, and benzodiazepines on bleeding incidence in patients with chemotherapy induced thrombocytopenia. Platelets 2010; 21(1):77-83.

\section{Sakariassen 1984}

Sakariassen KS, Cattaneo M, van der Berg A, Ruggeri ZM, Sixma JJ. DDAVP enhances platelet adherence and platelet aggregate growth on human artery subendothelium. Blood 1984;64:229-36.

\section{Schiffer 2001}

Schiffer CA, Anderson KC, Bennett CL, Bernstein S, Elting LS, Goldsmith M, et al. Platelet transfusion for patients with cancer: clinical practice guidelines of the American Society of Clinical Oncology. Journal of Clinical Oncology 2001;19:1519-38.

\section{Schünemann 2011}

Schünemann HJ, Oxman AD, Higgins JPT, Vist GE, Glasziou P, Guyatt GH. Chapter 11: Presenting results and 'Summary of findings' tables. In: Higgins JPT, Green S (editors). Cochrane Handbook for Systematic Reviews of Interventions Version 5.1.0 [updated March 2011]. The Cochrane Collaboration, 2011. Available from www.cochrane-handbook.org.

\section{Shehata 2009}

Shehata N, Tinmouth A, Naglie G, Freedman J, Wilson K. ABO-identical versus non-identical platelet transfusion: a systematic review. Transfusion 2009;49:2442-53.

\section{Silliman 2003}

Silliman CC, Boshkov LK, Mehdizadehkashi Z, Elzi DJ, Dickey WO, Podlosky L, et al. Transfusion-related acute lung injury: epidemiology and a prospective analysis of etiologic factors. Blood 2003;101(2):454-62.

\section{Simpson 2012}

Simpson E, Lin Y, Stanworth S, Birchall J, Doree C, Hyde C. Recombinant factor VIIa for the prevention and treatment of bleeding in patients without haemophilia. Cochrane Database of Systematic Reviews 2012, Issue 3. [DOI: 10.1002/14651858.CD005011.pub4]
Slichter 2005

Slichter SJ, Davis K, Enright H, Braine H, Gernsheimer T, Kao KJ, et al. Factors affecting posttransfusion platelet increments, platelet refractoriness, and platelet transfusion intervals in thrombocytopenic patients. Blood 2005; 105: 4106-14.

\section{Slichter 2007}

Slichter SJ. Evidence-based platelet transfusion guidelines. Hematology (American Society of Hematology Education Program) 2007:172-8.

\section{Slichter 2010}

Slichter SJ, Kaufman RM, Assmann SF, McCullough J, Triulzi DJ, Strauss RG, et al. Dose of prophylactic platelet transfusions and prevention of haemorrhage. New England Journal of Medicine 2010;362:600-13.

\section{Solomon 2010}

Solomon C, Pichlmaier U, Schoechl H, Hagl C, Raymondos K, Scheinichen D, et al. Recovery of fibrinogen after administration of fibrinogen concentrate to patients with severe bleeding after cardiopulmonary bypass surgery. British Journal of Anaesthesia 2010;104(5):555-62.

Stanworth 2010

Stanworth SJ, Dyer C, Choo L, Bakrania L, Copplestone A, Llewelyn C, et al. Do all patients with hematologic malignancies and severe thrombocytopenia need prophylactic platelet transfusions? Background, rationale, and design of a clinical trial (trial of platelet prophylaxis) to assess the effectiveness of prophylactic platelet transfusions. Transfusion Medicine Reviews 2010;24(3):163-71.

Stanworth 2013

Stanworth SJ, Estcourt LJ, Powter G, Kahan B, Dyer $\mathrm{C}$, Choo L, et al. A no-prophylaxis platelet transfusion strategy for hematologic cancers. New England Journal of Medicine 2013;368(19):1771-80. [PUBMED: WOS: 000318540000005]

\section{Sterne 2011}

Sterne JAC, Egger M, Moher D. Chapter 10: Addressing reporting biases. In: Higgins JPT, Green S (editors). Cochrane Handbook for Systematic Reviews of Intervention. Version 5.1.0 [updated March 2011]. The Cochrane Collaboration, 2011. Available from www.cochrane-handbook.org.

\section{Sørensen 2011}

Sørensen B, Tang M, Larsen OH, Laursen PN, FengerEriksen C, Rea CJ. The role of fibrinogen: a new paradigm in the treatment of coagulopathic bleeding. Thrombosis Research 2011;128(Suppl 1):S13-16.

Taylor 2010

Taylor C (Ed), Cohen H, Mold D, Jones H, et al. on behalf of the Serious Hazards of Transfusion (SHOT) Steering Group. The 2009 Annual SHOT Report. www.shotuk.org/ shot-reports/report-and-summary-2009/. SHOT Steering Group, (accessed 24 July 2016).

Tierney 2007

Tierney JF, Stewart LA, Ghersi D, Burdett S, Sydes MR. Practical methods for incorporating summary time-to-event 
data into meta-analysis. Trials 2007;8:16. [DOI: 10.1186/ 1745-6215-8-16]

\section{Tinmouth 2007}

Tinmouth AT. Chapter 18: platelet transfusion, alloimmunization and management of platelet refractoriness. Canadian Blood Services. 4th Edition. Ontario, Canada: Canadian Blood Services, 2007.

\section{TRAP 1997}

The Trial to Reduce Alloimmunization to Platelets Study Group. Leukocyte reduction and ultraviolet B irradiation of platelets to prevent alloimmunization and refractoriness to platelet transfusions. New England Journal of Medicine 1997;337:1861-70.

\section{Verma 2009}

Verma A, Agarwal P. Platelet utilization in the developing world: strategies to optimize platelet transfusion practices. Transfusion and Apheresis Science 2009;41(2):145-9.

\section{Wandt 2012}

Wandt H, Schaefer-Eckart K, Wendelin K, Pilz B, Wilhelm $\mathrm{M}$, Thalheimer M, et al. Therapeutic platelet transfusion versus routine prophylactic transfusion in patients with haematological malignancies: an open-label, multicentre, randomised study. Lancet 2012;380(9850):1309-16.

\section{WHO 1979}

World Health Organization (WHO). WHO Handbook for Reporting Results of Cancer Treatment. WHO Offset publication No. 48. Geneva: World Health Organization, 1979.

\section{Zeng 2011}

Zeng Y, Duan X, Xu J, Ni X. TPO receptor agonist for chronic idiopathic thrombocytopenic purpura. Cochrane Database of Systematic Reviews 2011, Issue 7. [DOI: 10.1002/14651858.CD008235.pub2]

\section{References to other published versions of this review}

\section{Estcourt 2012b}

Estcourt L, Stanworth SJ, Doree C, Hopewell S, Murphy MF, Tinmouth A, et al. Prophylactic platelet transfusion for prevention of bleeding in patients with haematological disorders after chemotherapy and stem cell transplantation. Cochrane Database of Systematic Reviews 2012, Issue 5. [DOI: 10.1002/14651858.CD004269.pub3]

\section{Estcourt 2014b}

Estcourt LJ, Gregg R, Stanworth S, Doree C, Trivella M, Murphy, MF, et al. Alternative agents versus prophylactic platelet transfusion for preventing bleeding in patients with haematological disorders after chemotherapy or stem cell transplantation. Cochrane Database of Systematic Reviews 2014, Issue 3. [DOI: 10.1002/14651858.CD010982]

\section{Stanworth 2004}

Stanworth SJ, Hyde C, Heddle N, Rebulla P, Brunskill S, Murphy MF. Prophylactic platelet transfusion for haemorrhage after chemotherapy and stem cell transplantation. Cochrane Database of Systematic Reviews 2004, Issue 4. [DOI: 10.1002/14651858.CD004269.pub2]

* Indicates the major publication for the study 


\section{CHARACTERISTICS OFSTUDIES}

\section{Characteristics of included studies [ordered by study ID]}

\section{Archimbaud 1999-T1}

Methods
Type of trial: multinational, multicentre, parallel-group 3-arm RCT

Country where trial was performed: not reported

Dates of trial: not reported

Follow-up until: not reported

\section{Inclusions:}

- Age $\geq 16$ years

- De novo AML as defined by the FAB classification system

- ECOG Performance Score of 0, 1, 2 or 3

\section{Exclusions:}

- FAB subtypes M3 and M7

- Blast transformation of chronic myeloid leukaemia

- History of clinically relevant coagulation disorders within the previous 6 months Number of participants randomised: 70

Number of participants analysed: 70

Age:

Intervention group 1: median 49 years (range 19 to 71 years)

Intervention group 2: median 48 years (range 20 to 77 years)

Comparator group (data combined with comparator group in Archimbaud 1999-T2): median 52 years (range 20 to 75 years)

Gender:

Intervention group 1: male 11 and female 13

Intervention group 2: male 14 and female 10

Comparator group (data combined with comparator group in Archimbaud 1999-T2): male 16 and female 18

Types of malignancy:

All participants had de novo AML

Chemotherapy regimens:

All participants were treated with the same intensive chemotherapy regimen. "First induction was with Daunorubicin $\left(45 \mathrm{mg} / \mathrm{m}^{2}\right)$ for 3 days, Cytarabine $\left(100 \mathrm{mg} / \mathrm{m}^{2}\right)$ twice a day for 7 days, and Etoposide $\left(100 \mathrm{mg} / \mathrm{m}^{2}\right)$ for 5 days (DAV $\left.3+7+5\right)$. The second course of chemotherapy was determined by age and by remission status. Participants younger than 60 years old received a second course of DAV $3+7+5$, if in remission, and Cytarabine $\left(1 \mathrm{~g} / \mathrm{m}^{2}\right)$ for 4 days and Mitoxantrone $\left(12 \mathrm{mg} / \mathrm{m}^{2}\right)$ for 3 days (MiDAC) if not in remission. All participants $\geq 60$ years old, regardless of remission status, received a second course consisting of Daunorubicin $\left(45 \mathrm{mg} / \mathrm{m}^{2}\right)$ for 2 days, Cytarabine (100 $\left.\mathrm{mg} / \mathrm{m}^{2}\right)$ twice a day for 5 days, and Etoposide $\left(100 \mathrm{mg} / \mathrm{m}^{2}\right.$ ) for 5 days (DAV $\left.2+5+5\right)$. Participants not in CR after a second induction were considered to have completed the trial. After CR, participants aged $<60$ years old received Cytarabine $\left(3 \mathrm{~g} / \mathrm{m}^{2}\right)$ for 6 days and Daunorubicin $\left(30 \mathrm{mg} / \mathrm{m}^{2}\right)$ for 2 days; participants $\geq 60$ years old received DAV $2+5+5$ followed by the trial drug" 
Archimbaud 1999-T1 (Continued)

\begin{tabular}{|c|c|}
\hline Interventions & $\begin{array}{l}\text { Intervention arm 1: } \\
\text { PEG-rHuMGDF } 2.5 \mu \mathrm{g} / \mathrm{kg} / \text { day from } 24 \text { hours after the last dose of chemotherapy until } \\
\text { a transfusion-independent platelet count } \geq 50 \times 10^{9} / \mathrm{L} . \mathrm{N}=24 \\
\text { Intervention arm 2: } \\
\text { PEG-rHuMGDF } 5 \mu \mathrm{g} / \mathrm{kg} / \text { day from } 24 \text { hours after the last dose of chemotherapy until } \\
\text { a transfusion-independent platelet count } \geq 50 \times 10^{9} / \mathrm{L} . \mathrm{N}=24 \\
\text { Comparator arm: } \\
\text { Placebo from } 24 \text { hours after the last dose of chemotherapy until a transfusion-indepen- } \\
\text { dent platelet count } \geq 50 \times 10^{9} / \mathrm{L} . \mathrm{N}=22\end{array}$ \\
\hline Outcomes & $\begin{array}{l}\text { Primary outcome: } \\
\text { Unclear } \\
\text { Secondary outcomes: } \\
\text { - Mortality (up to } 30 \text { days) } \\
\text { - Number of days when platelets were transfused (up to } 30 \text { days) } \\
\text { - Duration of thrombocytopenia } \\
\text { - Remission status (up to } 30 \text { days and up to } 90 \text { days) } \\
\text { - Thromboembolism (timing of assessment not reported) } \\
\text { - Drug or transfusion reactions (timing of assessment not reported) }\end{array}$ \\
\hline Notes & $\begin{array}{l}\text { First of } 2 \text { separate trials reported in a single paper. Second part recorded below as a } \\
\text { separate trial (Archimbaud 1999-T2). } 47 \text { participants in the } 2 \text { trials by Archimbaud } \\
\text { (Archimbaud 1999-T1; Archimbaud 1999-T2) were also included in Geissler (Geissler } \\
\text { 2003-T1; Geissler 2003-T2). Emailed Dieter Hoelzer on } 25 \text { March } 2015 \text { and received } \\
\text { reply on } 31 \text { March } 2015 \text { reporting that the authors no longer held the trial information } \\
\text { but recommended contacting AMGEN, the trial sponsor. Contacted AMGEN on } 25 \\
\text { March 2015, } 8 \text { April 2015, } 13 \text { April 2015, } 2 \text { June 2015, } 27 \text { July } 2015 \text { and } 4 \text { August } \\
\text { 2015. No data provided by AMGEN over this 6-month period. We will incorporate any } \\
\text { additional data provided by AMGEN into future reviews } \\
\text { Trial registration: not registered } \\
\text { Date of registration: N/A }\end{array}$ \\
\hline
\end{tabular}

Risk of bias

\begin{tabular}{l|ll}
\hline Bias & Authors' judgement & Support for judgement \\
\hline $\begin{array}{l}\text { Random sequence generation (selection } \\
\text { bias) }\end{array}$ & Unclear risk & Insufficient information \\
\hline Allocation concealment (selection bias) & Unclear risk & Insufficient information \\
\hline Blinding of participants (performance bias) & Low risk & Investigators, trial site staff and monitors \\
\hline were blind to treatment assignment
\end{tabular}

Alternatives, and adjuncts, to prophylactic platelet transfusion for people with haematological malignancies undergoing intensive 
Archimbaud 1999-T1 (Continued)

\begin{tabular}{|c|c|c|}
\hline $\begin{array}{l}\text { Blinding of outcome assessment (detection } \\
\text { bias) } \\
\text { All outcomes }\end{array}$ & Low risk & $\begin{array}{l}\text { Investigators, trial site staff and monitors } \\
\text { were blind to treatment assignment }\end{array}$ \\
\hline $\begin{array}{l}\text { Incomplete outcome data (attrition bias) } \\
\text { All outcomes }\end{array}$ & Low risk & $\begin{array}{l}\text { All participants who had at least } 1 \text { dose of } \\
\text { drug were included in the analyses }\end{array}$ \\
\hline Selective reporting (reporting bias) & Unclear risk & $\begin{array}{l}\text { Protocol and trial registration not available } \\
\text { to assess whether prespecified outcomes } \\
\text { have not been reported or other non-pre- } \\
\text { specified outcomes reported }\end{array}$ \\
\hline Other bias & High risk & $\begin{array}{l}\text { "Trial supported by AMGEN. The pub- } \\
\text { lication costs of this article were defrayed } \\
\text { in part by page charge payment. This arti- } \\
\text { cle must therefore be hereby marked "ad- } \\
\text { vertisement" in accordance with } 18 \text { U.S.C. } \\
\text { section } 1734 \text { solely to indicate this fact" }\end{array}$ \\
\hline
\end{tabular}

\section{Archimbaud 1999-T2}

Methods

Type of trial: multinational, multicentre, parallel-group 3-arm RCT

Country where trial was performed: not reported

Dates of trial: not reported

Follow-up until: not reported

Participants

\section{Inclusions:}

- Age $\geq 16$ years

- De novo AML as defined by the FAB classification system

- ECOG Performance Score of 0, 1, 2 or 3

\section{Exclusions:}

- FAB subtypes M3 and M7

- Blast transformation of chronic myeloid leukaemia

- History of clinically relevant coagulation disorders within the previous 6 months

Number of participants randomised: 38

Number of participants analysed: 38

Age:

Intervention group 1: median 55 years (range 21 to 78 years)

Intervention group 2: median 60 years (range 16 to 71 years)

Comparator group (data combined with comparator group in Archimbaud 1999-T1): median 52 years (range 20 to 75 years)

Gender:

Intervention group 1: male 5 and female 7

Intervention group 2: male 11 and female 3

Comparator group (data combined with comparator group in Archimbaud 1999-T1):

male 16 and female 18

Types of malignancy:

All participants had de novo AML 
Archimbaud 1999-T2 (Continued)

\section{Chemotherapy regimens:}

All participants were treated with the same intensive chemotherapy regimen. "First induction was with Daunorubicin $\left(45 \mathrm{mg} / \mathrm{m}^{2}\right)$ for 3 days, Cytarabine $\left(100 \mathrm{mg} / \mathrm{m}^{2}\right)$ twice a day for 7 days, and Etoposide $\left(100 \mathrm{mg} / \mathrm{m}^{2}\right)$ for 5 days (DAV $\left.3+7+5\right)$. The second course of chemotherapy was determined by age and by remission status. Participants younger than 60 years old received a second course of DAV $3+7+5$, if in remission, and Cytarabine $\left(1 \mathrm{~g} / \mathrm{m}^{2}\right)$ for 4 days and Mitoxantrone $\left(12 \mathrm{mg} / \mathrm{m}^{2}\right)$ for 3 days (MiDAC) if not in remission. All participants $\geq 60$ years old, regardless of remission status, received a second course consisting of Daunorubicin $\left(45 \mathrm{mg} / \mathrm{m}^{2}\right)$ for 2 days, Cytarabine (100 $\mathrm{mg} / \mathrm{m}^{2}$ ) twice a day for 5 days, and Etoposide $\left(100 \mathrm{mg} / \mathrm{m}^{2}\right.$ ) for 5 days (DAV 2+5+5). Participants not in CR after a second induction were considered to have completed the trial. After CR, participants aged $<60$ years old received Cytarabine $\left(3 \mathrm{~g} / \mathrm{m}^{2}\right)$ for 6 days and Daunorubicin $\left(30 \mathrm{mg} / \mathrm{m}^{2}\right)$ for 2 days; participants $\geq 60$ years old received DAV $2+5+5$ followed by the trial drug"

Intervention arm 2:

PEG-rHuMGDF $2.5 \mu \mathrm{g} / \mathrm{kg} /$ day for 7 days (day 8 to day 14 ). $\mathrm{N}=14$

Comparator arm:

Placebo (timing of doses not reported). $\mathrm{N}=12$

Outcomes

\section{Primary outcome:}

Unclear

\section{Secondary outcomes:}

- Mortality (up to 30 days)

- Number of days when platelets were transfused (up to 30 days)

- Duration of thrombocytopenia

- Remission status (up to 30 days and up to 90 days)

- Thromboembolism (timing of assessment not reported)

- Drug or transfusion reactions (timing of assessment not reported) separate trial (Archimbaud 1999-T1). 47 participants in the 2 trials by Archimbaud (Archimbaud 1999-T1; Archimbaud 1999-T2) were also included in Geissler (Geissler 2003-T1; Geissler 2003-T2). Emailed Dieter Hoelzer on 25 March 2015 and received reply on 31 March 2015 reporting that the authors no longer held the trial information but recommended contacting AMGEN, the trial sponsor. Contacted AMGEN on 25 March 2015, 8 April 2015, 13 April 2015, 2 June 2015, 27 July 2015 and 4 August 2015. No data provided by AMGEN over this 6-month period. We will incorporate any additional data provided by AMGEN into future reviews

Trial registration: not registered

Date of registration: N/A

\section{Risk of bias}


Archimbaud 1999-T2 (Continued)

\begin{tabular}{|c|c|c|}
\hline $\begin{array}{l}\text { Random sequence generation (selection } \\
\text { bias) }\end{array}$ & Unclear risk & Insufficient information \\
\hline Allocation concealment (selection bias) & Unclear risk & Insufficient information \\
\hline Blinding of participants (performance bias) & Low risk & $\begin{array}{l}\text { Investigators, trial site staff and monitors } \\
\text { were blind to treatment assignment }\end{array}$ \\
\hline Blinding of personnel (performance bias) & Low risk & $\begin{array}{l}\text { Investigators, trial site staff and monitors } \\
\text { were blind to treatment assignment }\end{array}$ \\
\hline $\begin{array}{l}\text { Blinding of outcome assessment (detection } \\
\text { bias) } \\
\text { All outcomes }\end{array}$ & Low risk & $\begin{array}{l}\text { Investigators, trial site staff and monitors } \\
\text { were blind to treatment assignment }\end{array}$ \\
\hline $\begin{array}{l}\text { Incomplete outcome data (attrition bias) } \\
\text { All outcomes }\end{array}$ & Low risk & $\begin{array}{l}\text { All participants who had at least } 1 \text { dose of } \\
\text { drug were included in the analyses }\end{array}$ \\
\hline Selective reporting (reporting bias) & Unclear risk & $\begin{array}{l}\text { Protocol and trial registration not available } \\
\text { to assess whether prespecified outcomes } \\
\text { have not been reported or other non-pre- } \\
\text { specified outcomes reported }\end{array}$ \\
\hline Other bias & High risk & $\begin{array}{l}\text { "Trial supported by AMGEN. The pub- } \\
\text { lication costs of this article were defrayed } \\
\text { in part by page charge payment. This arti- } \\
\text { cle must therefore be hereby marked "ad- } \\
\text { vertisement" in accordance with } 18 \text { U.S.C. } \\
\text { section } 1734 \text { solely to indicate this fact" }\end{array}$ \\
\hline
\end{tabular}

Geissler 2003-T1

Methods

Type of trial: multinational, multicentre, parallel-group 2-arm RCT

Country where trial was performed: Europe (individual countries not specified) and Australia

Dates of trial: July 1997 to August 1998

Follow-up until: 28 days after the last dose of chemotherapy

Participants

\section{Inclusions:}

- First remission from de novo AML

- Receiving consolidation chemotherapy

Exclusions:

None specified

Number of participants randomised: 46

Number of participants analysed: 45

Age:

Intervention arm: median 51.3 years (range 18 to 75 years)

Comparator arm (data combined with comparator group in (Geissler 2003-T2): median 
Geissler 2003-T1 (Continued)

55.1 years (range 21 to 73 years)
Gender:
Intervention arm: male 21 and female 16
Comparator arm (data combined with comparator group in (Geissler 2003-T2): male 6
and female 12
Types of malignancy:
All participants had de novo AML
Treatments:
All participants were treated with the same intensive chemotherapy regimen. "Patients
under 60 years received MiDAC (Cytarabine $1 \mathrm{~g} / \mathrm{m}^{2}$ twice daily days 1 to 4 , Mitoxantrone
$12 \mathrm{mg} / \mathrm{m}^{2}$ daily days 3 to 5 ) and participants 60 years and over received DAV $2+5+5$
(Daunorubicin $45 \mathrm{mg} / \mathrm{m}^{2}$ days 1 and 2 , Cytarabine $100 \mathrm{mg} / \mathrm{m}^{2}$ twice daily days 1 to 5,
and Etoposide $100 \mathrm{mg} / \mathrm{m}^{2}$ days 1 to 5 )"

Interventions

\section{Intervention arm:}

PEG-rHuMGDF $30 \mu \mathrm{g} / \mathrm{kg}$ as a single dose on day $-6 . \mathrm{N}=37$

\section{Comparator arm:}

Placebo based upon PEG-rHuMGDF $30 \mu \mathrm{g} / \mathrm{kg}$ as a single dose on day $-6 . \mathrm{N}=9$

\section{Outcomes}

\section{Primary outcome:}

Not reported

\section{Secondary outcomes:}

- Number of participants with any bleeding (up to 28 days)

- Number of days when platelets transfused (up to 28 days)

- Duration of thrombocytopenia

- Thromboembolism (up to 28 days)

First of 2 separate trials reported in a single paper. Second part recorded below as a separate trial (Geissler 2003-T2). 47 participants in the 2 trials by Geissler (Geissler 2003-T1; Geissler 2003-T2) were also included in Archimbaud (Archimbaud 1999T1; Archimbaud 1999-T2). Emailed Klaus Geissler on 25 March 2015 for further information with no response. Contacted AMGEN on 25 March 2015, 8 April 2015, 13 April 2015, 2 June 2015, 27 July 2015 and 4 August 2015. No data provided by AMGEN over this 6-month period. We will incorporate any additional data provided by AMGEN into future reviews

Trial registration: not registered

Date of registration: N/A

Risk of bias

Bias Authors' judgement

Support for judgement

Random sequence generation (selection Unclear risk

Insufficient information bias)

Allocation concealment (selection bias)

Unclear risk

Insufficient information 


\section{Geissler 2003-T1 (Continued)}

\begin{tabular}{|l|l|l} 
Blinding of participants (performance bias) & Low risk & $\begin{array}{l}\text { Double-blind placebo-controlled trial with } \\
\text { the placebo matched to the active interven- } \\
\text { tion }\end{array}$
\end{tabular}

tion

Blinding of personnel (performance bias) Low risk

Double-blind placebo-controlled trial with the placebo matched to the active intervention

Blinding of outcome assessment (detection Low risk bias)

All outcomes

Incomplete outcome data (attrition bias) Low risk All outcomes

Selective reporting (reporting bias)

Unclear risk

High risk

Geissler 2003-T2

Methods

Type of trial: multinational, multicentre, parallel-group 2-arm RCT

Country where trial was performed: Europe (individual countries not specified) and Australia

Dates of trial: July 1997 to August 1998

Follow-up until: 28 days after the last dose of chemotherapy

Participants

\section{Inclusions:}

- First remission from de novo AML

- Receiving consolidation chemotherapy

Exclusions:

None specified

Number of participants randomised: 44

Number of participants analysed: 42 
Geissler 2003-T2 (Continued)

\begin{tabular}{|c|c|}
\hline & $\begin{array}{l}\text { Age: } \\
\text { Intervention arm: median } 56.1 \text { years (range } 21 \text { to } 81 \text { years) } \\
\text { Comparator arm (data combined with comparator group in Geissler 2003-T1): median } \\
55.1 \text { years (range } 21 \text { to } 73 \text { years) } \\
\text { Gender: } \\
\text { Intervention arm: male } 17 \text { and female } 18 \\
\text { Comparator arm (data combined with comparator group in Geissler 2003-T1): male } 6 \\
\text { and female } 12 \\
\text { Types of malignancy: } \\
\text { All participants had de novo AML } \\
\text { Treatments: } \\
\text { All participants were treated with the same intensive chemotherapy regimen. "Patients } \\
\text { under } 60 \text { years received MiDAC (Cytarabine } 1 \mathrm{~g} / \mathrm{m}^{2} \text { twice daily days } 1 \text { to } 4 \text {, Mitoxantrone } \\
12 \mathrm{mg} / \mathrm{m}^{2} \text { daily days } 3 \text { to } 5 \text { ) and participants } 60 \text { years and over received DAV } 2+5+5 \\
\text { (Daunorubicin } 45 \mathrm{mg} / \mathrm{m}^{2} \text { days } 1 \text { and } 2 \text {, Cytarabine } 100 \mathrm{mg} / \mathrm{m}^{2} \text { twice daily days } 1 \text { to } 5 \text {, } \\
\text { and Etoposide } 100 \mathrm{mg} / \mathrm{m}^{2} \text { days } 1 \text { to } 5 \text { )" }\end{array}$ \\
\hline Interventions & $\begin{array}{l}\text { Intervention arm: } \\
\text { PEG-rHuMGDF } 30 \mu \mathrm{g} / \mathrm{kg}, 13 \text { doses from day }-6 \text { to day }+6 . \mathrm{N}=35 \\
\text { Comparator arm: } \\
\text { Placebo, } 13 \text { doses from day }-6 \text { to day }+6 . \mathrm{N}=9\end{array}$ \\
\hline Outcomes & $\begin{array}{l}\text { Primary outcome: } \\
\text { Not reported } \\
\text { Secondary outcomes: } \\
\text { - Number of participants with any bleeding (up to } 28 \text { days) } \\
\text { - Number of days when platelets transfused (up to } 28 \text { days) } \\
\text { - Duration of thrombocytopenia } \\
\text { - Thromboembolism (up to } 28 \text { days) }\end{array}$ \\
\hline Notes & $\begin{array}{l}\text { Second of } 2 \text { separate trials reported in a single paper. First part recorded above as a } \\
\text { separate trial (Geissler 2003-T1). } 47 \text { participants in the } 2 \text { trials by Geissler (Geissler } \\
\text { 2003-T1; Geissler 2003-T2) were also included in Archimbaud (Archimbaud 1999- } \\
\text { T1; Archimbaud 1999-T2). Emailed Klaus Geissler on } 25 \text { March } 2015 \text { for further } \\
\text { information with no response. Contacted AMGEN on } 25 \text { March 2015, } 8 \text { April } 2015 \text {, } \\
13 \text { April 2015, } 2 \text { June 2015, } 27 \text { July } 2015 \text { and } 4 \text { August } 2015 \text {. No data provided by } \\
\text { AMGEN over this 6-month period. We will incorporate any additional data provided } \\
\text { by AMGEN into future reviews } \\
\text { Trial registration: not registered } \\
\text { Date of registration: N/A }\end{array}$ \\
\hline
\end{tabular}

Risk of bias

\begin{tabular}{l|ll}
\hline Bias & Authors' judgement & Support for judgement \\
\hline $\begin{array}{l}\text { Random sequence generation (selection } \\
\text { bias) }\end{array}$ & Unclear risk & Insufficient information \\
\hline Allocation concealment (selection bias) & Unclear risk & Insufficient information \\
\hline
\end{tabular}

Alternatives, and adjuncts, to prophylactic platelet transfusion for people with haematological malignancies undergoing intensive 
Geissler 2003-T2 (Continued)

\begin{tabular}{|c|c|c|}
\hline Blinding of participants (performance bias) & Low risk & $\begin{array}{l}\text { Double-blind placebo-controlled trial with } \\
\text { the placebo matched to the active interven- } \\
\text { tion }\end{array}$ \\
\hline Blinding of personnel (performance bias) & Low risk & $\begin{array}{l}\text { Double-blind placebo-controlled trial with } \\
\text { the placebo matched to the active interven- } \\
\text { tion }\end{array}$ \\
\hline $\begin{array}{l}\text { Blinding of outcome assessment (detection } \\
\text { bias) } \\
\text { All outcomes }\end{array}$ & Low risk & $\begin{array}{l}\text { Double-blind placebo-controlled trial with } \\
\text { the placebo matched to the active interven- } \\
\text { tion }\end{array}$ \\
\hline $\begin{array}{l}\text { Incomplete outcome data (attrition bias) } \\
\text { All outcomes }\end{array}$ & Low risk & $\begin{array}{l}3 \text { participants not included in the efficacy } \\
\text { analysis. } 1 \text { participant not in remission at } \\
\text { trial entry and } 2 \text { because of early trial with- } \\
\text { drawal and insufficient data collection. } 1 \\
\text { participant not included in the safety anal- } \\
\text { yses because of insufficient data collection }\end{array}$ \\
\hline Selective reporting (reporting bias) & Unclear risk & $\begin{array}{l}\text { Protocol and trial registration not available } \\
\text { to assess whether prespecified outcomes } \\
\text { have not been reported or other non-pre- } \\
\text { specified outcomes reported }\end{array}$ \\
\hline Other bias & High risk & $\begin{array}{l}47 \text { participants from the trials by Archim- } \\
\text { baud (Archimbaud 1999-T1; Archimbaud } \\
\text { 1999-T2) were included in the } 2 \text { trials } \\
\text { by Geissler (Geissler 2003-T1; Geissler } \\
\text { 2003-T2). This may lead to bias through } \\
\text { selecting participants who were known to } \\
\text { be good responders. Trial funding was not } \\
\text { reported }\end{array}$ \\
\hline
\end{tabular}

Han 2015

Methods

Type of trial: single-centre, parallel-group 2-arm RCT

Country where trial was performed: China

Dates of trial: May 2010 to June 2011

Follow-up until: 60 days after the last dose of chemotherapy

Participants

Inclusions:

- Age $\geq 18$ years

- Haematological malignancy

- Due to receive a haploidentical HSCT

- Platelet count $100 \times 10^{9} / \mathrm{L}$ to $300 \times 10^{9} / \mathrm{L}$

Exclusions:

- Any of the following blood results if $>2 x$ upper limit of normal (prothrombin time, activated partial thromboplastin time, fibrinogen, D-dimer, alanine 
Han 2015 (Continued)

aminotransferase, bilirubin, blood urea nitrate or creatinine)

- Any grade 4/5 adverse event during conditioning chemotherapy

Number of participants randomised: 120

Number of participants analysed: 120

Age:

Intervention arm: median 31 years (range 18 to 57 years)

Comparator arm: median 30 years (range 19 to 48 years)

Gender:

Intervention arm: male 34 and female 26

Comparator arm: male 38 and female 22

Types of malignancy:

Intervention arm: 28 AML, 26 acute lymphoblastic leukaemia, 6 chronic myeloid leukaemia

Control arm: 32 AML, 20 acute lymphoblastic leukaemia, 8 chronic myeloid leukaemia

Treatments:

All participants received cytosine arabinoside $4 \mathrm{~g} / \mathrm{m}^{2} /$ day on days -10 and -9 , an intravenous injection of busulfan $0.8 \mathrm{mg} / \mathrm{kg}$ in 12 doses over 3 days (days $-8,-7$ and -6 ), cyclophosphamide $1.8 \mathrm{~g} / \mathrm{m}^{2} /$ day on days -5 and -4 , semustine $250 \mathrm{mg} / \mathrm{m}^{2}$ orally on day -3 , and rabbit antithymocyte globulin from day -5 to day -2 (the antithymocyte globulin dosage was $2.5 \mathrm{mg} / \mathrm{kg} / \mathrm{day}$ in 2010; starting in January 2011, it was adjusted to $1.5 \mathrm{mg} /$ $\mathrm{kg} /$ day in participants with standard risk

Interventions

\section{Intervention arm:}

rhTPO 15,000 units daily, from day +1 until platelet count $>20 \times 10^{9} / \mathrm{L}$ for 7 days or 60 days. $\mathrm{N}=60$

\section{Comparator arm:}

Matched placebo from day +1 until platelet count $>20 \times 10^{9} / \mathrm{L}$ for 7 days or 60 days. $\mathrm{N}=60$

Outcomes

\section{Primary outcome:}

- Incidence of platelet engraftment on day 60

Secondary outcomes:

- Number of participants with any bleeding (up to 21 days and up to 60 days)

- Overall mortality (30 days and 90 days)

- Mortality due to bleeding (up to 21 days)

- Overall survival

- Number of units of platelets transfused (up to day 60)

- Duration of thrombocytopenia

- Remission status (up to day 30 and up to day 90)

- Thromboembolism (up to 30 days and up to 90 days)

- Drug and transfusion reactions up to 30 days and up to 90 days)

Notes

Trial registration: ChiCTR-TRC-11001774

Date of registration: 3 December 2011 (retrospective registration)

Risk of bias

Bias

Authors' judgement

Support for judgement

Alternatives, and adjuncts, to prophylactic platelet transfusion for people with haematological malignancies undergoing intensive 
Han 2015 (Continued)

\begin{tabular}{|c|c|c|}
\hline $\begin{array}{l}\text { Random sequence generation (selection } \\
\text { bias) }\end{array}$ & Unclear risk & Insufficient information \\
\hline Allocation concealment (selection bias) & Unclear risk & Insufficient information \\
\hline Blinding of participants (performance bias) & High risk & Open-label trial \\
\hline Blinding of personnel (performance bias) & High risk & Open-label trial \\
\hline $\begin{array}{l}\text { Blinding of outcome assessment (detection } \\
\text { bias) } \\
\text { All outcomes }\end{array}$ & High risk & Open-label trial \\
\hline $\begin{array}{l}\text { Incomplete outcome data (attrition bias) } \\
\text { All outcomes }\end{array}$ & Low risk & All participants were analysed \\
\hline Selective reporting (reporting bias) & Unclear risk & Retrospectively registered \\
\hline Other bias & High risk & $\begin{array}{l}\text { Risk of sponsorship bias: funded by SUN- } \\
\text { SHINE Pharmaceutical Co Limited }\end{array}$ \\
\hline
\end{tabular}

Higby 1974

Methods

Type of trial: single-centre, parallel-group 2-arm RCT

Country where trial was performed: USA

Dates of trial: not reported

Follow-up until: not reported

Participants

\section{Inclusions:}

- AML

- Platelet count $<30 \times 10^{9} / \mathrm{L}$

Exclusions:

- Participants who were febrile

- Evidence of bleeding

- Evidence of haemolysis

- Remission of leukaemia

Number of participants randomised: 21

Number of participants analysed: 18

Age:

Intervention arm: mean 43.9 years (SD 19.4 years)

Comparator arm: mean 54.1 years (SD 18.6 years)

Gender:

Intervention arm: male 5 and female 4

Comparator arm: male 5 and female 4

Types of malignancy:

All participants had AML

Treatments:

All participants were treated with intensive chemotherapy regimen but the details were 
Higby 1974 (Continued)

not specified

\begin{tabular}{l|l} 
Interventions & $\begin{array}{l}\text { Intervention arm: } \\
\text { PPP, of equal volume to the platelets in the comparator arm, twice weekly. } \mathrm{N}=9 \\
\text { Comparator arm: }\end{array}$ \\
$\begin{array}{l}3 \text { units of platelets per } \mathrm{m}^{2} \text { body surface area (equivalent to } 3 \times 10^{11} \text { platelets per } \mathrm{m}^{2} \text { ) } \\
\text { twice weekly. } \mathrm{N}=9\end{array}$ \\
\hline Outcomes & $\begin{array}{l}\text { Primary outcome: } \\
\text { Not reported } \\
\text { Secondary outcomes: } \\
\text { - Number of participants with any bleeding (during } 1 \text { cycle of chemotherapy - } \\
\text { approximately } 28 \text { days) } \\
\bullet \quad \text { Formation of anti-platelet antibodies (timing of outcome assessment unclear) }\end{array}$ \\
\hline Notes & $\begin{array}{l}3 \text { participants were re-randomised after initial allocation from the PPP (intervention) } \\
\text { arm to the platelet transfusion (comparator) arm. These participants were included in the } \\
\text { PPP analysis but were excluded from the platelet transfusion arm analysis. participants } \\
\text { in the comparator arm were significantly older than those in the intervention arm } \\
\text { Trial registration: not registered } \\
\text { Date of registration: N/A }\end{array}$ \\
\hline
\end{tabular}

Risk of bias

\begin{tabular}{|c|c|c|}
\hline Bias & Authors' judgement & Support for judgement \\
\hline $\begin{array}{l}\text { Random sequence generation (selection } \\
\text { bias) }\end{array}$ & Unclear risk & Insufficient information \\
\hline
\end{tabular}

Allocation concealment (selection bias) Low risk

"Eligible patients were allocated to treatment regimen in the blood bank and without knowledge of the attending physicians"

Blinding of participants (performance bias) Low risk

"Eligible patients were allocated to a treatment regimen in the blood bank and were treated in the manner assigned without the knowledge of the attending physicians". Therefore, it is unlikely that participants were aware

Blinding of personnel (performance bias) Unclear risk

"Eligible patients were allocated to a treatment regimen in the blood bank and were treated in the manner assigned without the knowledge of the attending physicians"

Blinding of outcome assessment (detection Unclear risk bias)

Method of performing the bleeding assessment and the person performing the bleed-

All outcomes

ing assessment not stated

Alternatives, and adjuncts, to prophylactic platelet transfusion for people with haematological malignancies undergoing intensive 
Higby 1974 (Continued)

\begin{tabular}{|l|l|l}
$\begin{array}{l}\text { Incomplete outcome data (attrition bias) } \\
\text { All outcomes }\end{array}$ & Low risk & $\begin{array}{l}\text { All participants treated were included in the } \\
\text { analysis. } 3 \text { participants who had recovered } \\
\text { their platelet count were not included in } \\
\text { the analysis }\end{array}$
\end{tabular}

Selective reporting (reporting bias) Unclear risk

Protocol and trial registration not available to assess whether prespecified outcomes have not been reported or other non-prespecified outcomes reported

Other bias

High risk

There was a significant difference between the ages of the participants in the 2 groups (mean $\pm \mathrm{SD}$ ) $53.3 \pm 18.5$ (arm 1) vs. 43.8 $\pm 19.4(\operatorname{arm} 2)(\mathrm{P}<0.05(\mathrm{t}$-test $)) .3$ participants were re-randomised in the trial

Miao 2012

Methods

Type of trial: multicentre, parallel-group 4-arm RCT

Country where trial was performed: China

Dates of trial: August 2009 to May 2011

Follow-up until: not reported

Participants

\section{Inclusions:}

- Age 18 to 60 years

- Malignant blood cell disorder (including chronic myeloproliferative disorders and myelodysplastic syndrome)

- Undergoing an allogeneic HSCT

Exclusions:

- Pregnant or lactating women

- Chronic or active hepatitis B or C

- Participants undergoing repeat transplant

- Severe infection

- Severe heart disease

- Severe lung disease

- Diabetes mellitus

- Severe metabolic disease

- HIV positive

Number of participants randomised: 120

Number of participants analysed: 89

Age:

Intervention arm 1: median 34 years (no measure of dispersion reported)

Intervention arm 2: median 32 years (no measure of dispersion reported)

Intervention arm 3: median 36 years (no measure of dispersion reported)

Comparator arm: median 35 years (no measure of dispersion reported)

Gender:

Intervention arm 1: male 12 and female 11

Intervention arm 2: male 12 and female 8

Alternatives, and adjuncts, to prophylactic platelet transfusion for people with haematological malignancies undergoing intensive 
Intervention arm 3: male 13 and female 9

Comparator arm: male 13 and female 11

Types of malignancy:

Intervention arm 1: acute lymphoblastic leukaemia 5, AML 13, chronic myeloid leukaemia 2, non-Hodgkin lymphoma (subtype not specified) 3

Intervention arm 2: acute lymphoblastic leukaemia 6, AML 11, mixed lineage leukaemia 1 , myelodysplastic syndrome 2

Intervention arm 3: acute lymphoblastic leukaemia 6, AML 8, chronic myeloid leukaemia 6 , mixed lineage leukaemia 1 , myelodysplastic syndrome 3

Comparator arm: acute lymphoblastic leukaemia 7, AML 10, chronic myeloid leukaemia 4, myelodysplastic syndrome 1

\section{Treatments:}

All participants were treated with allogeneic HSCT with the following conditioning regimens (no doses were specified):

Intervention arm 1: busulfan and cyclophosphamide 13; busulfan, cyclophosphamide and anti-thymocyte globulin 1; total body irradiation and cyclophosphamide 7 ; total body irradiation, cyclophosphamide and anti-thymocyte globulin 2

Intervention arm 2: busulfan and cyclophosphamide 17; total body irradiation and cyclophosphamide 3

Intervention arm 3: busulfan and cyclophosphamide 17; busulfan, cyclophosphamide and anti-thymocyte globulin 1; total body irradiation and cyclophosphamide 3; total body irradiation, cyclophosphamide and anti-thymocyte globulin 1

Comparator arm: busulfan and cyclophosphamide 18; busulfan, cyclophosphamide and anti-thymocyte globulin 3; total body irradiation and cyclophosphamide 3

\section{Intervention arm 1:}

rhTPO 300 units $/ \mathrm{kg} /$ day (Sansei Shengyang Pharmaceutical company product) from day +1 until platelet count of $50 \times 10^{9} / \mathrm{L}$ or platelet count $>20 \times 10^{9} / \mathrm{L}$ for 7 days. $\mathrm{N}=$ 23

\section{Intervention arm 2:}

rhTPO 300 units $/ \mathrm{kg} /$ day from day +4 until platelet count of $50 \times 10^{9} / \mathrm{L}$ or platelet count $>20 \times 10^{9} / \mathrm{L}$ for 7 days. $\mathrm{N}=20$

Intervention arm 2:

rhTPO 300 units $/ \mathrm{kg} /$ day from day +7 until platelet count of $50 \times 10^{9} / \mathrm{L}$ or platelet count $>20 \times 10^{9} / \mathrm{L}$ for 7 days. $\mathrm{N}=24$

Comparator arm:

Standard care. $\mathrm{N}=22$

\section{Secondary outcomes:}

- Number of units of platelets transfused (timing of outcome assessment unclear)

- Duration of thrombocytopenia

- Thromboembolism (timing of outcome assessment unclear)

- Drug or transfusion reactions (timing of outcome assessment unclear) 
Miao 2012 (Continued)

\section{Risk of bias}

\begin{tabular}{|c|c|c|}
\hline Bias & Authors' judgement & Support for judgement \\
\hline $\begin{array}{l}\text { Random sequence generation (selection } \\
\text { bias) }\end{array}$ & Unclear risk & Insufficient information \\
\hline Allocation concealment (selection bias) & Unclear risk & Insufficient information \\
\hline Blinding of participants (performance bias) & High risk & $\begin{array}{l}\text { Open-label trial (no allocation conceal- } \\
\text { ment) }\end{array}$ \\
\hline Blinding of personnel (performance bias) & High risk & $\begin{array}{l}\text { Open-label trial (no allocation conceal- } \\
\text { ment) }\end{array}$ \\
\hline $\begin{array}{l}\text { Blinding of outcome assessment (detection } \\
\text { bias) } \\
\text { All outcomes }\end{array}$ & High risk & $\begin{array}{l}\text { Open-label trial (no allocation conceal- } \\
\text { ment) }\end{array}$ \\
\hline $\begin{array}{l}\text { Incomplete outcome data (attrition bias) } \\
\text { All outcomes }\end{array}$ & High risk & $\begin{array}{l}120 \text { participants enrolled but only } 89 \text { par- } \\
\text { ticipants included in the analysis, the rea- } \\
\text { sons for exclusion not reported }\end{array}$ \\
\hline Selective reporting (reporting bias) & Unclear risk & $\begin{array}{l}\text { Protocol and trial registration not available } \\
\text { to assess whether prespecified outcomes } \\
\text { have not been reported or other non-pre- } \\
\text { specified outcomes reported }\end{array}$ \\
\hline Other bias & Unclear risk & $\begin{array}{l}\text { This trial was not reported sufficiently to } \\
\text { exclude other sources of significant bias }\end{array}$ \\
\hline
\end{tabular}

Moskowitz 2007-T1

Methods

Type of trial: single-centre, parallel-group 3-arm RCT

Country where trial was performed: USA

Dates of trial: August 1996 to September 1998

Follow-up until: not reported

Participants

\section{Inclusions:}

- Diagnosis of follicular lymphoma, grade III, DLBCL, transformed DLBCL, anaplastic large cell lymphoma, mantle cell lymphoma and peripheral $\mathrm{T}$ cell

- First relapse or primary refractory disease after an anthracycline-based chemotherapy regimen

- Minimum platelet count $40 \times 10^{9} / \mathrm{L}$

- Normal baseline cardiac function based upon echocardiogram or gated blood pool scan with an ejection fraction of $>50 \%$ as measured since last chemotherapy Exclusions:

- Parenchymal brain disease at relapse 
- Warfarin, heparin (other than flushes for central venous catheters), ticlopidine hydrochloride or aspirin within 7 days of enrolment

- History of thromboembolic disease within the last 12 months, with the exception of catheter-related thromboses

- Concurrent idiopathic thrombocytopenic purpura

- Concurrent enrolment on any other protocol using an investigational or nonapproved drug or biological

- Use of haematopoietic growth factors other than filgrastim within 2 weeks of trial entry

Number of participants randomised: 22

Number of participants analysed: 20

Overall median age of the participants in both Moskowitz trials (Moskowitz 2007-T1; Moskowitz 2007-T2): 44 years (range 20 to 68 years). Data not reported by trial or by arm

\section{Gender:}

Both trials by Moskowitz trials (Moskowitz 2007-T1; Moskowitz 2007-T2) combined for the description of participant gender. Data not reported by trial or arm

Intervention (PEG-rHuMGDF $2.5 \mu \mathrm{g} / \mathrm{kg} /$ day): male 4 and female 2

Intervention (PEG-rHuMGDF $5 \mu \mathrm{g} / \mathrm{kg} /$ day): male 11 and female 5

Comparator: male 9 and female 7

\section{Types of malignancy:}

Both trials by Moskowitz trials (Moskowitz 2007-T1; Moskowitz 2007-T2) combined for the description of underlying malignancies. Data not reported by trial or arm Intervention (PEG-rHuMGDF $2.5 \mu \mathrm{g} / \mathrm{kg} / \mathrm{day}$ ): DLBCL 5, anaplastic large cell lymphoma 1

Intervention (PEG-rHuMGDF $5 \mu \mathrm{g} / \mathrm{kg} / \mathrm{day}$ ): DLBCL 9, anaplastic large cell lymphoma 2, peripheral T cell lymphoma 3, follicular lymphoma (grade 3) 2

Comparator: DLBCL 13, mantle cell lymphoma 1, peripheral T cell lymphoma 2

\section{Treatments:}

All participants received the same chemotherapy regimen: etoposide $100 \mathrm{mg} / \mathrm{m}^{2}$ on days 1 to 3; carboplatin $5 \mathrm{x}$ [creatinine clearance +25 ] $\mathrm{mg}$ with a maximum dose of $800 \mathrm{mg}$ on day 2 ; and ifosfamide $5 \mathrm{~g} / \mathrm{m}^{2}$ on day 2

\section{Intervention arm 1:}

PEG-rHuMGDF $2.5 \mu \mathrm{g} / \mathrm{kg} /$ day on days 4 to 10 postchemotherapy. $\mathrm{N}=8$

Intervention arm 2:

PEG-rHuMGDF $5 \mu \mathrm{g} / \mathrm{kg} /$ day on days 4 to 10 postchemotherapy. $\mathrm{N}=8$

Comparator arm:

Placebo. $\mathrm{N}=6$

\section{Primary:}

Not clear

\section{Secondary:}

- Mortality (up to 90 days)

- Overall survival

- Thromboembolism (timing unclear)

- Drug/transfusion reactions (timing unclear)

- Platelet transfusions (not in a format that could be analysed in this review) 
Moskowitz 2007-T1 (Continued)

$\begin{array}{ll}\text { Notes } & \text { First of } 2 \text { separate trials reported in a single paper. Second part recorded below as a } \\ \text { separate trial (Moskowitz 2007-T2). Emailed Craig Moskowitz on } 25 \text { March } 2015 \text { for } \\ \text { further information with no response. Contacted AMGEN on 25 March 2015, } 8 \text { April } \\ \text { 2015, } 13 \text { April 2015, 2 June 2015, 27 July } 2015 \text { and 4 August 2015. No data provided } \\ \text { by AMGEN over this 6-month period. We will incorporate any additional data provided } \\ \text { by AMGEN into future reviews } \\ \text { Trial registration: not registered } \\ \text { Date of registration: N/A }\end{array}$

\section{Risk of bias}

\begin{tabular}{|c|c|c|}
\hline Bias & Authors' judgement & Support for judgement \\
\hline $\begin{array}{l}\text { Random sequence generation (selection } \\
\text { bias) }\end{array}$ & Unclear risk & Insufficient information \\
\hline Allocation concealment (selection bias) & Low risk & $\begin{array}{l}\text { "All Memorial Sloan-Kettering Cancer } \\
\text { Center (MSKCC) staff and all Amgen per- } \\
\text { sonnel directly involved in patient care and } \\
\text { data assessment were blinded with respect } \\
\text { to trial drug assignment" }\end{array}$ \\
\hline Blinding of participants (performance bias) & Low risk & $\begin{array}{l}\text { "All Memorial Sloan-Kettering Cancer } \\
\text { Center (MSKCC) staff and all Amgen per- } \\
\text { sonnel directly involved in patient care and } \\
\text { data assessment were blinded with respect } \\
\text { to trial drug assignment" }\end{array}$ \\
\hline
\end{tabular}

Blinding of personnel (performance bias) Low risk

"All Memorial Sloan-Kettering Cancer Center (MSKCC) staff and all Amgen personnel directly involved in patient care and data assessment were blinded with respect to trial drug assignment"

Blinding of outcome assessment (detection Low risk bias)

All outcomes

Incomplete outcome data (attrition bias) Low risk All outcomes

Selective reporting (reporting bias)
High risk
"All Memorial Sloan-Kettering Cancer Center (MSKCC) staff and all Amgen personnel directly involved in patient care and data assessment were blinded with respect to trial drug assignment"

3 participants excluded who developed complications prior to treatment. All other participants accounted for in final analysis

Protocol and trial registration not available. Duration of thrombocytopenia was a prespecified outcome; however, it was not reported. The primary outcome was 
Moskowitz 2007-T1 (Continued)

the number of cycles during which thrombocytopenia was experienced during the ifosfamide, carboplatin and etoposide regimen. However, only the percentage of grade IV thrombocytopenia was reported rather than the number. Total number of courses of chemotherapy not reported

Other bias

High risk

Appears to be a partially industry supported trial because AMGEN staff were involved in the trial. The paper did not clearly state this

Moskowitz 2007-T2

Methods

Type of trial: single-centre, parallel-group 2-arm RCT

Country where trial was performed: USA

Dates of trial: August 1996 to September 1998

Follow-up until: not reported

Participants

\section{Inclusions:}

- Diagnosis of grade III follicular lymphoma, DLBCL, transformed DLBCL, anaplastic large cell lymphoma, mantle cell lymphoma, peripheral $\mathrm{T}$ cell

- First relapse or primary refractory disease after an anthracycline-based chemotherapy regimen

- Minimum platelet count of $40 \times 10^{9} / \mathrm{L}$

- Normal baseline cardiac function based upon echocardiogram or gated blood pool scan with an ejection fraction of $>50 \%$ as measured since last chemotherapy

\section{Exclusions:}

- Parenchymal brain disease at relapse

- Warfarin, heparin (other than flushes for central venous catheters), ticlopidine hydrochloride or aspirin within 7 days of enrolment

- History of thromboembolic disease within the last 12 months, with the exception of catheter-related thromboses

- Concurrent idiopathic thrombocytopenic purpura

- Concurrent enrolment on any other protocol using an investigational or nonapproved drug or biological

- Use of haematopoietic growth factors other than filgrastim within 2 weeks of trial entry

Number of participants randomised: 19

Number of participants analysed: 18

Age:

Overall median age of the participants in both Moskowitz trials (Moskowitz 2007-T1; Moskowitz 2007-T2): 44 years (range 20 to 68 years). Data not reported by trial or by arm

Gender:

Both trials by Moskowitz trials (Moskowitz 2007-T1; Moskowitz 2007-T2) combined for the description of participant gender. Data not reported by trial or arm 
Moskowitz 2007-T2 (Continued)

Intervention (PEG-rHuMGDF $2.5 \mu \mathrm{g} / \mathrm{kg} /$ day): male 4 and female 2

Intervention (PEG-rHuMGDF $5 \mu \mathrm{g} / \mathrm{kg} /$ day): male 11 and female 5

Comparator: male 9 and female 7

Types of malignancy:

Both trials by Moskowitz trials (Moskowitz 2007-T1; Moskowitz 2007-T2) combined for the description of underlying malignancies. Data not reported by trial or arm

Intervention (PEG-rHuMGDF $2.5 \mu \mathrm{g} / \mathrm{kg} / \mathrm{day}$ ): DLBCL 5, anaplastic large cell lymphoma 1

Intervention (PEG-rHuMGDF $5 \mu \mathrm{g} / \mathrm{kg} / \mathrm{day}$ ): DLBCL 9, anaplastic large cell lymphoma 2, peripheral $\mathrm{T}$ cell lymphoma 3, follicular lymphoma (grade three) 2

Comparator: DLBCL 13, mantle cell lymphoma 1, peripheral T cell lymphoma 2

Treatments:

All participants received the same chemotherapy regimen: etoposide $100 \mathrm{mg} / \mathrm{m}^{2}$ on days 1 to 3 ; carboplatin $5 \mathrm{x}$ [creatinine clearance +25 ] $\mathrm{mg}$ with a maximum dose of $800 \mathrm{mg}$ on day 2 ; and ifosfamide $5 \mathrm{~g} / \mathrm{m}^{2}$ on day 2

Interventions

Intervention arm:

PEG-rHuMGDF $5 \mu \mathrm{g} / \mathrm{kg} /$ day on days $4-10$ postchemotherapy. $\mathrm{N}=9$

Comparator arm:

Placebo. $\mathrm{N}=10$

Outcomes

Primary:

Not clear

Secondary:

- Mortality (up to 90 days)

- Overall survival

- Thromboembolism (timing unclear)

- Drug/transfusion reactions (timing unclear)

- Platelet transfusions (not in a format that could be analysed in this review)

Notes

Second of 2 separate trials reported in a single paper. First part recorded above as a separate trial (Moskowitz 2007-T1). Emailed Craig Moskowitz on 25 March 2015 for further information with no response. Contacted AMGEN on 25 March 2015, 8 April 2015, 13 April 2015, 2 June 2015, 27 July 2015 and 4 August 2015. No data provided by AMGEN over this 6-month period. We will incorporate Any additional data provided by AMGEN into future reviews

Trial registration: not registered

Date of registration: N/A

\section{Risk of bias}

\begin{tabular}{lll}
\hline Bias & Authors' judgement & Support for judgement \\
\hline $\begin{array}{l}\text { Random sequence generation (selection } \\
\text { bias) }\end{array}$ & Unclear risk & Insufficient information \\
\hline $\begin{array}{l}\text { Allocation concealment (selection bias) } \\
\text { Low risk }\end{array}$ & & $\begin{array}{l}\text { "All Memorial Sloan-Kettering Cancer } \\
\text { Center (MSKCC) staff and all Amgen per- } \\
\text { sonnel directly involved in patient care and }\end{array}$
\end{tabular}


Moskowitz 2007-T2 (Continued)

data assessment were blinded with respect to trial drug assignment"

Blinding of participants (performance bias) Low risk

Blinding of personnel (performance bias) Low risk
"All Memorial Sloan-Kettering Cancer Center (MSKCC) staff and all Amgen personnel directly involved in patient care and data assessment were blinded with respect to trial drug assignment"

"All Memorial Sloan-Kettering Cancer Center (MSKCC) staff and all Amgen personnel directly involved in patient care and data assessment were blinded with respect to trial drug assignment"

Blinding of outcome assessment (detection Low risk bias)

All outcomes

"All Memorial Sloan-Kettering Cancer Center (MSKCC) staff and all Amgen personnel directly involved in patient care and data assessment were blinded with respect to trial drug assignment"

Incomplete outcome data (attrition bias) Low risk All outcomes

Selective reporting (reporting bias) High risk

Other bias

High risk
3 participants excluded who developed complications prior to treatment. All other participants accounted for in final analysis

Protocol and trial registration not available. Duration of thrombocytopenia was a prespecified outcome; however, it was not reported. Primary outcome was the number of cycles during which thrombocytopenia was experienced during the ifosfamide, carboplatin and etoposide regimen. However, only the percentage of grade IV thrombocytopenia was reported rather than the number. Total number of courses of chemotherapy not reported

This appears to be a partially industry supported trial because AMGEN staff were involved in the trial. The paper did not clearly state this 
Participants

Interventions

\section{Inclusions:}

- Age $\geq 18$ years

- Newly diagnosed, previously untreated de novo AML

- ECOG Performance Status 0 to 3

Exclusions:

- Acute promyelocytic leukaemia or acute megakaryoblastic leukaemia

- Blast transformation of chronic myeloid leukaemia

- AML secondary to myelodysplastic syndrome or other bone marrow disorders

- Known allergy to an Escherichia coli-derived pharmaceutical

- Clinically relevant coagulation disorder unrelated to AML (including deep vein thrombosis, pulmonary embolism, stroke, myocardial infarction or unstable angina) within the last 6 months

\section{Number of participants randomised: 60}

Number of participants analysed: 57

Age:

Intervention arm 1: 12 participants aged $<60$ years; 7 participants aged $\geq 60$ years Intervention arm 2: 12 participants aged $<60$ years; 7 participants aged $\geq 60$ years Comparator arm: 11 participants aged $<60$ years; 8 aged $\geq 60$ years

Gender:

Intervention arm 1: male 11 and female 8

Intervention arm 2: male 10 and female 9

Comparator arm: male 14 and female 5

Types of malignancy:

All participants had AML

Treatments:

Participants in all arms of the trial were treated with the same chemotherapy regimen: Participants aged $<60$ years:

First cycle of chemotherapy with daunorubicin $45 \mathrm{mg} / \mathrm{m}^{2}$ days 1 to 3 , cytarabine 100 $\mathrm{mg} / \mathrm{m}^{2}$ continuous infusion days 1 to 7 and high-dose cytarabine $2 \mathrm{~g} / \mathrm{m}^{2}$ twice daily on days 8 to 10 . Second to fourth cycles of chemotherapy with cytarabine $3 \mathrm{~g} / \mathrm{m}^{2}$ twice daily days 1,3 and 5

Participants aged $\geq 60$ years:

First cycle of chemotherapy with daunorubicin $45 \mathrm{mg} / \mathrm{m}^{2}$ days 1 to 3, and cytarabine $200 \mathrm{mg} / \mathrm{m}^{2}$ continuous infusion days 1 to 7 . Second to fourth cycles of chemotherapy with cytarabine $1.5 \mathrm{~g} / \mathrm{m}^{2}$ over twice daily days 1 to 4

\section{Intervention arm 1:}

PEG-rHuMGDF $2.5 \mu \mathrm{g} / \mathrm{kg} /$ day starting on day after last dose of chemotherapy and continuing until platelet count $50 \times 10^{9} / \mathrm{L}$ or 28 days (whichever came first). $\mathrm{N}=19$

Intervention arm 2:

PEG-rHuMGDF $5 \mu \mathrm{g} / \mathrm{kg} /$ day starting on day after last dose of chemotherapy and continuing until platelet count $50 \times 10^{9} / \mathrm{L}$ or 28 days (whichever came first). $\mathrm{N}=19$

Comparator arm:

Placebo starting on day after last dose of chemotherapy and continuing until platelet count $50 \times 10^{9} / \mathrm{L}$ or 28 days (whichever came first). $\mathrm{N}=19$ 
Schiffer 2000 (Continued)

\begin{tabular}{l|l}
\hline Outcomes & $\begin{array}{l}\text { Primary outcome: } \\
\text { - Duration of thrombocytopenia } \\
\text { Secondary outcomes: } \\
\text { - Number of days when platelets transfused (up to day 35) } \\
\text { - Remission status (up to day 35) } \\
\text { - Thromboembolism (up to day 35) }\end{array}$ \\
\hline Notes & $\begin{array}{l}\text { Contacted Charles Schiffer on 25 March 2015 who replied on 25 March 2015 reporting } \\
\text { that the authors no longer held the original data but that AMGEN the sponsor should } \\
\text { be contacted. Contacted AMGEN on 25 March 2015, } 8 \text { April 2015, } 13 \text { April } 2015,2\end{array}$ \\
June 2015, 27 July 2015 and 4 August 2015. No data provided by AMGEN over this \\
6-month period. We will incorporate any additional data provided by AMGEN into \\
future reviews \\
Trial registration: not registered \\
Date of registration: N/A
\end{tabular}

\section{Risk of bias}

\begin{tabular}{|c|c|c|}
\hline Bias & Authors' judgement & Support for judgement \\
\hline $\begin{array}{l}\text { Random sequence generation (selection } \\
\text { bias) }\end{array}$ & Unclear risk & Insufficient information \\
\hline Allocation concealment (selection bias) & Unclear risk & Insufficient information \\
\hline Blinding of participants (performance bias) & Low risk & $\begin{array}{l}\text { Participants and participating physicians } \\
\text { blinded to the intervention }\end{array}$ \\
\hline Blinding of personnel (performance bias) & Low risk & $\begin{array}{l}\text { Participants and participating physicians } \\
\text { blinded to the intervention }\end{array}$ \\
\hline $\begin{array}{l}\text { Blinding of outcome assessment (detection } \\
\text { bias) } \\
\text { All outcomes }\end{array}$ & Low risk & $\begin{array}{l}\text { Participants and participating physicians } \\
\text { blinded to the intervention }\end{array}$ \\
\hline $\begin{array}{l}\text { Incomplete outcome data (attrition bias) } \\
\text { All outcomes }\end{array}$ & Low risk & $\begin{array}{l}\text { Survival curves and all participants ac- } \\
\text { counted for }\end{array}$ \\
\hline Selective reporting (reporting bias) & Unclear risk & $\begin{array}{l}\text { Protocol and trial registration not available } \\
\text { to assess whether prespecified outcomes } \\
\text { have not been reported or other non-pre- } \\
\text { specified outcomes reported }\end{array}$ \\
\hline Other bias & High risk & $\begin{array}{l}\text { "Supported by research grants by Amgen. } \\
\text { The publication costs of this article were } \\
\text { defrayed in part by page charge payment. } \\
\text { Therefore, and solely to indicate this fact, } \\
\text { this article is hereby marked "advertise- }\end{array}$ \\
\hline
\end{tabular}


Schiffer 2000 (Continued)

ment" in accordance with 18 U.S.C. section 1734 "

AML: acute myeloid leukaemia; DLBCL: diffuse large B cell lymphoma; ECOG: Eastern Cooperative Oncology Group; FAB: FrenchAmerican-British; HSCT: haematopoietic stem cell transplant; n: number of participants; N/A: not applicable; PEG-rHuMGDF: pegylated recombinant human megakaryocyte growth and development factor; PPP: platelet-poor plasma; RCT: randomised controlled trial; rhTPO: recombinant human thrombopoietin; SD: standard deviation.

\section{Characteristics of excluded studies [ordered by study ID]}

\begin{tabular}{|c|c|}
\hline Study & Reason for exclusion \\
\hline ASH 2003 & Review article \\
\hline Avvisati 1989 & Incorrect intervention \\
\hline Bai 2004a & Wrong participant group \\
\hline Bai 2004b & Wrong pa rticipant group \\
\hline Basciano 2012 & Review article \\
\hline Basser 1996 & Wrong participa nt group \\
\hline Basser 1997 & Wrong participant group \\
\hline Basser 2000 & Incorrect intervention \\
\hline Basser 2002 & Review article \\
\hline Bauman 2011 & Not an RCT \\
\hline Berstein 2002 & Not an RCT \\
\hline Blajchman 2001 & Review article \\
\hline Blajchman 2003 & Review article \\
\hline Bowen 2010 & Wrong participa nt group \\
\hline Brenner 2004 & Incorrect intervention \\
\hline Bussel 2006 & Wrong participa nt group \\
\hline Bussel 2007 & Wrong participa nt group \\
\hline
\end{tabular}


(Continued)

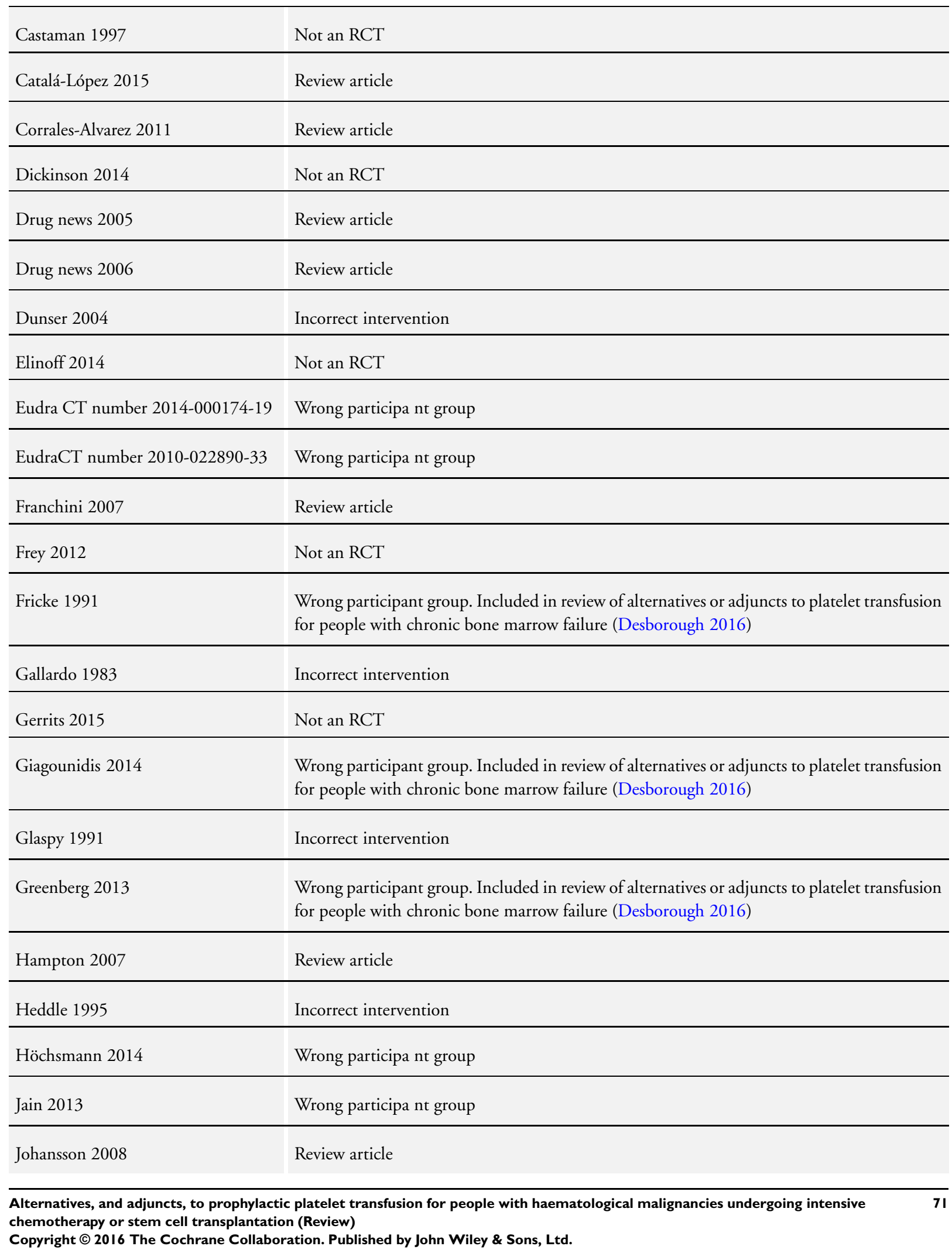


(Continued)

\begin{tabular}{|c|c|}
\hline Kantarjian 2010a & $\begin{array}{l}\text { Wrong participant group. Included in review of alternatives or adjuncts to platelet transfusion } \\
\text { for people with chronic bone marrow failure (Desborough 2016) }\end{array}$ \\
\hline Kantarjian 2010b & Wrong participa nt group \\
\hline Kellum 2010 & Wrong participa nt group \\
\hline Knoefler 2013 & Not an RCT \\
\hline Korte 2009 & Wrong participa nt group \\
\hline Kristensen 1993 & Not an RCT \\
\hline Kruskemper 1966 & Incorrect intervention \\
\hline Levy 2008 & Review article \\
\hline Li 2012 & Incorrect intervention \\
\hline Liesveld 2013 & Not an RCT \\
\hline Louis 1967 & Incorrect intervention \\
\hline Malyszko 1990 & Wrong participa nt group \\
\hline Mannucci 1986 & $\begin{array}{l}\text { Wrong participant group. Included in review of alternatives or adjuncts to platelet transfusion } \\
\text { for people with chronic bone marrow failure (Desborough 2016) }\end{array}$ \\
\hline Matsumoto 2007 & Incorrect intervention \\
\hline Mittelman 2012 & Not an RCT \\
\hline Mizer 1998 & Review article \\
\hline Nair 2006 & Incorrect intervention \\
\hline Nash 2000 & Not an RCT \\
\hline Natale 2009 & Wrong participa nt group \\
\hline NCT00102726 & Wrong participa nt group \\
\hline NCT00358540 & Not an RCT \\
\hline NCT00413283 & Wrong participa nt group \\
\hline NCT00472290 & Not an RCT \\
\hline
\end{tabular}


(Continued)

\begin{tabular}{|c|c|}
\hline NCT00614523 & Wrong participa nt group \\
\hline NCT00688272 & Wrong participa nt group \\
\hline NCT00903422 & Wrong participa nt group \\
\hline NCT00922883 & Not an RCT \\
\hline NCT01072162 & Wrong participa nt group \\
\hline NCT01147809 & Wrong participa nt group \\
\hline NCT01194167 & Not an RCT \\
\hline NCT01328587 & Not an RCT \\
\hline NCT01500538 & Not an RCT \\
\hline NCT01516619 & Not an RCT \\
\hline NCT01550185 & Not an RCT \\
\hline NCT01757145 & Not an RCT \\
\hline NCT01791101 & Not an RCT \\
\hline NCT01893372 & Wrong participa nt group \\
\hline NCT01957176 & Not an RCT \\
\hline NCT01980030 & Not an RCT \\
\hline NCT02046291 & Not an RCT \\
\hline NCT02052882 & Wrong participa nt group \\
\hline NCT02093325 & Wrong participa nt group \\
\hline NCT02094417 & Wrong participa nt group \\
\hline NCT02323178 & Not an RCT \\
\hline NCT02446145 & Wrong participa nt group \\
\hline Norris 2011 & Review article \\
\hline Oliva 2013 & Wrong participa nt group \\
\hline
\end{tabular}


(Continued)

\begin{tabular}{|c|c|}
\hline Olnes 2012 & Not an RCT \\
\hline Palmblad 2008 & Not an RCT \\
\hline Peeters 2008 & Review article \\
\hline Pihusch 2005 & Incorrect intervention \\
\hline Platzbecker 2015 & $\begin{array}{l}\text { Wrong participant group. Included in review of alternatives or adjuncts to platelet transfusion } \\
\text { for people with chronic bone marrow failure (Desborough 2016) }\end{array}$ \\
\hline Prica 2014 & Review article \\
\hline Rasche 1982 & Incorrect intervention \\
\hline Rasche 1986 & Incorrect intervention \\
\hline Risitano 2014 & Wrong participa nt group \\
\hline Schuster 2002 & Wrong participa nt group \\
\hline Sekeres 2011 & Wrong participa nt group \\
\hline Seza 1997 & Wrong participa nt group \\
\hline Shpilberg 1993 & Incorrect intervention \\
\hline Somlo 1999 & Wrong participa nt group \\
\hline Squizzato 2007 & Review article \\
\hline Svensson 2014 & Not an RCT \\
\hline Takami 2002 & Incorrect intervention \\
\hline Thompson 2000 & Incorrect intervention \\
\hline Townsley 2015 & Not an RCT \\
\hline Vadhan-Raj 2000 & Review article \\
\hline Vannucchi 1996 & Incorrect intervention \\
\hline Wang 2009 & Review article \\
\hline
\end{tabular}

Wang 2012

Wrong participant group. Included in review of alternatives or adjuncts to platelet transfusion for people with chronic bone marrow failure (Desborough 2016) 
(Continued)

\begin{tabular}{ll}
\hline Wang 2013 & Wrong participant group \\
\hline Wardrop 2013 & Review article \\
\hline Will 2009a & Not an RCT \\
\hline Will 2009b & Not an RCT \\
\hline Williams 2009 & Wrong participa nt group \\
\hline Winer 2015 & Wrong participa nt group \\
\hline Wire 2012 & Wrong participa nt group \\
\hline Wolff 2001 & Not an RCT \\
\hline Wroblewski 2010 & Wrong participa nt group \\
\hline Wu 2014 & Not an RCT \\
\hline Xu 2008 & Not an RCT \\
\hline
\end{tabular}

RCT: randomised controlled trial .

Characteristics of ongoing studies [ordered by study ID]

\section{EudraCT 2015-000929-37}

Trial name or title EPAG 2015: a phase II randomized placebo-controlled trial to assess the impact on outcome of Eltrombopag administered to elderly patients with acute myeloid leukemia receiving induction chemotherapy

Methods

Type of trial: multicentre, parallel-group 2-arm randomised controlled trial Country where trial is being performed: France

Follow-up: 5 years

Participants Inclusions:

- Age $\geq 60$ years

- de novo AML according to the WHO 2008 classification

- Eligible for chemotherapy

- ECOG Performance Status $<3$

- Sorror score $\leq 3$

- Informed consent to participate

- Adequate baseline organ function defined by the criteria below:

$\circ$ total bilirubin $\leq 1.5 \times$ ULN except cases clearly not indicative of inadequate liver function

$\circ$ alanine aminotransferase and aspartate aminotransferase $\leq 3 \times$ ULN

$\circ$ creatinine $\leq 2.5 \times$ ULN 
EudraCT 2015-000929-37 (Continued)

\section{Exclusions:}

$\circ$ adequate cardiac function with left ventricular ejection fraction $\geq 50 \%$

- Diagnosis of acute promyelocytic (M3) or megakaryocytic leukaemia (M7)

- AML with adverse cytogenetic according to the MRC 2010 classification

- AML secondary to myelodysplastic syndrome or myeloproliferative disease

- Previous exposure to anthracycline

- Previous AML treatment other than hydroxyurea

- Any serious medical condition, laboratory abnormality or psychiatric illness that would place the participant at an unacceptable risk or prevent them from giving informed consent

- History of thromboembolic event or other condition requiring ongoing use of anticoagulation either with warfarin or low-molecular-weight heparin

- History of another malignancy within the past 3 years except basal cell carcinoma of the skin or carcinoma in situ of the cervix

- Pre-existing cardiovascular disease (including congestive heart failure, NYHA grade III/IV) or arrhythmia known to increase the risk of thromboembolic events (e.g. atrial fibrillation), or people with a QTc > 450 msec (QTc > 480 msec for people with bundle branch block)

- Requiring platelets transfusion with platelets $>10 \times 10^{9} / \mathrm{L}$, for whatever reason

- History of treatment with romiplostim or other TPO mimetic

- Uncontrolled active infection

- Clinical symptoms suggesting active central nervous system leukaemia

- Known active HIV, hepatitis B or C infection

- Pregnancy or breastfeeding

Interventions Intervention arm:

Eltrombopag $200 \mathrm{mg} /$ day (duration not clear)

Comparator arm:

Matching placebo daily (duration not clear)

\begin{tabular}{|l} 
Primary outcomes: \\
Outcomes \\
Secondary outcomes: \\
- Response rate (complete remission) at day 45 \\
- Leukaemia-free survival at 12 months \\
- Overall survival at 2,3 and 5 years. \\
- Percentage of participants with platelets count $>100 \times 10^{9} / \mathrm{L}$ at day 45 \\
- Time to platelet transfusion independence $\left(>3\right.$ days with platelets $\left.\geq 10 \times 10^{9} / \mathrm{L}\right)$ \\
- Number of haemorrhagic events $\geq$ grade 3 up to day 45 \\
- Number of days with platelets $<10 \times 10^{9} / \mathrm{L}$ \\
- Number of platelets transfusion \\
- Time to platelets count $>100 \times 10^{9} / \mathrm{L}$ \\
- Time to neutrophil count $>0.5 \times 10^{9} / \mathrm{L}$ \\
- Time to haemoglobin $>80 \mathrm{~g} / \mathrm{L}$ \\
- Time to red blood cell transfusion independence \\
- Safety assessment of eltrombopag utilising Common Terminology Criteria for Adverse Events criteria \\
$\mathrm{v} 4$ \\
- Quality of life
\end{tabular}


EudraCT 2015-000929-37 (Continued)

Contact information Trial contact: Ariane Mineur (ariane.mineur@chu-bordeaux.fr)

Notes $\quad$ Expected number of participants: 100

Expected completion date: not reported

\section{NCT01397149}

Trial name or title

Eltrombopag in thrombocytopenic chronic lymphocytic leukemia (CLL) participants (CLL2S trial of GCLLSG)

Methods

Type of trial: multicentre parallel-group 2-arm randomised controlled trial

Country where trial is being performed: Austria and Germany

Follow-up: 7 months

Participants

Inclusions:

- Confirmed diagnosis of CLL (based immunophenotyping performed at the central reference

laboratory of the German CLL trial Group in Cologne)

- Platelet count $<50 \times 10^{9} / \mathrm{L}$ at time of screening (measured and confirmed twice)

- Receiving alkylating agents or fludarabine-based therapy (or both) as second- or higher-line treatment

- ECOG Performance Status 0 to 2

- Age $\geq 18$ years

- Signed written informed consent, according to International Conference on Harmonization - Good

Clinical Practice, and national/local regulation, prior to performing any trial-specific procedures

- Negative pregnancy test and willingness to use highly effective methods of contraception (per institutional standard) during treatment and for 6 months (male or female) after the end of treatment (adequate: oral contraceptives, intrauterine device or barrier method in conjunction with spermicidal jelly)

- Able to understand and comply with protocol requirements and instructions and intend to complete the trial as planned

- Adequate renal function (creatinine must not exceed ULN reference range by more than $50 \%$ ) at trial entry

- Adequate liver function: bilirubin $\leq 1.5 \times$ ULN. Alanine transferase or aspartate aminotransferase $\leq 3$

$\mathrm{x}$ ULN without liver involvement with CLL and $\leq 5 \mathrm{x}$ ULN in case of the liver involvement with CLL

- Prothrombin time and activated partial thromboplastin time must be within $80 \%$ to $120 \%$ of the normal range with no history of hypercoagulable state

- Total albumin must not be below the lower limit of normal by $>20 \%$

Exclusions:

- Thrombocytopenia that is primarily caused by immune thrombocytopenic purpura

- Refractory CLL: defined as treatment failure (failure to achieve a complete or partial response) or disease progression within 6 months of last fludarabine- or bendamustine- (or both) based therapy. NOTE: people refractory to rituximab monotherapy as last therapy are permitted

- No prior therapy for CLL

- Active autoimmune haemolytic anaemia requiring corticosteroid therapy > $100 \mathrm{mg}$ equivalent to hydrocortisone, or chemotherapy

- Platelet count $>50 \times 10^{9} / \mathrm{L}$ at screening

- Richter's transformation

- Central nervous system involvement of B-CLL

- Active infectious disease requiring systemic antibiotics, antifungal or antiviral treatment

Alternatives, and adjuncts, to prophylactic platelet transfusion for people with haematological malignancies undergoing intensive 
- Past or current malignancy other than CLL (with the exception of basal cell carcinoma of the skin or in situ carcinoma of the cervix or breast) unless tumour was successfully treated with curative intent at least 2 years prior to trial entry

- Clinically significant cardiac disease including unstable angina, acute myocardial infarction within 6 months, congestive heart failure, etc.

- History of significant cerebrovascular disease

- Recurring venous thrombosis or pulmonary embolism

- Glucocorticoids unless given in doses hydrocortisone $\leq 100 \mathrm{mg} /$ day (or equivalent dose of other glucocorticoids) and for exacerbations other than CLL (e.g. asthma)

- Known HIV positivity

- Active hepatitis B or C

- Treatment with an investigational drug within 30 days or 5 half-lives (whichever is longer) preceding the first dose of eltrombopag

- Known or suspected of not being able to comply with a trial protocol

- Recent history of arterial or venous thrombosis (stroke, transient ischaemic attack, myocardial infarction, deep vein thrombosis or pulmonary embolism) within the preceding 6 months

- Recurrent arterial or venous thromboembolic events

Interventions

Intervention arm:

Eltrombopag. Dose and timing to be confirmed following a phase 1 trial

Comparator arm:

Placebo matched to eltrombopag dosing regimen

Outcomes

Primary outcomes:

- Change in platelet count from 1 week before treatment to during treatment (measured 2 or 3 times/ week during treatment); and 30 days after end of treatment

\section{Secondary outcomes:}

- Adverse events up to 8 months

- Change in vital signs up to 7 months

- Change in clinical laboratory parameters up to 7 months

- Bleeding events up to 7 months

- Number of required platelet transfusions up to 7 months

- Number of chemotherapy dose delay/dose reduction up to 7 months

- CLL overall response rate up to 7 months

- Time to CLL progression up to 2 years

October 2011

Contact information Principal investigator: Stephan Stilgenbauer (stephan.stilgenbauer@uniklinik-ulm.de)

Notes

Expected number of participants: not reported

Expected completion date: November 2014 
Methods

Type of trial: multicentre cross-over randomised controlled trial

Country where trial is being performed: USA

Follow-up: 62 months

Participants

\section{Inclusions:}

- Cytomorphologically documented diagnosis of AML

- Remission status documented by a bone marrow examination up to 28 days prior to trial registration

- Recovered from induction and first consolidation (if applicable) therapy adverse effects (or $\leq$ grade 1 )

- $\geq 18$ years of age and $\leq 70$ years of age

- ECOG Performance Status 0, 1 or 2

- Willing to provide blood samples for research purposes

- Absolute neutrophil count $>1 \times 10^{9} / \mathrm{L}$

- Platelet count $>100 \times 10^{9} / \mathrm{L}$

- Total direct serum bilirubin $\leq 1.5 \times$ ULN

- Alanine aminotransferase and aspartate aminotransferase $\leq 3 \times$ ULN

- Blood urea nitrate and serum creatinine $<2$ x ULN

- Albumin $\geq 25 \mathrm{~g} / \mathrm{L}$

- Prothrombin time and partial thromboplastin time $80 \%$ to $120 \%$ of institutional normal range

- Able to swallow and retain orally administered medication

- History of central nervous system leukaemia are eligible if there is documentation of no current central nervous system involvement on cerebrospinal fluid examination within 28 days of registration

\section{Exclusions:}

- Acute promyelocytic leukaemia

- Cytotoxic drug therapy within 21 days of registration

- Haematopoietic colony stimulating growth factors within 14 days of registration

- Received packed red blood cells or platelets within 7 days of registration

- Received investigational agents within 30 days of registration or any investigational agents other than eltrombopag/placebo during trial

- Signed institutional review board-approved informed consent

- Pregnant or breastfeeding (women of childbearing potential must have a negative serum pregnancy test within 14 days of registration. Women of childbearing potential and sexually active men must use an accepted and effective method of contraception)

- Known East Asian ancestry (Chinese, Japanese, Taiwanese and Korean)

- Clinically significant gastrointestinal abnormalities such as malabsorption syndrome or major resection of the stomach or bowels

- Clinical evidence of hepatomegaly or splenomegaly

- Known risk for torsades de pointes

- Active or unresolved infection and must be off all antibiotics for at least 7 days prior to registration

- Current evidence of invasive fungal infection

- Known hepatitis B, hepatitis $\mathrm{C}$ active disease

- Known HIV seropositivity

- Prior or concomitant malignancy in the past 5 years that is currently active and likely to interfere with the participant's treatment for AML or that is likely to increase the participant's morbidity or mortality

- Prior chemotherapy or radiotherapy (unless related to AML treatment)

- Concurrent organ damage or medical problems that would prohibit therapy 


\section{NCT01656252 (Continued)}

\begin{tabular}{|c|c|}
\hline Interventions & $\begin{array}{l}\text { Intervention arm 1: } \\
\text { Cytarabine twice daily on days } 1,3 \text { and } 5 \text {. Eltrombopag (dose and schedule to be determined in Phase 1) } \\
\text { with first cycle of high-dose consolidation chemotherapy and placebo with second cycle } \\
\text { Intervention arm 2: } \\
\text { Cytarabine twice daily on days } 1,3 \text { and } 5 \text {. Placebo with first cycle of high-dose consolidation therapy and } \\
\text { eltrombopag (dose and schedule to be determined in Phase } 1 \text { ) with second cycle }\end{array}$ \\
\hline Outcomes & $\begin{array}{l}\text { Primary outcome: } \\
\text { - Platelet count recovery up to } 62 \text { months } \\
\text { Secondary outcomes: } \\
\text { - Plasma concentrations of eltrombopag in participants with AML in complete remission receiving } \\
\text { intensive consolidation chemotherapy (selected dosing regimen only) up to } 62 \text { months } \\
\text { - Platelet transfusion requirements up to } 62 \text { months } \\
\text { - Red blood cell transfusion requirements up to } 62 \text { months } \\
\text { - Bleeding event occurrence up to } 62 \text { months } \\
\text { - Time to platelet count recovery up to } 62 \text { months } \\
\text { - Impact of eltrombopag on the depth of platelet nadir following a cycle of consolidation chemotherapy } \\
\text { up to } 62 \text { months } \\
\text { - Duration of platelet nadir in the setting of eltrombopag exposure up to } 62 \text { months } \\
\text { - Safety and tolerability of eltrombopag when given at the optimal dose in the setting of consolidation } \\
\text { chemotherapy up to } 62 \text { months } \\
\text { - Exploratory: to determine if eltrombopag has an effect on TPO or EPO (or both) in this setting up to } \\
62 \text { months }\end{array}$ \\
\hline Starting date & July 2012 \\
\hline Contact information & $\begin{array}{l}\text { Principal investigator: Hillard M Lazarus (hillard.lazarus@uhhospitals.org) } \\
\text { Research nurses: Carolyn Andrews (candrews@precogllc.org) or Toni Bjurstrom (tbjurstrom@precogllc.org) }\end{array}$ \\
\hline
\end{tabular}

Notes $\quad$ Expected number of participants: 90

Expected completion date: December 2016

\section{NCT01890746}

Trial name or title A safety and efficacy trial of eltrombopag in subjects with AML

Methods Type of trial: multicentre parallel-group 2-arm randomised controlled trial Country where trial is being performed: Australia, Belgium, Canada, Greece, Hungary, Israel, Poland, Russia, South Korea and USA

Follow-up: 2 years

Participants

Inclusion:

- Age $\geq 18$ years

- Diagnosed with AML according to the WHO 2008 classification

- Eligible for induction by daunorubicin + cytarabine.

- Eligible to give informed consent to participate in the trial

- Total bilirubin $\leq 1.5 \times$ ULN except for Gilbert's syndrome, or other conditions that are not indicative of inadequate liver function (i.e. elevation of indirect bilirubin (haemolytic) in the absence of alanine 


\section{NCT01890746 (Continued)}

aminotransferase abnormality)

- Alanine aminotransferase $\leq 3 \times$ ULN

- Serum creatinine $\leq 2.5 \times$ ULN

- Left ventricular ejection fraction $\geq 50 \%$ as assessed by echocardiogram or multigated acquisition scan

- QT interval corrected for heart rate according to Bazett's formula $<450 \mathrm{msec}$ or $<480 \mathrm{msec}$ for people with bundle branch block

- Women must be either of non-childbearing potential or women with childbearing potential and men with reproductive potential must be willing to practice acceptable methods of contraception during the trial

- Men with a female partner of childbearing potential must have either had a prior vasectomy or agree to use effective contraception from time of randomisation until 30 days after the last dose of investigational product

- Women of childbearing potential must have a negative serum pregnancy test within 7 days of first dose of trial treatment and agree to use effective contraception during the trial and for 30 days following the last dose of investigational product

\section{Exclusion:}

- Diagnosis of acute promyelocytic (M3) or acute megakaryocytic leukaemia (M7)

- Previous history of exposure to an anthracycline compound

- Previous AML treatment (other than hydroxyurea)

- Any serious medical condition, laboratory abnormality or psychiatric illness that, in the view of the treating physician, would place the participant at an unacceptable risk if he or she were to participate in the trial or would prevent that person from giving informed consent

- History of thromboembolic event or other condition requiring ongoing use of anticoagulation either with warfarin or low-molecular-weight heparin. Note: occlusion of a central line is not exclusion

- Treatment with an investigational drug within 30 days or 5 half-lives, whichever is longer, preceding the first dose of trial medication

- Current and continued use during trial treatment period of known Breast cancer resistance protein inhibitors or known P-gp inhibitors.

- Known active hepatitis B, hepatitis C or HIV infection

- Known hypersensitivity to any of the trial drugs or their excipients

\section{Interventions $\quad$ Intervention arm:}

Daunorubicin bolus IV infusion on days 1 to 3 + cytarabine continuous IV infusion on days 1 to 7 followed by eltrombopag once daily orally starting on day 4 of initial induction chemotherapy. If platelet count is not $>10 \times 10^{9} / \mathrm{L}$ after 7 days, the dose will be increased until a platelet count of at least $20 \times 10^{9} / \mathrm{L}$ is achieved/ until remission is assessed/maximum of 42 days from the start of the chemotherapy induction. Participants who are not aplastic after first cycle of induction chemotherapy will receive second induction chemotherapy with a modified daunorubicin dose on days 1 to $3+$ cytarabine on days 1 to 7

\section{Comparator arm:}

Daunorubicin bolus IV infusion on days 1 to 3 + cytarabine continuous IV infusion on days 1 to 7 followed by matching placebo once daily oral dose starting on day 4 of initial induction chemotherapy. If platelet count is not $>10 \times 10^{9} / \mathrm{L}$ after 7 days, the matching placebo will be given until a platelet count of at least $20 \times 10^{9} /$ $\mathrm{L}$ is achieved/until remission is assessed/maximum of 42 days from the start of the chemotherapy induction. Participants who are not aplastic after first cycle of induction chemotherapy will receive a second induction chemotherapy with a modified daunorubicin dose on days 1 to $3+$ cytarabine on days 1 to 7

Outcomes

\section{Primary outcomes:}

- Number of participants with adverse events up to 2 years

- Change from baseline in the left ventricular ejection fraction up to 8 weeks after most recent chemotherapy cycle 


\section{NCT01890746 (Continued)}

- Left ventricular ejection fraction will be assessed by either an echocardiogram or multiple-gated acquisition scan at baseline, during the screening evaluation period, and within 14 days of final disease response assessment

- Clinical laboratory assessment as measure of safety and tolerability up to 8 weeks after most recent chemotherapy cycle

\section{Secondary outcomes:}

- Platelet transfusions up to 8 weeks after most recent chemotherapy cycle

- Time to platelet count $\geq 20 \times 10^{9} / \mathrm{L}$ and $\geq 100 \times 10^{9} / \mathrm{L}$ up to 8 weeks after most recent chemotherapy cycle. Platelet recovery defined as platelet counts $\geq 20 \times 10^{9} / \mathrm{L}$ for 3 consecutive days, unaided by transfusion

- Medical resource utilisation information pertaining to unscheduled (not scheduled per protocol) hospitalisations (i.e. total hospital days), unscheduled surgery visits, unscheduled laboratory tests and unscheduled procedures will be recorded during therapy and follow-up periods

- Proportion of participants who achieve platelet count recovery by day 21

- Duration of platelet transfusion independence, defined as a time period where participants do not receive any platelet transfusions during the treatment period and follow-up

- Time to absolute neutrophil count engraftment defined as absolute neutrophil count recovery $0.5 \times 10$

$9 / \mathrm{L}$ sustained for 3 days up to 8 weeks after most recent chemotherapy cycle

- Number of bleeding events up to 8 weeks after most recent chemotherapy cycle

- Assessment of bleeding using WHO scale will be performed throughout the trial from screening until the response bone marrow biopsy assessment. Number of bleeding events will be recorded to assess the incidence and severity of haemorrhagic events

- Overall survival at 2 years

- Off-treatment medical resource utilisation up to 8 weeks after most recent chemotherapy cycle

- Composite of pharmacokinetic parameters of daunorubicin and daunorubicinol on cycle 1 day 3 . Pharmacokinetic samples will be collected at predose; 1 minute; 0.5, 1, 3, 7, 24, 48, 72, 96, 120 and 144 hours post day 3 dose

- Composite of pharmacokinetic parameters of daunorubicin and daunorubicinol on cycle 2 day 1 .

Pharmacokinetic samples will be collected at predose; 1 minute; 0.5, 1, 3, 7 and 24 hours post day 1 dose

- Changes in absolute neutrophil counts up to 8 weeks after most recent chemotherapy cycle

- Changes in haemoglobin up to 8 weeks after most recent chemotherapy cycle

Starting date September 2013

Contact information US GSK Clinical Trials Call Center: (GSKClinicalSupportHD@gsk.com)

Notes $\quad$ Expected number of participants: 120

Expected completion date: August 2016

Popat 2015

Trial name or title Eltrombopag for post transplant thrombocytopenia

Methods Type of trial: single-centre parallel-group 2-arm randomised controlled trial

Country where trial is being performed: USA

Follow-up: 57 days 
Popat 2015 (Continued)

\begin{tabular}{l}
\hline Inclusions: \\
Participants \\
- Participants $\geq 35$ days postHSCT \\
neutrophil count $\geq 1.5 \times 10^{9} / \mathrm{L}$ anytime within the 7 days before enrolment \\
- Age $>18$ years \\
Exclusions: \\
- Recurrence or progression of primary malignancy after HSCT \\
- Alanine aminotransferase $\geq 2.5 \times$ ULN \\
- Serum bilirubin $>2 \mathrm{mg} / \mathrm{dL}$ (unless due to Gilbert's syndrome) \\
- Documented deep vein thrombosis within 1 year before enrolment on the trial, except if upper arm \\
thrombosis related to central venous catheters, within 3 months before enrolment on the trial \\
- ECOG Performance Status $>2$ \\
- Pregnancy: women of childbearing potential and men must agree to use contraception prior to trial \\
entry and for the duration of trial participation. A woman of childbearing potential is defined as a woman \\
who has not been naturally postmenopausal for at least 12 consecutive months or with no previous surgical \\
sterilisation. A negative pregnancy test result will be required before any trial drug is given
\end{tabular}

Interventions Intervention arm:

Eltrombopag $50 \mathrm{mg} /$ day orally for 8 weeks (East-Asian participants start at $25 \mathrm{mg} /$ day)

Comparator arm:

Placebo once daily orally for 8 weeks

Outcomes Primary outcome:

Number of participants with platelet count $\geq 50 \times 10^{9} / \mathrm{L}$ at day 57 without platelet transfusion

Secondary outcome:

Development of a platelet count $\geq 30 \times 10^{9} / \mathrm{L}$ at day 57 without platelet transfusion within 7 days

Starting date February 2010

Contact information Principal Investigator: Uday Popat (upopat@mdanderson.org)

Notes $\quad$ Expected number of participants: 64

Expected completion date: February 2017

Vadhan-Raj 2010

Trial name or title Study of AMG 531 to evaluate the safety \& efficacy in patients with non-Hodgkin's lymphoma (NCT00299182)

Methods Type of trial: single-centre, parallel-group factorial design randomised controlled trial

Country where trial was performed: USA

Follow-up until: not reported

Participants Inclusions:

- Participants with a diagnosis of previously untreated aggressive non-Hodgkin's lymphoma, including participants with mantle cell lymphoma, who received treatment with R-HyperCVAD and RAra-C/MTX. Participants in whom rituximab was not used, due to contraindications, were eligible. Participants whose

Alternatives, and adjuncts, to prophylactic platelet transfusion for people with haematological malignancies undergoing intensive 
Vadhan-Raj 2010 (Continued)

therapy was switched to (R)Hyper-CVAD after initial treatment with (R)CHOP, because of aggressive disease were also eligible for the trial

- Age $\geq 18$ years

- Karnofsky Performance Scale $\geq 70$

- Adequate haematological (neutrophil count $\geq 1 \times 10^{9} / \mathrm{L}$, platelet count $\geq 100 \times 10^{9} / \mathrm{L}$ and

haemoglobin $\geq 80 \mathrm{~g} / \mathrm{L}$ ), renal (serum creatinine $<2 \mathrm{mg} / \mathrm{dL}$ ), and hepatic function (total bilirubin $\leq 2 \mathrm{x}$, serum glutamate pyruvate transaminase or serum glutamate oxaloacetate transaminase $\leq 3 \mathrm{x}$ the upper limit of the respective normal range)

- Participants (men and women) with childbearing potential (defined as not postmenopausal for 12 months or no previous surgical sterilisation) had to use adequate contraception

- Institutional Review Board approved signed informed consent

\section{Exclusions:}

- Pregnant or lactating women

- History of central nervous system involvement

- Co-morbid medical or psychiatric illnesses that preclude treatment with intense dose chemotherapy

- Participants with history of deep vein thrombosis or pulmonary embolism

- History of any platelet disorders including idiopathic thrombocytopenic purpura, thrombotic thrombocytopenic purpura or bleeding disorders

- Prior surgery or radiotherapy within 2 weeks of trial entry

- Participants with significant cardiac disease (NYHA Class III or IV), dysrhythmia, or recent history of myocardial ischaemia or ischaemia, transient ischaemic attack or cerebrovascular accident within the previous 6 months of trial entry

\section{Interventions $\quad$ Intervention arm 1:}

AMG 531 at 1,3 or $10 \mu \mathrm{g} / \mathrm{kg}$ on day -5 and +5 from cycle 2 of chemotherapy up to a maximum of 6 cycles Intervention arm 2:

AMG 531 at 1,3 , or $10 \mu \mathrm{g} / \mathrm{kg}$ on day +5 and +7 from cycle 2 of chemotherapy up to a maximum of 6 cycles Comparator arm:

Placebo on either day -5 and +5 ; or on day +5 and +7

Outcomes

\section{Primary outcome:}

- Optimal biological dose of AMG 531 given to treat thrombocytopenia (low platelet counts) in participants who have received chemotherapy

\section{Secondary outcomes:}

- Bleeding

- Number of units of platelets transfused

- Duration of thrombocytopenia

- Venous thromboembolism

Starting date March 2006

Contact information Principal Investigator: Professor Vadhan-Raj (svadhanr@mdanderson.org)

Notes

Published in abstract form only. Lead investigator, Professor Vadhan-Raj (svadhanr@mdanderson.org) contacted on 13 July 2015 and 7 August 2015 requesting further information. Personal communication from Professor Vadhan-Raj on 23 August 2015 reporting that this trial will be published as a full-text article. No further information available at this point

Number of participants: 50

Completion date: April 2012

Alternatives, and adjuncts, to prophylactic platelet transfusion for people with haematological malignancies undergoing intensive 
AML: acute myeloid leukaemia; CLL: chronic lymphocytic leukaemia; IV: intravenous; msec: millisecond; ECOG: Eastern Cooperative Oncology Group; MRC: Medical Research Council; EPO: erythropoietin; NYHA: New York Heart Association; (R)CHOP: rituximab, cyclophosphamide, doxorubicin, vincristine and prednisolone; (R)Hyper-CVAD: rituximab, cyclophosphamide, doxarubicin, dexamethasone, vincristine; RAra-C/MTX: rituximab, cytarabine and methotrexate; TPO: thrombopoietin; ULN: upper limit of normal; WHO: World Health Organization. 
DATA ANDANALYSES

Comparison 1. Thrombopoietin (TPO) mimetics versus placebo or standard care

\begin{tabular}{|c|c|c|c|c|}
\hline Outcome or subgroup title & $\begin{array}{l}\text { No. of } \\
\text { studies }\end{array}$ & $\begin{array}{c}\text { No. of } \\
\text { participants }\end{array}$ & Statistical method & Effect size \\
\hline $\begin{array}{l}1 \text { Number of participants with at } \\
\text { least } 1 \text { bleeding episode }\end{array}$ & 1 & & Odds Ratio (M-H, Random, 95\% CI) & Subtotals only \\
\hline $\begin{array}{l}2 \text { Number of participants with } \\
\text { life-threatening bleeding }\end{array}$ & 3 & & Odds Ratio (M-H, Random, 95\% CI) & Totals not selected \\
\hline $2.1 \mathrm{Up}$ to 30 days & 3 & & Odds Ratio (M-H, Random, 95\% CI) & $0.0[0.0,0.0]$ \\
\hline $2.2 \mathrm{Up}$ to 90 days & 1 & & Odds Ratio (M-H, Random, 95\% CI) & $0.0[0.0,0.0]$ \\
\hline 3 Platelet transfusions & 1 & & Mean Difference (IV, Random, 95\% CI) & Subtotals only \\
\hline 4 All-cause mortality & 1 & & Odds Ratio (M-H, Random, 95\% CI) & Totals not selected \\
\hline 4.1 Up to 30 days & 1 & & Odds Ratio (M-H, Random, 95\% CI) & $0.0[0.0,0.0]$ \\
\hline $4.2 \mathrm{Up}$ to 90 days & 1 & & Odds Ratio (M-H, Random, 95\% CI) & $0.0[0.0,0.0]$ \\
\hline 5 Duration of thrombocytopenia & 1 & & Mean Difference (IV, Random, 95\% CI) & Totals not selected \\
\hline $\begin{array}{l}5.1 \text { TPO mimetic from day } \\
+1 \text { to platelet count of } 50 \times 10 \\
9 / \mathrm{L}\end{array}$ & 1 & & Mean Difference (IV, Random, 95\% CI) & $0.0[0.0,0.0]$ \\
\hline $\begin{array}{l}5.2 \text { TPO mimetic from day } \\
+7 \text { to platelet count of } 50 \times 10 \\
9 / \mathrm{L}\end{array}$ & 1 & & Mean Difference (IV, Random, 95\% CI) & $0.0[0.0,0.0]$ \\
\hline $\begin{array}{l}5.3 \text { TPO mimetic from day } \\
+4 \text { to platelet count of } 50 \times 10 \\
9 / \mathrm{L}\end{array}$ & 1 & & Mean Difference (IV, Random, 95\% CI) & $0.0[0.0,0.0]$ \\
\hline $\begin{array}{l}6 \text { Participants in complete } \\
\text { remission }\end{array}$ & 2 & & Odds Ratio (M-H, Random, 95\% CI) & Subtotals only \\
\hline $6.1 \mathrm{Up}$ to 30 days & 2 & 177 & Odds Ratio (M-H, Random, 95\% CI) & $0.99[0.30,3.29]$ \\
\hline 6.2 Up to 90 days & 1 & 120 & Odds Ratio (M-H, Random, 95\% CI) & $1.0[0.06,16.37]$ \\
\hline
\end{tabular}

Comparison 2. Prophylactic platelet transfusion versus platelet-poor plasma (PPP)

\begin{tabular}{|c|c|c|c|c|}
\hline Outcome or subgroup title & $\begin{array}{l}\text { No. of } \\
\text { studies }\end{array}$ & $\begin{array}{c}\text { No. of } \\
\text { participants }\end{array}$ & Statistical method & Effect size \\
\hline $\begin{array}{l}1 \text { Number of participants with at } \\
\text { least } 1 \text { bleeding episode }\end{array}$ & 1 & & Odds Ratio (M-H, Random, 95\% CI) & Subtotals only \\
\hline $\begin{array}{l}2 \text { Number of participants with } \\
\text { life-threatening bleeding }\end{array}$ & 1 & & Odds Ratio (M-H, Random, 95\% CI) & Subtotals only \\
\hline 3 Mortality due to bleeding & 1 & & Odds Ratio (M-H, Random, 95\% CI) & Subtotals only \\
\hline $\begin{array}{l}4 \text { Adverse events: formation of } \\
\text { anti-human leukocyte antigen } \\
\text { antibodies }\end{array}$ & 1 & & Odds Ratio (M-H, Random, 95\% CI) & Subtotals only \\
\hline
\end{tabular}




\section{Analysis I.I. Comparison I Thrombopoietin (TPO) mimetics versus placebo or standard care, Outcome I Number of participants with at least I bleeding episode.}

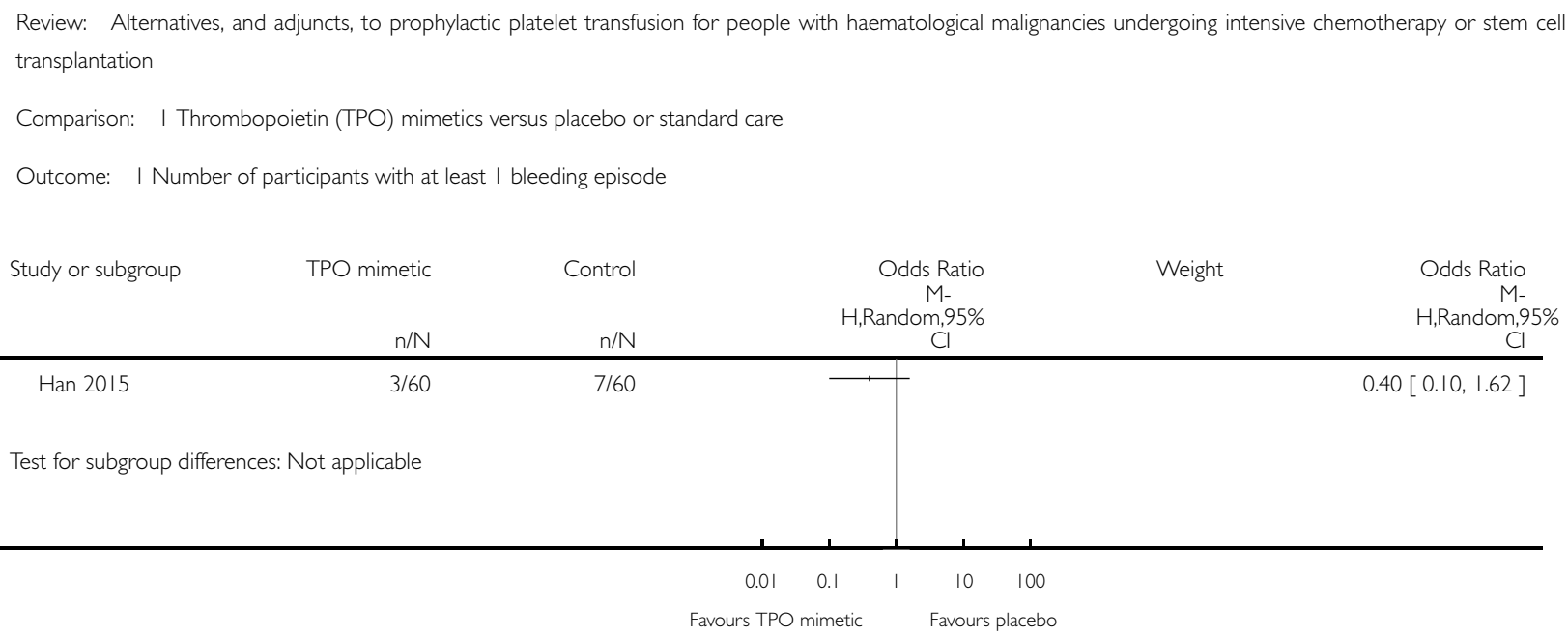

\section{Analysis I.2. Comparison I Thrombopoietin (TPO) mimetics versus placebo or standard care, Outcome 2 Number of participants with life-threatening bleeding.}

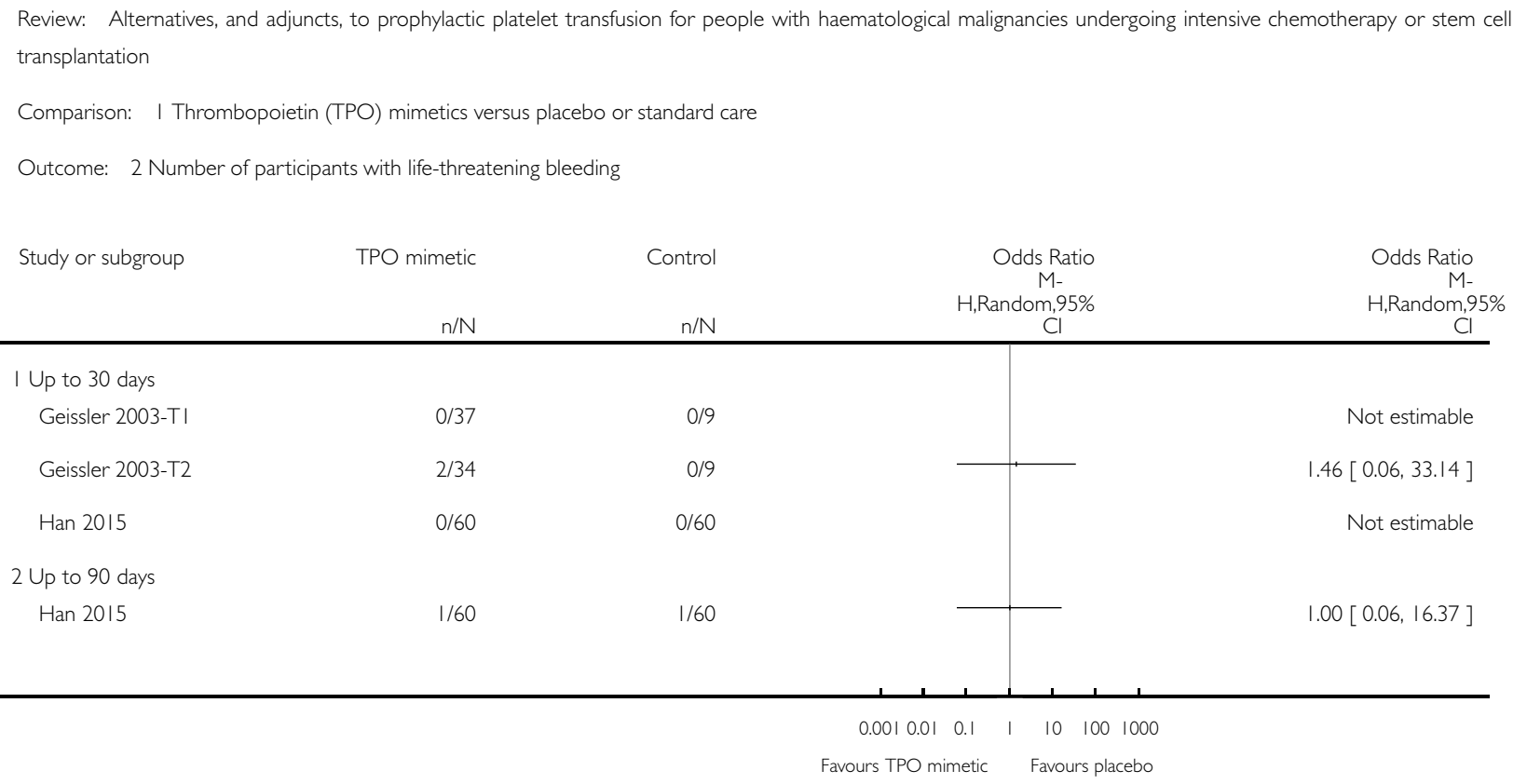

Alternatives, and adjuncts, to prophylactic platelet transfusion for people with haematological malignancies undergoing intensive chemotherapy or stem cell transplantation (Review)

Copyright $\Subset 2016$ The Cochrane Collaboration. Published by John Wiley \& Sons, Ltd. 


\section{Analysis I.3. Comparison I Thrombopoietin (TPO) mimetics versus placebo or standard care, Outcome 3}

\section{Platelet transfusions.}

Review: Alternatives, and adjuncts, to prophylactic platelet transfusion for people with haematological malignancies undergoing intensive chemotherapy or stem cell transplantation

Comparison: I Thrombopoietin (TPO) mimetics versus placebo or standard care

Outcome: 3 Platelet transfusions

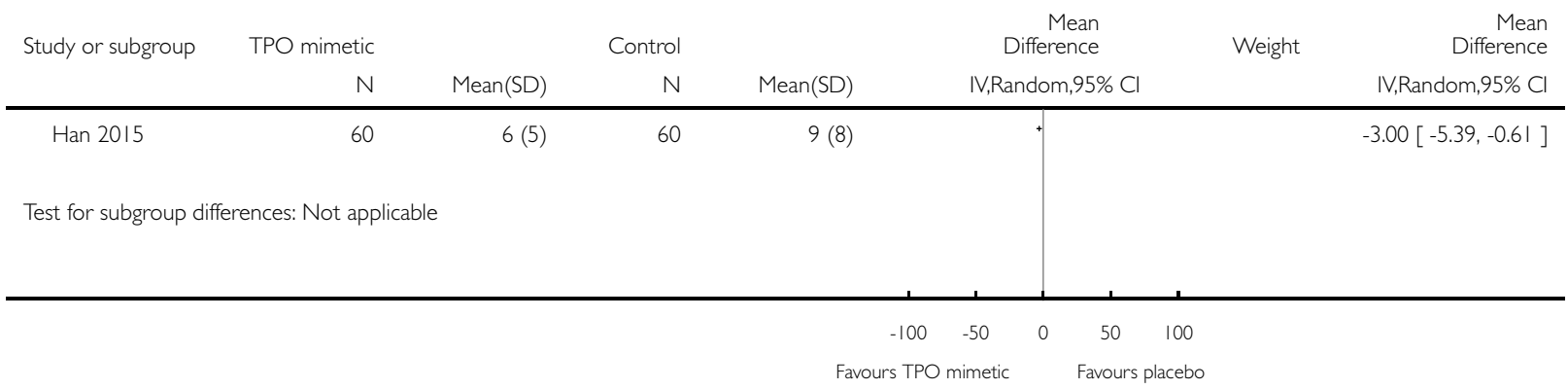




\section{Analysis I.4. Comparison I Thrombopoietin (TPO) mimetics versus placebo or standard care, Outcome 4}

All-cause mortality.

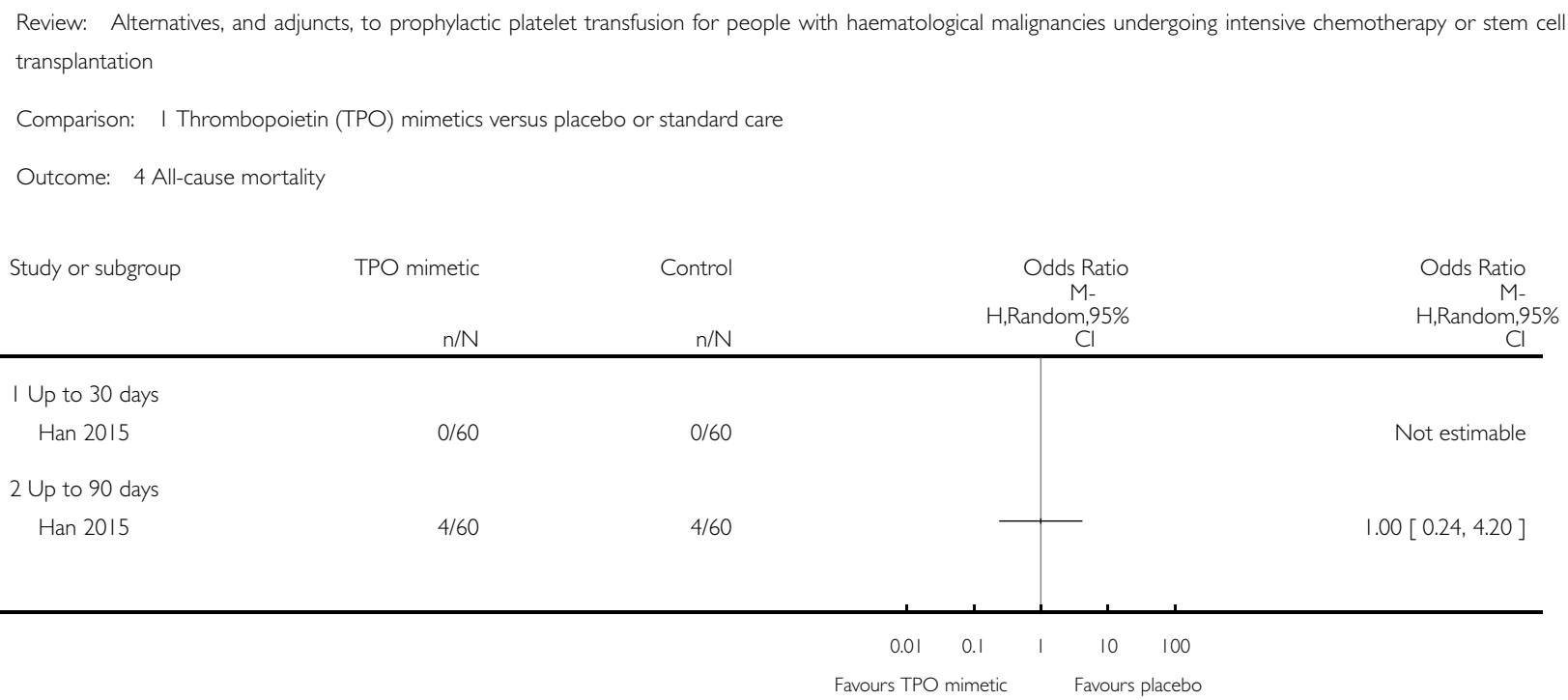

\section{Analysis I.5. Comparison I Thrombopoietin (TPO) mimetics versus placebo or standard care, Outcome 5 Duration of thrombocytopenia.}

Review: Alternatives, and adjuncts, to prophylactic platelet transfusion for people with haematological malignancies undergoing intensive chemotherapy or stem cell transplantation

Comparison: I Thrombopoietin (TPO) mimetics versus placebo or standard care

Outcome: 5 Duration of thrombocytopenia

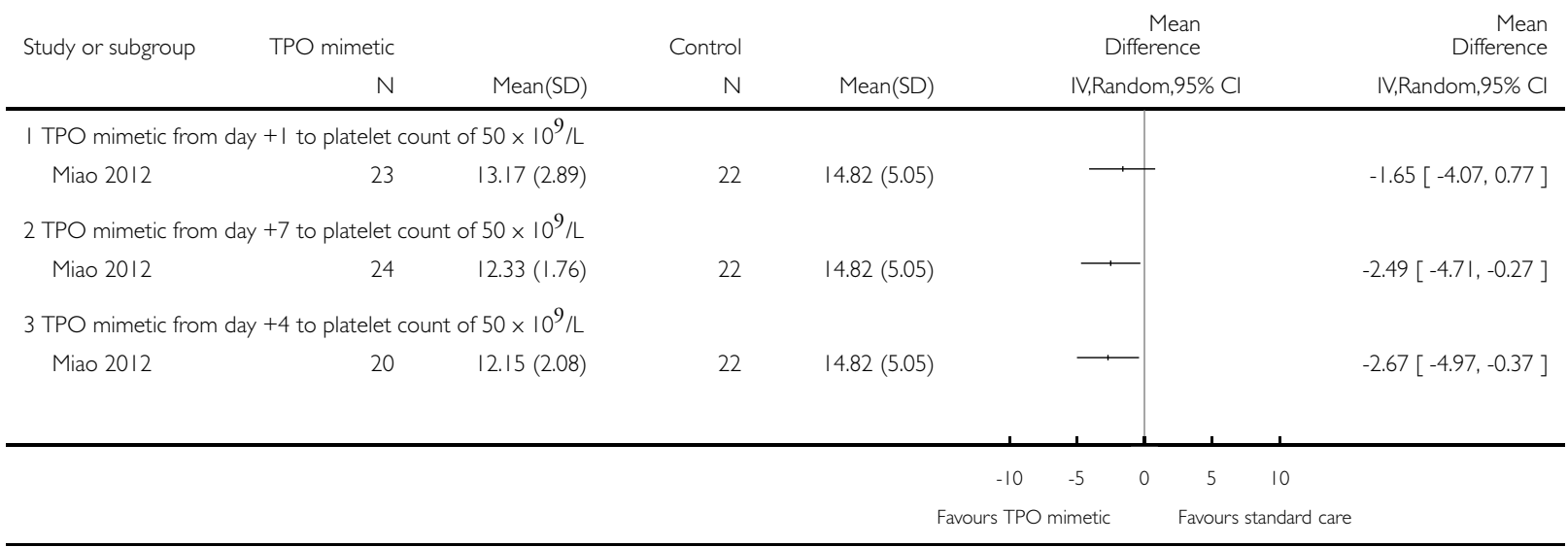

Alternatives, and adjuncts, to prophylactic platelet transfusion for people with haematological malignancies undergoing intensive 


\section{Analysis I.6. Comparison I Thrombopoietin (TPO) mimetics versus placebo or standard care, Outcome 6}

Participants in complete remission.

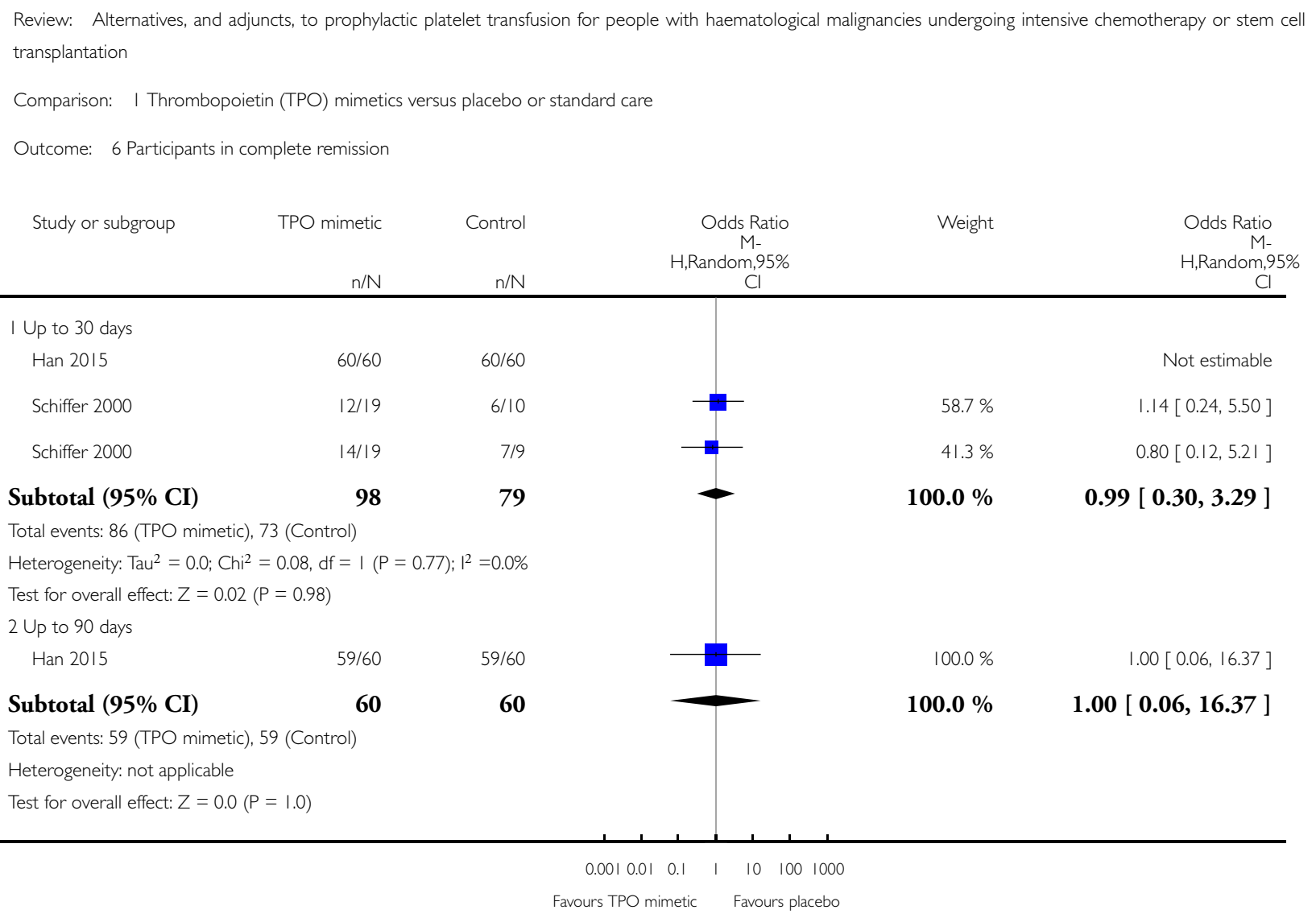


Analysis 2.I. Comparison 2 Prophylactic platelet transfusion versus platelet-poor plasma (PPP), Outcome I Number of participants with at least I bleeding episode.

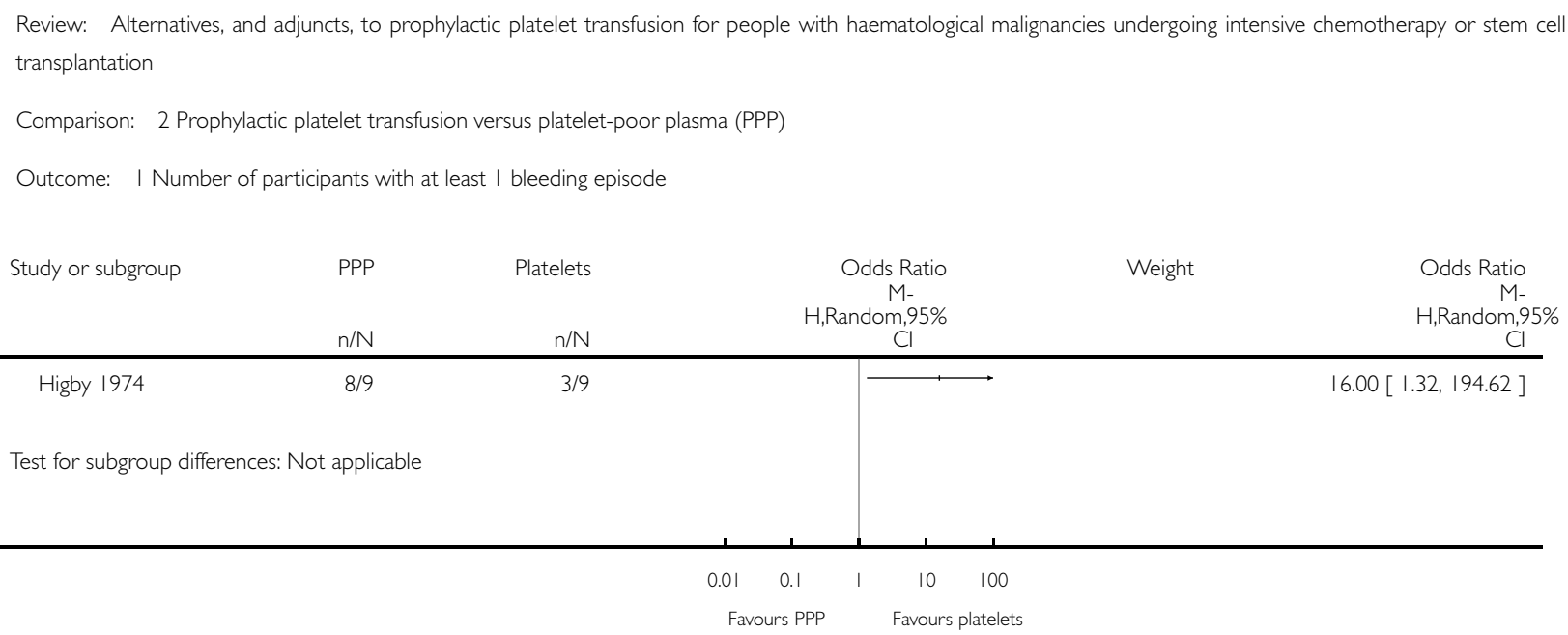

Analysis 2.2. Comparison 2 Prophylactic platelet transfusion versus platelet-poor plasma (PPP), Outcome 2 Number of participants with life-threatening bleeding.

Review: Alternatives, and adjuncts, to prophylactic platelet transfusion for people with haematological malignancies undergoing intensive chemotherapy or stem cell transplantation

Comparison: 2 Prophylactic platelet transfusion versus platelet-poor plasma (PPP)

Outcome: 2 Number of participants with life-threatening bleeding

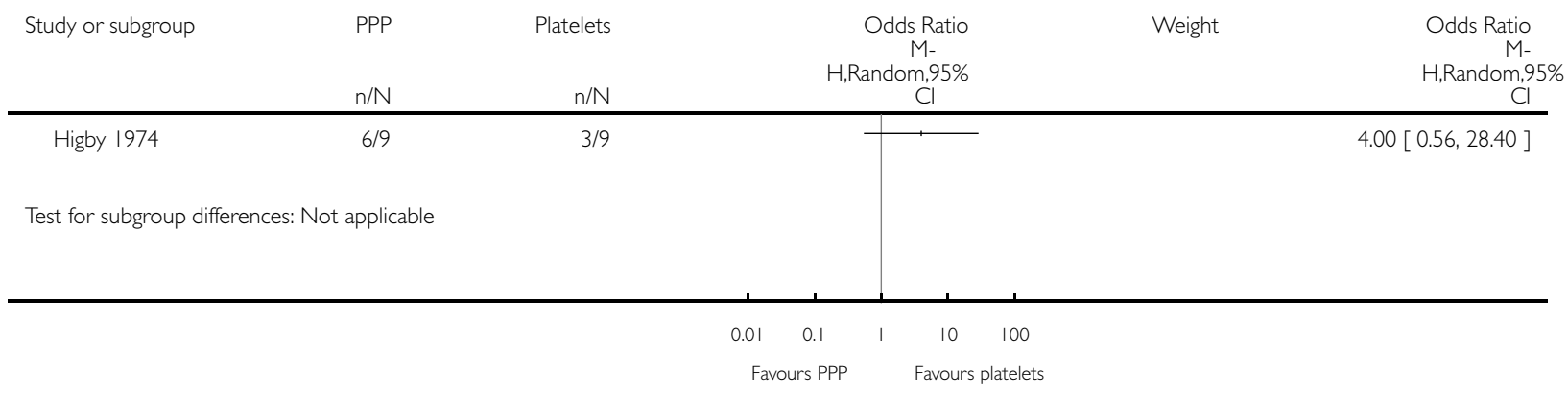


Analysis 2.3. Comparison 2 Prophylactic platelet transfusion versus platelet-poor plasma (PPP), Outcome 3 Mortality due to bleeding.

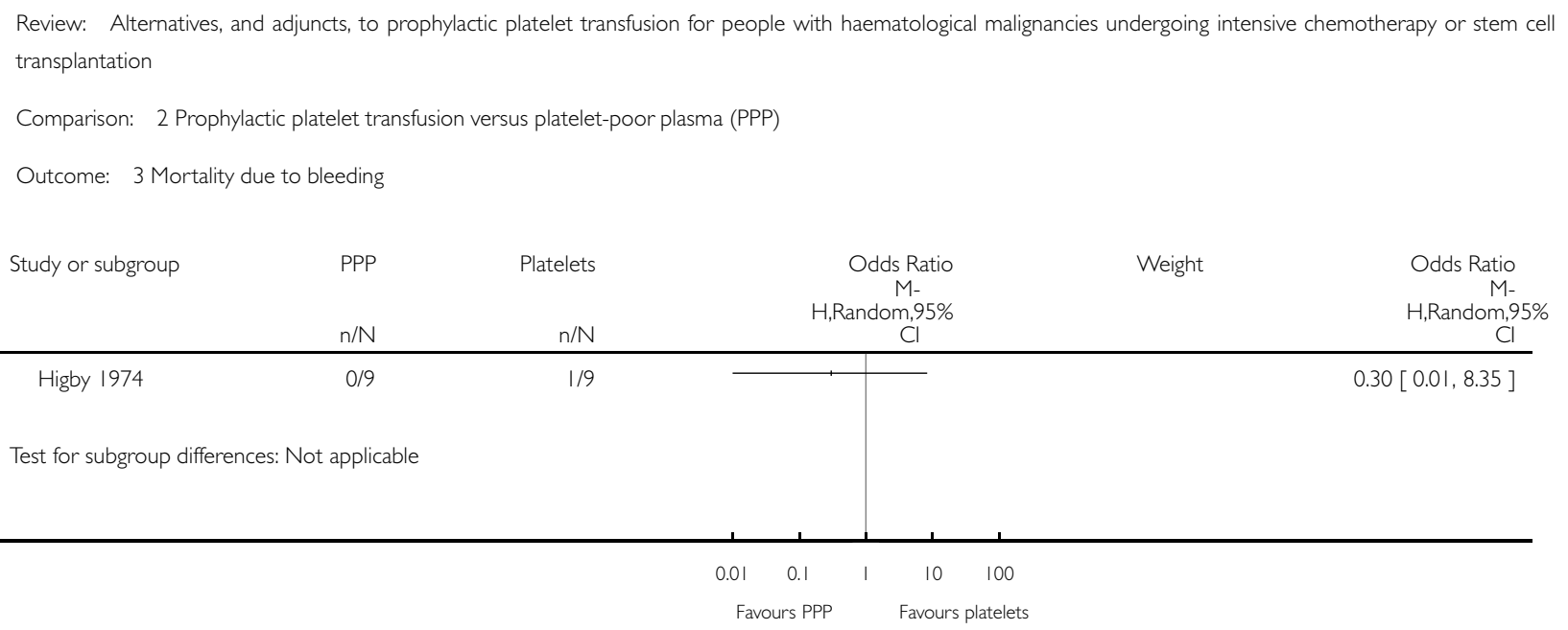

\section{Analysis 2.4. Comparison 2 Prophylactic platelet transfusion versus platelet-poor plasma (PPP), Outcome 4 Adverse events: formation of anti-human leukocyte antigen antibodies.}

Review: Alternatives, and adjuncts, to prophylactic platelet transfusion for people with haematological malignancies undergoing intensive chemotherapy or stem cell transplantation

Comparison: 2 Prophylactic platelet transfusion versus platelet-poor plasma (PPP)

Outcome: 4 Adverse events: formation of anti-human leukocyte antigen antibodies

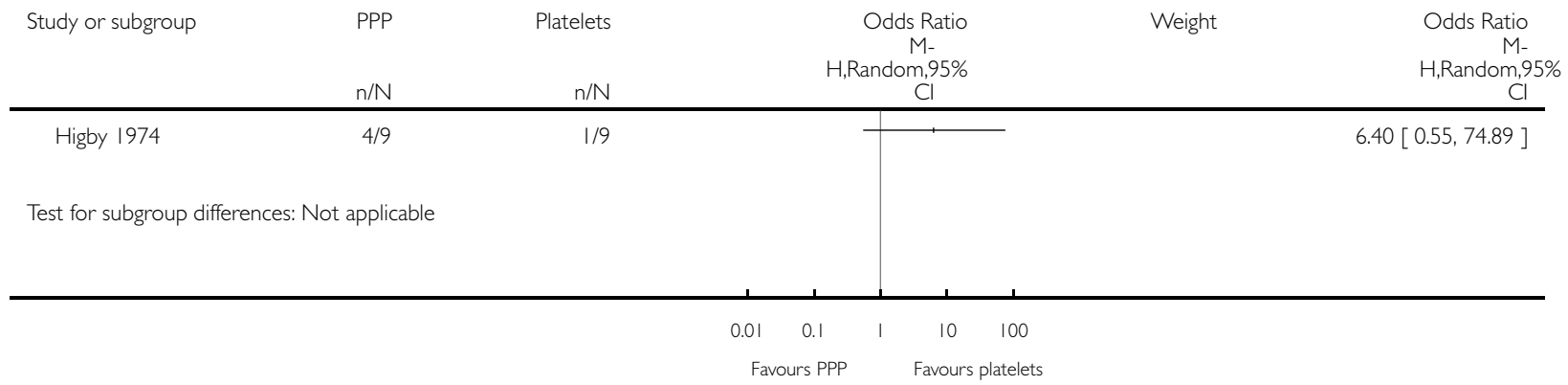




\section{A P P E N D I C E S}

\section{Appendix I. CENTRAL (the Cochrane Library) search strategy}

CENTRAL (the Cochrane Library 2016, Issue 4).

\#1 MeSH descriptor: [Hematologic Neoplasms] explode all trees

\#2 MeSH descriptor: [Hematologic Diseases] this term only

\#3 MeSH descriptor: [Leukemia] explode all trees

\#4 MeSH descriptor: [Lymphoma] explode all trees

\#5 MeSH descriptor: [Neoplasms, Plasma Cell] explode all trees

\#6 MeSH descriptor: [Anemia, Aplastic] explode all trees

\#7 MeSH descriptor: [Bone Marrow Diseases] explode all trees

\#8 MeSH descriptor: [Thrombocytopenia] explode all trees

\#9 (thrombocytopeni* or thrombocytopaeni* or leukemi* or leukaemi* or lymphom* or aplast* anemi* or aplast* anaemi* or myelodysplas* or myeloproliferat* or myelom* or plasm??ytom*)

\#10 (lymphogranulomato* or histiocy* or granulom* or thrombocythemi* or thrombocythaemi* or polycythemi* or polycythaemi* or myelofibros* or AML or CLL or CML or Hodgkin* or nonhodgkin* or reticulosis or reticulosarcom*)

\#11 (burkitt* next (lymph* or tumo?r)) or lymphosarcom* or brill-symmer* or sezary

\#12 ((haematolog* or hematolog* or blood or red cell* or white cell* or lymph* or marrow or platelet*) near/3 (malignan* or oncolog* or cancer* or neoplasm* or carcinoma*))

\#13 MeSH descriptor: [Antineoplastic Agents] explode all trees

\#14 MeSH descriptor: [Remission Induction] explode all trees

\#15 MeSH descriptor: [Antineoplastic Protocols] explode all trees

\#16 MeSH descriptor: [Stem Cell Transplantation] explode all trees

\#17 MeSH descriptor: [Bone Marrow Transplantation] this term only

\#18 MeSH descriptor: [Radiotherapy] explode all trees

\#19 MeSH descriptor: [Lymphatic Irradiation] this term only

\#20 (chemotherap* or antineoplast* or anti-neoplast* or radiotherap* or radio-therap* or chemoradiotherap* or chemo-radiotherap* or stem cell* or progenitor cell* or (bone marrow near/2 (transplant* or graft* or engraft* or rescu*))

\#21 ((haematolog* or hematolog* or hemato-oncolog* or haemato-oncolog*) near/2 patients)

\#22 (ASCT or ABMT or PBPC or PBSCT or PSCT or BMT or SCT or HSCT)

\#23 (malignan* or oncolog* or cancer*):ti

$\# 24 \# 1$ or $\# 2$ or \#3 or \#4 or \#5 or \#6 or \#7 or \#8 or \#9 or \#10 or \#11 or \#12 or \#13 or \#14 or \#15 or \#16 or \#17 or \#18 or \#19 or \#

20 or \#21 or \#22 or \#23

\#25 MeSH descriptor: [Factor VIIa] explode all trees

\#26 (factor viia or factor 7a or rfviia or fviia or novoseven* or novo seven* or eptacog* or proconvertin)

\#27 ((activated near/2 factor seven) or (activated near/2 factor vii) or (activated near/3 rfvii) or (activated near/2 fvii))

\#28 (factor seven or factor vii or factor 7):ti

$\# 29$ \#25 or \#26 or \#27 or \#28

\#30 MeSH descriptor: [Fibrinogen] explode all trees

\#31 ("fibrinogen NEXT concentrate*” or "factor I" or haemocomplettan* or riastap*)

\#32 ((platelet* or thrombocyte*) near/5 (substitute* or artificial*))

\#33 platelet-poor plasma*

$\# 34 \# 30$ or \#31 or \#32 or \#33

\#35 MeSH descriptor: [Deamino Arginine Vasopressin] explode all trees

\#36 (desmopressin* or vasopressin deamino or nocutil or octim or minurin or deamino-8-d-arginine vasopressin or vasopressin 1desamino-8-arginine or desmotabs or ddavp or or adiuretin or octostim or desmogalen)

\#37 MeSH descriptor: [Thrombopoietin] explode all trees and with qualifier(s): [Administration \& dosage - AD, Adverse effects - AE, Therapeutic use - TU]

\#38 MeSH descriptor: [Recombinant Fusion Proteins] explode all trees and with qualifier(s): [Administration \& dosage - AD, Adverse effects - AE, Therapeutic use - TU]

\#39 MeSH descriptor: [Receptors, Fc] explode all trees and with qualifier(s): [Administration \& dosage - AD, Therapeutic use - TU]

Alternatives, and adjuncts, to prophylactic platelet transfusion for people with haematological malignancies undergoing intensive 
\#40 MeSH descriptor: [Receptors, Thrombopoietin] explode all trees and with qualifier(s): [Administration \& dosage - AD, Agonists - AG, Therapeutic use - TU]

\#41 (eltrombopag* or promacta* or revolade* or romiplastin* or romiplostim* or nplate)

\#42 (amg531 or amg 531 or amg-531 or sb497115 or sb 497115 or sb-497115 or fab59 or fab 59 or fab-59 or AKR501 or AKR 501

or AKR-501 or YM477 or YM 477 or YM-477 or Peg-TPOmp*)

\#43 ((TPO or thrombopoietin) next (mimetic* or receptor agonist* or agonist* or agent*))

$\# 44 \# 35$ or \#36 or \#37 or \#38 or \#39 or \#40 or \#41 or \#42 or \#43

\#45 (((haemosta* or hemosta* or antihaemorrhag* or antihemorrhag* or anti haemorrhag* or anti-hemorrhag*) near/5 (drug* or agent* or treat* or therap*)) or ((coagulat* or clotting) adj factor $\left.\left.{ }^{*}\right)\right)$

\#46 \#29 or \#34 or \#44 or \#45

\#47 \#24 and \#46

\section{Appendix 2. MEDLINE (Ovid) search strategy}

MEDLINE (Ovid, 1946 to 19 May 2016).

1. exp Hematologic Neoplasms/ or Hematologic Diseases/

2. exp Leukemia/ or exp Lymphoma/

3. exp Neoplasms, Plasma Cell/

4. exp Anemia, Aplasticl

5. exp Bone Marrow Diseases/

6. exp Thrombocytopenia/

7. (thrombocytopeni* or thrombocytopaeni* or leukemi* or leukaemi* or lymphom* or aplast* anemi* or aplast* anaemi* or myelodysplas* or myeloproliferat* or myelom* or plasm??ytom*).tw,kf,ot.

8. (lymphogranulomato* or histiocy* or granulom* or thrombocythemi* or thrombocythaemi* or polycythemi* or polycythaemi* or myelofibros* or AML or CLL or CML or Hodgkin* or nonhodgkin* or reticulosis or reticulosarcom*).tw,kf,ot.

9. ((burkitt* adj (lymph* or tumo?r)) or lymphosarcom* or brill-symmer* or sezary).tw,kf,ot.

10. ((haematolog* or hematolog* or blood or red cell* or white cell* or lymph* or marrow or platelet*) adj3 (malignan* or oncolog* or cancer* or neoplasm*)).tw,kf,ot.

11. exp Antineoplastic Agents/ or exp Remission Induction/ or exp Antineoplastic Protocols/

12. exp Stem Cell Transplantation/ or Bone Marrow Transplantation/ or exp Radiotherapy/

13. exp Lymphatic Irradiation/

14. (chemotherap* or antineoplast* or anti-neoplast* or radiotherap* or radio-therap* or chemoradiotherap* or chemo-radiotherap* or stem cell* or progenitor cell* or (bone marrow adj2 (transplant* or graft* or engraft* or rescu*))).tw,kf,ot.

15. (ASCT or ABMT or PBPC or PBSCT or PSCT or BMT or SCT or HSCT).tw,kf,ot.

16. ((haematolog* or hematolog* or haemato-oncolog* or hemato-oncolog*) adj2 patients).tw,kf,ot.

17. (malignan* or oncolog* or cancer*).ti.

18. or/1-17

19. Factor VIIa/

20. (factor viia or factor 7a or rfviia or fviia or novoseven* or novo seven* or eptacog* or proconvertin).tw.

21. ((activated adj2 factor seven) or (activated adj2 factor vii) or (activated adj3 rfvii) or (activated adj2 fvii)).tw.

22. (factor seven or factor vii or factor 7).ti.

23. 19 or 20 or 21 or 22

24. Fibrinogen/ad, ae, sd, tu, th

25. *Fibrinogen/

26. (fibrinogen concentrate* or factor I or haemocomplettan* or riastap*).tw.

27. 24 or 25 or 26

28. ((platelet* or thrombocyte* $^{*}$ adj5 (substitute* or $\left.\left.^{\text {artificial }}{ }^{*}\right)\right)$.tw.

29. platelet-poor plasma*.tw.

30. *Deamino Arginine Vasopressin/

31. Deamino Arginine Vasopressin/ad, ae, st, tu, to

32. (desmopressin* or vasopressin deamino or nocutil or octim or minurin or deamino-8-d-arginine vasopressin or vasopressin 1 desamino-8-arginine or desmotabs or DDAVP or adiuretin or octostim or desmogalen).tw.

Alternatives, and adjuncts, to prophylactic platelet transfusion for people with haematological malignancies undergoing intensive 
33. or $/ 28-32$

34. Thrombopoietin/ad, tu

35. Recombinant Fusion Proteins/ad, tu

36. Receptors, Fc/ad, tu

37. Receptors, Thrombopoietin/ad, ag, tu

38. (eltrombopag* or promacta* or revolade* or romiplastin* or romiplostim* or nplate*).tw.

39. (amg531 or amg 531 or amg-531 or sb497115 or sb 497115 or sb-497115 or fab59 or fab 59 or fab-59 or AKR501 or AKR 501 or AKR-501 or YM477 or YM 477 or YM-477 or Peg-TPOmp*).tw.

40. ((TPO or thrombopoietin) adj (mimetic* or receptor agonist* or agonist* or agent*)).tw.

41. or/34-40

42. (((haemosta* or hemosta* or antihaemorrhag* or antihemorrhag* or anti haemorrhag* or anti-hemorrhag*) adj5 (drug* or agent* or treat* or therap* $\left.{ }^{*}\right)$ or $\left(\left(\right.\right.$ coagulat* or clotting) adj factor*) ${ }^{*}$.tw.

43. 23 or 27 or 33 or 41 or 42

44. randomized controlled trial.pt.

45. controlled clinical trial.pt.

46. randomi*.tw.47. placebo.ab.

48. clinical trials as topic.sh.

49. randomly.ab.

50. groups.ab.

51. trial.ti.

52. or/44-51

53. 18 and 43 and 52

54. ANIMALS/ not HUMANS/

55. (rats or dogs or cats or sheep or mice or mouse or murine or ovine or canine or feline or animal* or model*).ti.

56.54 or 55

57.53 not 56

\section{Appendix 3. Embase (Ovid) search strategy}

Embase (Ovid, 1974 to 19 May 2016).

1. Hematologic Malignancy/

2. Lymphoma/

3. NonHodgkin Lymphoma/

4. Hodgkin Disease/

5. exp Myeloproliferative Disorder/

6. Plasmacytoma/

7. exp Aplastic Anemia/

8. exp Thrombocytopenia/

9. (thrombocytopeni* or thrombocytopaeni* or leukemi* or leukaemi* or lymphom* or aplast* anemi* or aplast* anaemi* or myelodysplas* or myeloproliferat* or myelom* or plasm??ytom*).tw,kf,ot.

10. (lymphogranulomato* or histiocy* or granulom* or thrombocythemi* or thrombocythaemi* or polycythemi* or polycythaemi* or myelofibros* or AML or CLL or CML or Hodgkin* or nonhodgkin* or reticulosis or reticulosarcom*).tw,kf,ot.

11. ((burkitt* adj (lymph* or tumo?r)) or lymphosarcom* or brill-symmer* or sezary).tw,kf,ot.

12. ((haematolog* or hematolog* or blood or red cell* or white cell* or lymph* or marrow or platelet*) adj3 (malignan* or oncolog* or cancer* or neoplasm*)).tw,kf,ot.

13. exp Chemotherapy/

14. exp Stem Cell Transplantation/

15. exp Bone Marrow Transplantation/

16. exp Radiotherapy/

17. (chemotherap* or antineoplast* or anti-neoplast* or radiotherap* or radio-therap* or chemoradiotherap* or chemo-radiotherap* or stem cell* or progenitor cell* or (bone marrow adj2 (transplant* or graft* or engraft* or rescu*))).tw,kf,ot.

18. ((haematolog* or hematolog* or haemato-oncolog* or hemato-oncolog*) adj2 patients).tw.

Alternatives, and adjuncts, to prophylactic platelet transfusion for people with haematological malignancies undergoing intensive 
19. (ASCT or ABMT or PBPC or PBSCT or PSCT or BMT or SCT or HSCT).tw,kf,ot.

20. (malignan* or oncolog* or cancer*).ti.

21. or/1-20

22. Factor VIIa/

23. (factor viia or factor 7 a or rfviia or fviia or novoseven* or novo seven* or eptacog* or proconvertin).tw.

24. ((activated adj2 factor seven) or (activated adj2 factor vii) or (activated adj3 rfvii) or (activated adj2 fvii)).tw.

25. (factor seven or factor vii or factor 7).ti.

26. 22 or 23 or 24 or 25

27. Fibrinogen/ae, ct, ad, cb, cm, cr, dv, do, dt, to, iv, pa, sc, th

28. Fibrinogen Concentrate/

29. (fibrinogen concentrate* or factor I or haemocomplettan* or riastap*).tw.

30. 27 or 28 or 29

\left. 31. ((platelet* ${\text { or thrombocyte*) adj5 (substitute* } \text { or }^{*} \text { artificial }}^{*}\right)$ ).tw.

32. platelet-poor plasma*.tw.

33. *Desmopressin/

34. Desmopressin/ad, ae, $\mathrm{dt}$

35. (desmopressin* or vasopressin deamino or nocutil or octim or minurin or deamino-8-d-arginine vasopressin or vasopressin 1desamino-8-arginine or desmotabs or ddavp or adiuretin or octostim or desmogalen).tw.

36. or $/ 31-35$

37. *Thrombopoietin Receptor/

38. Eltrombopag/

39. Romiplostim/

40. (eltrombopag* or promacta* or revolade* or romiplastin* or romiplostim* or nplate*).tw.

41. (amg531 or amg 531 or amg-531 or sb497115 or sb 497115 or sb-497115 or fab59 or fab 59 or fab-59 or AKR501 or AKR 501 or AKR-501 or YM477 or YM 477 or YM-477 or Peg-TPOmp*).tw.

42. ((TPO or thrombopoietin) adj (mimetic* or receptor agonist* or agonist*)).tw.

43. or/37-42

44. (((haemosta* or hemosta* or antihaemorrhag* or antihemorrhag* or anti haemorrhag* or anti-hemorrhag*) adj5 (drug* or agent* or treat* or therap* $)$ ) or $(($ coagulat* or clotting) adj factor*) $)$.tw.

45.26 or 30 or 36 or 43 or 44

46. 21 and 45

47. Randomized Controlled Trial/

48. Randomization

49. Single Blind Procedure/

50. Double Blind Procedure/

51. Crossover Procedure/

52. Placebo/

53. exp Clinical Trial/

54. Prospective trial/

55. (randomi* or double-blind* or single-blind* or RCT*).tw.

56. (random* adj2 (allocat* or assign* or divid* or receiv*)).tw.

57. (crossover* ${ }^{*}$ or cross over* or cross-over* or placebo*).tw.

58. ((treble or triple) adj blind $\left.{ }^{*}\right)$.tw.

59. or/47-58

60. Case trial/

61. case report*.tw.

62. (note or editorial).pt.

63. or/60-62

64.59 not 63

65. 46 and 64

66. (animal* or cat or cats or dog or dogs or pig or pigs or sheep or rabbit* or mouse or mice or rat or rats or feline or canine or porcine or ovine or murine or model*).ti.

67.65 not 66

Alternatives, and adjuncts, to prophylactic platelet transfusion for people with haematological malignancies undergoing intensive 
68. limit 68 to embase

\section{Appendix 4. PubMed (epublications only)}

PubMed (epublications only, 19 May 2016).

\#1 (thrombocytop* OR leukemi* OR leukaemi* OR lymphoma* OR aplastic anemia OR aplastic anaemia OR myelodysplas* OR myeloproliferat* OR multiple myeloma OR plasma cell myeloma OR plasmacytoma OR thrombocythemi* OR thrombocythaemi* OR polycythemi* OR polycythaemi* OR myelofibros* OR hodgkin* OR nonhodgkin*)

\#2 ((haematolog* OR hematolog* OR blood OR red cell* OR white cell* OR lymphom* OR marrow OR platelet*) AND (malignan* OR oncolog* OR cancer OR cancers OR neoplasm* or carcinoma*))

\#3 \#1 OR \#2

\#4 (“factor viia” [TI] OR “factor 7a”[TI] OR rfviia[TI] OR fviia[TI] OR novoseven*[TI] OR "novo seven*”[TI] OR eptacog*[TI] OR proconvertin[TI] OR “fibrinogen concentrate " [TI] OR “factor I”[TI] OR haemocomplettan[TI] OR octafibrin[TI] OR riastap[TI]) \#5 "activated factor seven" [TI] OR "activated factor vii” [TI] OR "activated rfvii" [TI] OR "activated fvii" [TI]

\#6 (factor seven[TI] OR factor vii[TI] OR factor 7[TI])

\#7((platelet* OR thrombocyte*) AND (substitute* OR artificial $\left.{ }^{*}\right)$ )

\#8 (platelet-poor plasma* OR desmopressin* OR vasopressin deamino OR nocutil OR octim OR minurin OR deamino-8-d-arginine vasopressin OR vasopressin 1-desamino-8-arginine OR desmotabs OR ddavp or adiuretin OR octostim OR desmogalen)

\#9 (eltrombopag* OR promacta* OR revolade* OR romiplastin* OR romiplostim* OR nplate*)

\#10 (amg531 OR amg 531 OR amg-531 OR sb497115 OR sb 497115 OR sb-497115 OR fab59 OR fab 59 OR fab-59 OR AKR501

OR AKR 501 OR AKR-501 OR YM477 OR YM 477 OR YM-477 OR Peg-TPOmp*)

\#11 ((TPO OR thrombopoietin) AND (mimetic* OR receptor agonist* OR agonist* OR agent*))

\#12 ((haemosta* OR hemosta* OR antihaemorrhag* OR antihemorrhag* OR anti haemorrhag* OR anti-hemorrhag*) AND (drug OR drugs OR agent* OR treatment* OR therapy OR therapies)) OR (coagulat* factor OR clotting factor OR coagulat* factors OR clotting factors))

\#13 \#4 OR \#5 OR \#6 OR \#7 OR \#8 OR \#9 OR \#10 OR \#11 OR \#12

\#14 \#3 AND \#13

\#15 (random* OR blind* OR control group* OR placebo OR controlled trial OR controlled trial OR trials OR systematic review OR meta-analysis OR metaanalysis OR literature OR medline OR cochrane OR embase) AND ((publisher[sb] OR inprocess[sb]) NOT pubstatusnihms)

\#16 \#14 AND \#15

\section{Appendix 5. CINAHL (EBSCOhost) search strategy}

CINAHL (EBSCOhost, 1982 to 19 May 2016).

S1 (MH "Hematologic Neoplasms+")

S2 (MH Leukemia+)

S3 (MH Lymphoma+)

S4 (MH "Plasmacytoma+")

S5 (MH "Anemia, Aplastic+")

S6 (MH "Bone Marrow Diseases+")

S7 (MH Thrombocytopenia+)

S8 (thrombocytopeni* or thrombocytopaeni* or leukemi* or leukaemi* or lymphom* or aplast* anemi* or aplast* anaemi* or myelodysplas* or myeloproliferat* or myelom* or plasm??ytom*)

S9 (lymphogranulomato* or histiocy* or granulom* or thrombocythemi* or thrombocythaemi* or polycythemi* or polycythaemi* or myelofibros* or AML or CLL or CML or Hodgkin* or nonhodgkin* or reticulosis or reticulosarcom*)

S10 (burkitt* lymph* or burkitt* tumo?r or lymphosarcom* or brill-symmer* or sezary)

S11 ((haematolog* or hematolog* or blood or red cell* or white cell* or lymph* or marrow or platelet*) N3 (malignan* ${ }^{*}$ or oncolog* ${ }^{*}$ cancer* or neoplasm* or carcinoma*))

S12 ((haematolog* or hematolog* or blood or red cell* or white cell* or lymph* or marrow or platelet*) N3 (malignan* or oncolog* ${ }^{*}$ or cancer* or neoplasm* or carcinoma*))

S13 (MH “Antineoplastic Agents+")

Alternatives, and adjuncts, to prophylactic platelet transfusion for people with haematological malignancies undergoing intensive 
S14 (MH "Hematopoietic Stem Cell Transplantation")

S15 (MH "Bone Marrow Transplantation")

S16 (MH Radiotherapy+)

S17 (chemotherap* or antineoplast* or anti-neoplast* or radiotherap* or radio-therap* or chemoradiotherap* or chemo-radiotherap* or stem cell* or progenitor cell* or (bone marrow N2 (transplant* or graft* or engraft* or rescu*)))

S18 ((haematolog* or hematolog* or haemato-oncolog* or hemato-oncolog*) N2 patients)

S19 (ASCT or ABMT or PBPC or PBSCT or PSCT or BMT or SCT or HSCT)

S20 TI (malignan* or oncolog* or cancer*)

S21 S1 OR S2 OR S3 OR S4 OR S5 OR S6 OR S7 OR S8 OR S9 OR S10 OR S11 OR S12 OR S13 OR S14 OR S15 OR S16 OR S17 OR S18 OR S19

S22 (MH "BLOOD COAGULATION FACTORS+")

S23 (factor viia or factor 7a or rfviia or fviia or novoseven* or novo seven* or eptacog* or proconvertin or fibrinogen concentrate* or factor I OR haemocomplettan* OR octafibrin* OR riastap*)

S24 ((activated N2 factor seven) or (activated N2 factor vii) or (activated N3 rfvii) or (activated N2 fvii))

S25 TI (factor seven or factor vii or factor 7)

S26 ((platelet* or thrombocyte*) N5 (substitute* or artificial*))

S27 platelet-poor plasma*

S28 (MH Desmopressin)

S29 (desmopressin* or vasopressin deamino or nocutil or octim or minurin or deamino-8-d-arginine vasopressin or vasopressin 1desamino-8-arginine or desmotabs or ddavp or adiuretin or octostim or desmogalen)

S30 (MH "Benzoic Acids Therapeutic Use")

S31 (MH "Receptors, Cell Surface Therapeutic Use")

S32 (eltrombopag* or promacta* or revolade* or romiplastin* or romiplostim* or nplate*)

S33 (amg531 or amg 531 or amg-531 or sb497115 or sb 497115 or sb-497115 or fab59 or fab 59 or fab-59 or AKR501 or AKR 501 or AKR-501 or YM477 or YM 477 or YM-477 or Peg-TPOmp*)

S34 ((TPO or thrombopoietin) W1 (mimetic* or receptor agonist* or agonist* or agent*))

S35 (( (haemosta* or hemosta* or antihaemorrhag* or antihemorrhag* or anti haemorrhag* or anti-hemorrhag*) N5 (drug* or agent* or treat* or therap*) $\left.{ }^{*}\right)$ or ((coagulat* or clotting) W1 factor*))

S36 S22 OR S23 OR S24 OR S25 OR S26OR S27 OR S28 OR S29 OR S30 OR S31 OR S32 OR S33 OR S34 OR S35

S37 S21 AND S36

S38 (MH CLINICAL TRIALS+)

S39 PT Clinical Trial

S40 TI ((controlled trial $\left.{ }^{*}\right)$ or $\left(\right.$ clinical trial $\left.\left.{ }^{*}\right)\right)$ OR AB ((controlled trial*) or (clinical trial $\left.\left.{ }^{*}\right)\right)$

S41 TI ((singl* blind*) OR (doubl* blind*) OR (trebl* blind*) OR (tripl* blind*) OR (singl* mask*) OR (doubl* mask*) OR (tripl* mask $\left.{ }^{*}\right)$ ) OR AB ((singl* blind $\left.{ }^{*}\right)$ OR (doubl* blind $\left.{ }^{*}\right)$ OR (trebl* blind*) OR (tripl* blind ${ }^{*}$ ) OR (singl* mask*) OR (doubl* mask*) OR $\left(\right.$ tripl* $\left.\left.^{*} \operatorname{mask}^{*}\right)\right)$

S42 TI randomi* OR AB randomi*

S43 MH RANDOM ASSIGNMENT

S44 TI ((phase three) or (phase III) or (phase three)) or AB ((phase three) or (phase III) or (phase three))

S45 TI (random* N2 (assign* or allocat*)) ) OR ( AB (random* N2 (assign* or allocat*))

S46 MH PLACEBOS

S47 MH QUANTITATIVE STUDIES

S48 TI placebo* OR AB placebo*

S49 S38 OR S39 OR S40 OR S41 OR S42 OR S43 OR S44 OR S45 OR S46 OR S47 OR S48

S50 S37 AND S49

Alternatives, and adjuncts, to prophylactic platelet transfusion for people with haematological malignancies undergoing intensive 


\section{Appendix 6. Transfusion Evidence Library search strategy}

UKBTS/SRI Transfusion Evidence Library (www.transfusionevidencelibrary.com) (1950 to 19 May 2016).

Clinical Specialty: Haematology, Malignant AND Subject Area: Alternatives to Blood

OR

Keywords: (malignancy OR malignancies OR cancer OR cancers OR stem cell transplantation OR chemotherapy OR leukemia OR leukaemia OR lymphoma OR hodgkin OR hodgkins OR nonhodgkin OR aplastic OR thrombocytopenia OR thrombocytopenic OR myeloma OR plasmacytoma OR myelodysplasia) AND (antifibrinolytics OR factor viia OR fibrinogen OR haemocomplettan OR platelet-poor plasma* OR eltrombopag* OR promacta* OR revolade* OR romiplastin* OR romiplostim* OR nplate* OR agonist or $\mathrm{TPO})$ )

\section{Appendix 7. Web of Science (CPCI-S) search strategy}

Web of Science: Conference Proceedings Citation Index-Science (CPCI-S) (Thomson Reuters, 1990 to 19 May 2016).

Topic: (“factor viia” OR “factor 7a” OR rfviia OR fviia OR novoseven OR “novo seven” OR eptacog OR proconvertin OR “fibrinogen concentrate" OR "factor I" OR haemocomplettan OR octafibrin OR riastap OR "activated factor seven” OR "activated factor vii" OR "activated rfvii” OR “activated fvii” OR “factor seven” OR “factor vii” OR “factor 7” OR "platelet-poor plasma” OR desmopressin OR eltrombopag OR promacta OR revolade OR romiplastin OR romiplostim OR nplate OR “thrombopoietin receptor*” OR "thrombopoietin agonist*" OR "thrombopoietin mimetic*”) AND

Topic: (thrombocytop* OR leukemi* OR leukaemi* OR lymphoma* OR aplastic anemia OR aplastic anaemia OR myelodysplas* OR myeloproliferat* OR myeloma OR plasmacytoma OR thrombocythemi* OR thrombocythaemi* OR polycythemi* OR polycythaemi* OR myelofibros* OR Hodgkin* OR haematological OR hematological)) AND

Topic: (systematic* OR random* OR blind* OR trial* OR control*)

\section{Appendix 8. LILACS search strategy}

Lilacs (BIREME/PAHO/WHO, 1982 to 19 May 2016).

((“factor viia" OR "factor 7a" OR rfviia OR fviia OR novoseven OR “novo seven” OR eptacog OR proconvertin OR "fibrinogen concentrate” OR "factor I" OR haemocomplettan OR octafibrin OR riastap OR “activated factor seven” OR "activated factor vii” OR "activated rfvii” OR "activated fvii” OR "factor seven” OR "factor vii" OR "factor 7" OR "platelet-poor plasma” OR desmopressin OR eltrombopag OR promacta OR revolade OR romiplastin OR romiplostim OR nplate OR “thrombopoietin receptor\$” OR “thrombopoietin agonist\$” OR “thrombopoietin mimetic\$”) AND (thrombocytop\$ OR leukemi\$ OR leukaemi\$ OR lymphoma\$ OR aplastic anemia OR aplastic anaemia OR myelodysplas\$ OR myeloproliferat\$ OR myeloma OR plasmacytoma OR hrombocythemi\$ OR thrombocythaemi \$ OR polycythemi\$ OR polycythaemi \$ OR myelofibros\$ OR Hodgkin \$ OR haematological OR hematological)) AND db:(“LILACS”) AND type of trial:(“clinical' trials" OR "systematic' reviews")

\section{Appendix 9. IndMed search strategy}

IndMed (ICMR-NIC, 1985 to 19 May 2016).

((factor viia OR rfvii OR rfviia OR fvii OR fviia OR factor seven OR factor vii OR novoseven OR novo seven OR eptacog OR proconvertin OR fibrinogen OR factor I OR haemocomplettan OR octafibrin OR riastap OR platelet-poor plasma OR desmopressin OR eltrombopag OR promacta OR revolade OR romiplastin OR romiplostim OR nplate OR thrombopoietin receptor OR thrombopoietin agonist OR thrombopoietin mimetic) AND (thrombocytopenia OR leukemia OR leukaemia OR lymphoma OR aplastic OR myelodysplasia OR myeloproliferative OR myeloma OR plasmacytoma OR thrombocythemia OR thrombocythaemia OR polycythaemia OR myelofibrosis OR Hodgkin OR nonhodgkin OR haematological OR hematological OR haematopoietic OR hematopoietic) AND (randomized OR randomised OR randomly OR blind OR blinded OR trial OR control group)

Alternatives, and adjuncts, to prophylactic platelet transfusion for people with haematological malignancies undergoing intensive 


\section{Appendix 10. KoreaMed and PakMediNet search strategy}

KoreaMed (KAMJE, 1997 to 19 May 2016). PakMediNet (2001 to 19 May 2016).

"factor viia"[ALL] AND "Randomized Controlled Trial” [PT]

novoseven[ALL] AND "Randomized Controlled Trial” [PT]

fibrinogen[ALL] AND "Randomized Controlled Trial” [PT]

haemocomplettan[ALL] AND "Randomized Controlled Trial” [PT]

octafibrin[ALL] AND "Randomized Controlled Trial” [PT]

riastap[ALL] AND "Randomized Controlled Trial” [PT]

"platelet-poor plasma” [ALL] AND "Randomized Controlled Trial” [PT]

desmopressin[ALL] AND "Randomized Controlled Trial” [PT]

eltrombopag[ALL] AND "Randomized Controlled Trial" [PT]

promacta[ALL] AND "Randomized Controlled Trial” [PT]

revolade[ALL] AND "Randomized Controlled Trial” [PT]

romiplostim[ALL] AND "Randomized Controlled Trial" [PT]

nplate[ALL] AND "Randomized Controlled Trial” [PT]

"thrombopoietin receptor agonist*"[ALL] "Randomized Controlled Trial" [PT]

\section{Appendix I I. ClinicalTrials.gov and ICTRP search strategy}

Clinicaltrials.gov and World Health Organization International Clinical Trials Registry (ICTRP) (apps.who.int/ trialsearch/) for ongoing trials to 19 May 2016.

Search Terms/Title: randomized OR randomised

Conditions: hematological neoplasm OR hematological malignancies OR leukemia OR lymphoma OR thrombocytopenia OR multiple myeloma OR plasmacytoma OR aplastic anemia OR thrombocythemia OR polycythemia OR myelofibrosis OR hodgkin OR nonhogkin OR plasmacytoma

Intervention: factor viia OR rFVIIa OR recombinant factor vii OR activated factor vii OR desmopressin OR eptacog OR proconvertin OR fibrinogen concentrate OR haemocomplettan OR octafibrin OR riastap OR platelet-poor plasma OR eltrombopag OR promacta OR revolade OR romiplostim OR thrombopoietin receptor agonist

\section{Appendix 12. ISRCTN search strategy}

ISRCTN Register (www.controlled-trials.com/isrctn/) for ongoing trials to 19 May 2016.

Text: random OR randomised OR randomized OR randomly

Condition: (hematological OR haematological OR leukemia OR leukaemia OR lymphoma OR thrombocytopenia OR myeloma OR aplastic OR thrombocythemia OR polycythemia OR myelofibrosis OR hodgkin OR nonhodgkin OR plasmacytoma) AND

Intervention: factor viia OR rFVIIa OR factor vii OR novoseven OR desmopressin OR eptacog OR proconvertin OR fibrinogen concentrate OR haemocomplettan OR octafibrin OR riastap OR platelet-poor plasma OR eltrombopag OR promacta OR revolade OR romiplostim OR nplate OR receptor agonist)

\section{Appendix 13. EU Clinical Trials Register search strategy}

EU Clinical Trials Register (www.clinicaltrialsregister.eu/ctr-search) for ongoing trials to 19 May 2016.

(hematological OR haematological OR leukemi* OR leukaemi* OR lymphoma OR thrombocytopeni* OR myeloma OR aplastic OR thrombocythemia OR polycythemia OR myelofibrosis OR hodgkin* OR nonhodgkin* OR plasmacytoma) AND (novoseven OR rFVIIa OR desmopressin OR eptacog OR proconvertin* OR fibrinogen OR haemocomplettan* OR octafibrin* OR riastap* OR eltrombopag* OR promacta* OR revolade* OR romiplostim* OR nplate* OR thrombopoietin) AND random*

OR

factor viia AND random*

OR

recombinant factor vii AND random*

OR

Alternatives, and adjuncts, to prophylactic platelet transfusion for people with haematological malignancies undergoing intensive 
platelet-poor plasma AND random*

\section{Appendix 14. Hong Kong Clinical Trials Registry search strategy}

Hong Kong Clinical Trials Register (www.hkclinicaltrials.com/) for ongoing trials to 19 May 2016.

Disease Group: Blood and blood-forming organs

Title: randomized OR randomised

\section{WHAT'S NEW}

Last assessed as up-to-date: 19 May 2016.

\begin{tabular}{|c|c|c|}
\hline Date & Event & Description \\
\hline 19 May 2016 & New search has been performed & New search performed. \\
\hline
\end{tabular}

\section{H I S T O R Y}

Protocol first published: Issue 3, 2014

Review first published: Issue 8, 2016

\begin{tabular}{l|l|l}
\hline Date & Event & Description \\
\hline 6 March 2014 & New citation required but conclusions have not changed & $\begin{array}{l}\text { The previous review (Estcourt 2012b) has now been } \\
\text { split in to five separate reviews. Protocols have been } \\
\text { published for these five separate reviews (Desborough } \\
\text { 2016; Estcourt 2014e; Estcourt 2014b; Estcourt 2014c; } \\
\text { Estcourt 2014d). } \\
\text { Two new outcomes have been added to the protocol ( } \\
\text { Estcourt 2014b) (platelet transfusion interval, quality of } \\
\text { life) } \\
\text { The primary and secondary outcomes have been re- } \\
\text { ported over time-frames prespecified within the protocol } \\
\text { (Estcourt 2014b) } \\
\text { A new search strategy was created for this review and all } \\
\text { studies were identified using this new search strategy }\end{array}$ \\
\hline
\end{tabular}




\section{CONTRIBUTIONSOFAUTHORS}

MD: searching, selection of trials, eligibility and quality assessment, data extraction and analysis, and content expert.

LE: protocol development, searching, selection of trials, eligibility and quality assessment, data extraction and analysis, and content expert.

CD: protocol development, searching and selection of trials.

MT: protocol development and statistical expert.

$\mathrm{SH}$ : protocol development and methodological expert.

SS: protocol development and content expert.

MM: protocol development and content expert.

\section{DECLARATIONSOF INTEREST}

MD: none declared.

LE: partly funded by the NIHR Cochrane Programme Grant - Safe and Appropriate Use of Blood Components.

CD: none declared.

MT: partly funded by the NIHR Cochrane Programme Grant - Safe and Appropriate Use of Blood Components.

SH: partly funded by the NIHR Cochrane Programme Grant - Safe and Appropriate Use of Blood Components.

SS: none declared.

MM: none declared.

\section{SOURCES OF SUPPORT}

\section{Internal sources}

- NHS Blood and Transplant, Research and Development, UK.

To support the work of the Systematic Review Initiative

\section{External sources}

- Cochrane Haematological Malignancies Group, Germany.

(Editorial support)

- National Institute of Health Research (NIHR) Cochrane Programme Grant, UK.

To provide funding for systematic reviewers and methodological support from the Centre for Statistics in Medicine, Oxford 


\section{DIFFERENCESBETWEEN PROTOCOLANDREVIEW}

Postprotocol changes to the review

\section{Data synthesis}

In the protocol we prespecified that we would use the fixed-effect model for analysis. However, there were considerable small baseline differences between the trials resulting in clinical heterogeneity and we considered the random-effects model to be more appropriate in order to take account of this (Estcourt 2014b).

We did not prespecify in the protocol how we would deal with any unit of analysis issues.

\section{Multi-arm trials}

We managed multi-arm trials by splitting results from the control arm equally between the intervention arms.

\section{Cross-over trials}

We found no cross-over trials.

\section{Cluster-randomised trials}

We found no cluster randomised trials.

Aspects of the protocol that were not implemented due to lack of data

\section{Interventions}

The following interventions were not included in any trials and consequently could not be analysed:

- artificial platelet substitutes;

- recombinant activated factor VIIa;

- fibrinogen;

- desmopressin.

\section{Publication bias}

We did not perform a formal assessment of publication bias (small-trial bias) because the review included fewer than 10 trials (Sterne 2011). 


\section{Primary outcomes}

No trial reported data on any of the following primary outcomes and consequently we performed no analysis.

- Total number of days on which bleeding occurred per participant.

- Time from randomisation to first bleeding episode.

\section{Secondary outcomes}

No trial reported data on any of the following secondary outcomes and consequently we performed no analysis.

- Number of red cell transfusions per participant.

- Number of red cell components per participant.

- Platelet transfusion interval.

- Proportion of participants requiring additional interventions to stop bleeding.

- Total time in hospital from start of trial.

- Quality of life.

\section{Subgroup analyses}

Analysis of subgroups could not be performed due to problems with trial reporting. Planned subgroup analyses included:

- presence of fever (greater than $38^{\circ} \mathrm{C}$ );

- underlying disease;

- type of treatment (autologous HSCT, allogeneic HSCT, or chemotherapy alone);

- age of participant (paediatric, adults, older adults (over 60 years)).

\section{Heterogeneity}

We did not perform assessment of heterogeneity between trials due to the lack of standardised reporting of outcomes.

\section{Sensitivity analyses}

Sensitivity analysis was not performed due to an inadequate number of adequately reported trials.

\section{For future updates of this review}

\section{Unit of analysis issues}

We did not prespecify in the protocol (Estcourt 2014b) how we would deal with unit of analysis issues. For future updates of the review we plan to deal with unit of analysis issues in the following manner.

\section{Multi-arm trials}

When dose and timing are sufficiently similar between subgroups and separate meta-analysis is not necessary, we will include them in the same analysis by splitting the control group data. 


\section{Cross-over trials}

We will not assess outcomes that would be compromised by a cross-over design: mortality, proportion of participants in complete remission and quality of life. We will assess other outcomes if the timing of the outcome measure occurs before the cross-over and if outcomes after the cross-over are not biased by the treatment before the cross-over. This will be determined individually for each trial.

\section{Cluster-randomised trials}

We will analyse cluster-randomised trials at the individual participant level but will take into account the cluster design and will seek statistical advice.

\section{Sensitivity analyses}

We will assess the robustness of the overall results with a sensitivity analysis with respect to those trials deemed to be at high risk of bias. For dichotomous data, we will assess the influence of participant drop-out, analysing separately randomised controlled trials (RCTs) with less than $20 \%$ drop-out, RCTs with $20 \%$ to $50 \%$ drop-out and RCTs with greater than 50\% drop-out. We will use the randomeffects model for sensitivity analyses as part of the exploration of heterogeneity.

\section{NOT E S}

The previous review Estcourt 2012b has now been split into four separate reviews.

\section{Glossary of terms used in this review}

\section{Acute myeloid leukaemia}

New blood cells are normally made in the bone marrow in a controlled way. Acute myeloid leukaemia is a cancer where the bone marrow makes too many of one type of blood cell. This can fill the bone marrow and stop it making normal blood cells.

\section{Allogeneic transfusion}

A blood transfusion where the blood has been donated by another person. This is compared to autologous where a person's own blood is taken from them and then given back at a later date.

\section{Antifibrinolytic agent}

After a blood clot has been formed and bleeding has stopped, it is broken down again as part of the healing process. Fibrinolysis is the process of breaking down blood clots. Antifibrinolytic agents block this process, meaning that the clots are present for longer.

\section{Artificial platelets}

Platelets are made from donated blood. Platelets, or agents that act like platelets, can be made in a laboratory instead. There are many different approaches to doing this. For this review, we use the umbrella term: artificial platelets. 


\section{Bone marrow}

Bone marrow is found inside bones. It contains blood-producing stem cells. The bone marrow stem cells make red cells (which transport oxygen around the body), white cells (which fight infection) and platelets.

\section{Desmopressin}

Desmopressin is a modified version of a hormone (chemical messenger) that is usually made by the body. It works by increasing the number of proteins involved in blood clotting. It also makes platelets more active.

\section{Fibrinogen concentrate}

Fibrinogen is a protein made by the liver. It is found in the blood and is involved in normal blood clotting. Fibrinogen concentrate is purified fibrinogen made from pooling together the blood of many different blood donors.

\section{Intensive chemotherapy}

Chemotherapy is the use of drugs to treat cancer. In the treatment of many blood, lymph node and bone marrow cancers, chemotherapy can cure the cancer. The chemotherapy is potent and damages normal blood-producing cells as well as the cancer. It takes time for the normal blood-producing cells to recover after the chemotherapy.

\section{Lymphoma}

Lymphoma is a cancer of the lymph nodes. It may sometimes also affect the blood, bone marrow and other parts of the body.

\section{Platelets}

Platelets are small disc-shaped cells that are found in the blood. They are involved in normal blood clotting.

\section{Prophylactic or therapeutic}

Prophylactic treatments are given to prevent an event (such as bleeding) from occurring. Therapeutic treatments are given when an event (such as active bleeding) occurs.

\section{Platelet-poor plasma}

Platelet-poor plasma is also known as frozen plasma or fresh frozen plasma. Platelet-poor plasma is made from donated blood. It does not contain any platelets. It does contain many other factors that help blood to clot normally.

\section{Recombinant activated factor VII}

Factor VII is a protein made by the liver. When it becomes activated, it gives one of the first signals to the body that a clot should be made. Recombinant activated factor VII is manufactured in a laboratory using genetically engineered cells (recombinant technology). The advantage of using recombinant technology is the risks of passing on infection in the blood are reduced. The disadvantage is that this technology is expensive. 


\section{Stem cell transplantation}

One curative treatment for some types of cancer of the blood and bone marrow is stem cell transplantation. Stem cells are normally present inside a person's bone marrow. They make new blood cells including red cells (which transport oxygen around the body), white cells (which fight infection) and platelets. If a person needs a stem cell transplant, the stem cells may be taken from their own body (autologous stem cell transplantation) or may come from a donor (allogeneic stem cell transplantation). The donated cells can either be taken from the donor's bone marrow or from their blood.

A few days before a stem cell transplant takes place, the person is treated with intensive chemotherapy. Intensive chemotherapy is very potent and damages normal blood-producing cells as well as the cancer. After the chemotherapy, people are given the stem cells to regrow their bone marrow so they can make blood cells again.

\section{Thrombopoietin}

Thrombopoietin is a hormone (chemical messenger) that is made by the liver. It makes the bone marrow produce more platelets.

\section{Thrombopoietin mimetics}

Thrombopoietin mimetics are drugs that copy the action of thrombopoietin. 